\title{
Transition Metal-Promoted Reactions in Aqueous Media and Biological Settings
}

Dr. Paolo Destito, Dr. Cristian Vidal, Dr. Fernando López, Prof. José L. Mascareñas

\section{Peer reviewed version}

This is the peer reviewed version of the following article: P. Destito, C. Vidal, F. López, J. L. Mascareñas, Chem. Eur. J. 2021, 27, 4789, which has been published in final form at https://doi.org/10.1002/chem.202003927.

This article may be used for non-commercial purposes in accordance with Wiley Terms and Conditions for Use of Self-Archived Versions

\section{How to cite:}

Destito, P.; Vidal, C.; and López, F.; Mascareñas, J. L. (2021), Transition Metal-Promoted Reactions in Aqueous Media and Biological Settings. Chem. Eur. J., 27: 4789-4816. doi: 10.1002/ chem.202003927

\section{Copyright information:}

(C) 2020 Wiley-VCH GmbH. This article may be used for non-commercial purposes in accordance with Wiley Terms and Conditions for Use of Self-Archived Versions 


\title{
Chemistry \\ Chemistry Europe
}

A European Journal

European Chemical Societies Publishing

\begin{abstract}
)
(1)

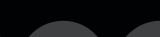

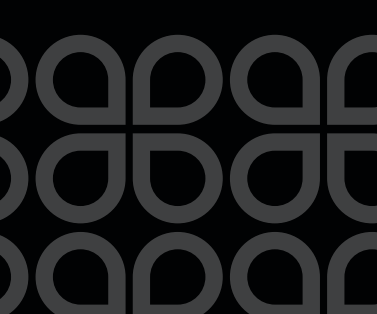

Accepted Article

Title: Transition Metal-promoted Reactions in Aqueous Media and Biological Settings

Authors: Jose Luis Mascarenas, Paolo Destito, Cristian Vidal, and Fernando López

This manuscript has been accepted after peer review and appears as an Accepted Article online prior to editing, proofing, and formal publication of the final Version of Record (VoR). This work is currently citable by using the Digital Object Identifier (DOI) given below. The VoR will be published online in Early View as soon as possible and may be different to this Accepted Article as a result of editing. Readers should obtain the VoR from the journal website shown below when it is published to ensure accuracy of information. The authors are responsible for the content of this Accepted Article.
\end{abstract}

To be cited as: Chem. Eur. J. 10.1002/chem.202003927

Link to VoR: https://doi.org/10.1002/chem.202003927 
Transition Metal-promoted

Reactions in Aqueous Media

\section{and Biological Settings}

Paolo Destito, ${ }^{[a]}$ Cristian Vidal, ${ }^{[a]}$ Fernando

López $^{\star[a, b]}$ and José L. Mascareñas*[a]

Dedication ((optional))

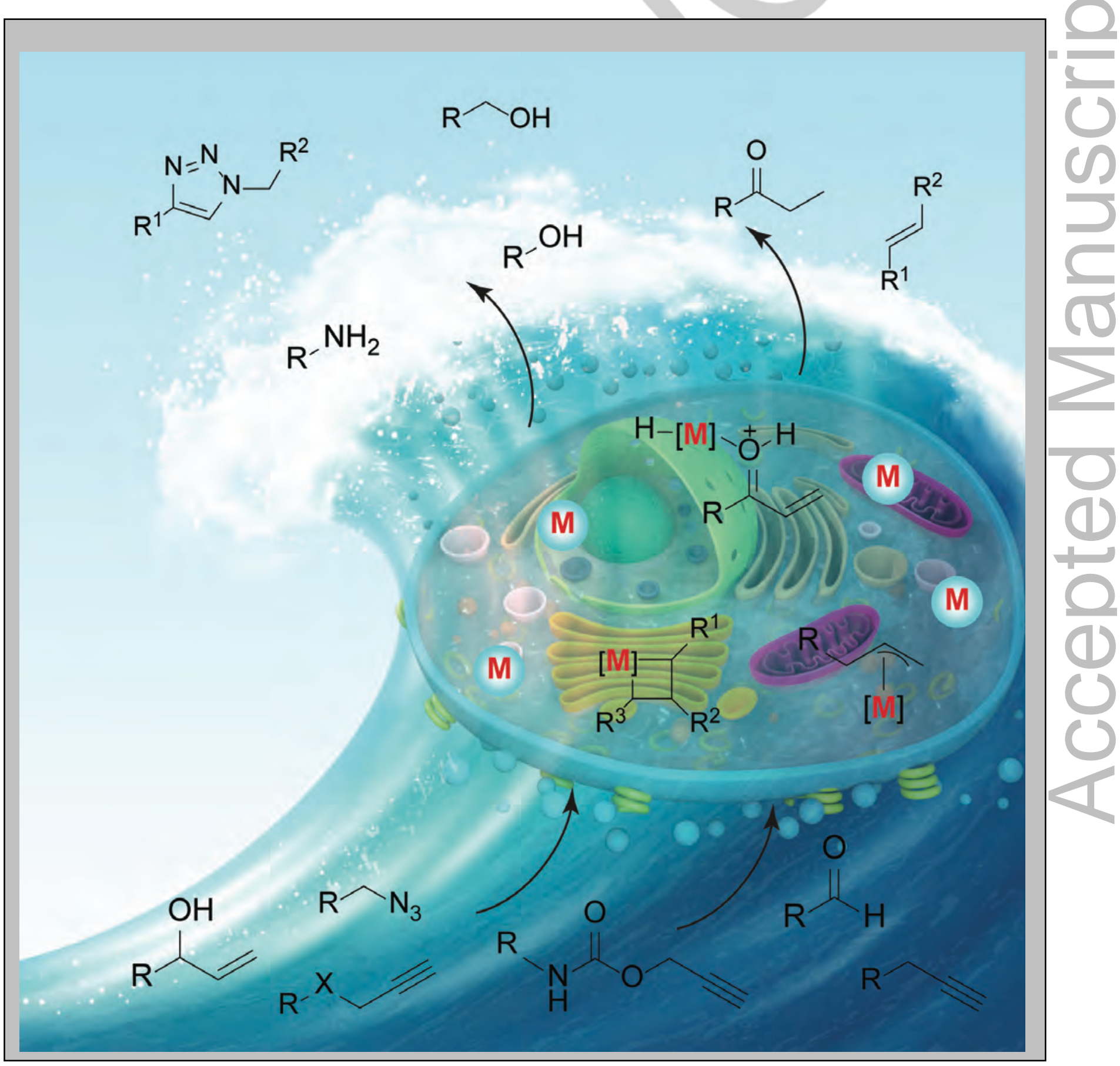


Abstract: During the last decade, there has been a tremendous interest for developing non-natural biocompatible transformations in biologically relevant media. Among the different encountered strategies, the use of transition metal complexes offers unique possibilities due to their high transformative power. However, translating the potential of metal catalysts to biological settings, including living cells or small-animal models such as mice or zebrafish, poses numerous challenges associated to their biocompatibility, and their stability and reactivity in crowded aqueous environments. Herein, we describe the most relevant advances in this direction, with a particular emphasis on the systems' structure, their mode of action and the mechanistic bases of each transformation. Thus, the key challenges from an organometallic perspective might be more easily identified.

\section{Introduction}

Most chemical reactions occurring in nature, including those required to sustain life, take place in aqueous media. [1] "In vitro" enzymatic reactions are also typically performed in water mixtures and aqueous buffers. ${ }^{[2]}$ However, most reactions used in synthetic organic chemistry are carried out in organic solvents; albeit this has not always been the case. The birth of modern organic chemistry can be considered to take place in 1828, when Friedrich Wöhler discovered the synthesis of urea by heating an aqueous solution of ammonium cyanate, ${ }^{[3]}$ which represented the end of the vitalism hypothesis of Berzelius. Since this achievement, there were numerous contributions in the field of chemistry in which water was the main reaction milieu. This is the case of the Baeyer-Villiger oxidation, ${ }^{[4]}$ the Hoffman elimination, ${ }^{[5]}$ the WolffKishner reduction, ${ }^{\left[{ }^{6]}\right.}$ or the Curtius rearrangement. ${ }^{[7]}$ However, since the mid of the 20th century, the use of water as reaction media has been mostly overlooked, and most reactions have been accomplished in organic solvents. ${ }^{[8]}$ There are two main reasons for that, the first is related to the compatibility with bulk water of reagents and reaction intermediates, and even some functional groups, and the second has to do with the limited aqueous solubility of organic compounds, which was generally considered a prerequisite for reactivity (corpora non agunt nisi soluta, "substances do not interact unless dissolved).

A key development that contributed to bounce back water as solvent for organic reactions was the demonstration by Rideout and Breslow in 1980 that water can accelerate Diels-Alder cycloadditions. ${ }^{[9]}$ In this work, they found that not only the reaction rate but also the selectivity are favored by using water instead of

[a] Dr. Paolo Destito, Dr. Cristian Vidal, Dr. F. López, Prof. J. L. Mascareñas,

Centro Singular de Investigación en Química Biolóxica e Materiais Moleculares (CIQUS) and Departamento de Química Orgánica. Universidade de Santiago de Compostela

15782, Santiago de Compostela, Spain E-mail: joseluis.mascareñas@usc.es ; fernando.lopez@csic.es

[b] Dr. F. López

Instituto de Química Orgánica General (CSIC), Juan de la Cierva, 3 28006, Madrid, Spain standard organic solvents. This discovery attracted the attention of many chemists and fostered further research to understand the origin of this effect, which was translated into a renewed enthusiasm in the use of water as solvent. In this context, Sharpless et al, coined the term "on water", ${ }^{[10]}$ referring to those transformations that take place in aqueous suspension, due to the insolubility of the reagents, and occur more quickly than when they are carried out homogeneously using conventional organic solvents. Another very important impulse took place when Bertozzi coined the concept of bioorthogonal chemistry. ${ }^{[11]}$ Bioorthogonal reactions not only can take place in water, but in biologically complex media, and usually occur with high selectivity and biocompatibility.

On the other hand, the increasing concern of society about the environmental impact of human activity has significantly promoted the use of water as a solvent within the context of Green Chemistry. ${ }^{[12]}$

Considering all this breeding ground, it is not surprising that the use of water as reaction media has also touched the field of organometallic catalysis; despite transition metal-mediated reactions have long been thought to be incompatible with water. In recent years, there has been an important growth in the discovery and development metal-promoted reactions that proceed in water, in some cases even more efficiently than in organic solvents. ${ }^{[13]}$ Although the field is still underdeveloped, the crescent demonstration of the compatibility between some transition metal reagents and aqueous environments is triggering significant efforts to translate the power of organometallic catalysis to biological and even living settings. This is not only important from a fundamental perspective, but it is also leading to very innovative developments in chemical biology and biomedicine.

This article intends to review the most important contributions that demonstrate the power of transition metal catalysis in biorelevant complex aqueous media, and even in living settings. We have organized the review to distinguish between reactions that involve the cleavage or the formation of new bonds, and on the type of transformation, rather than on the type of metal complex used. Consequently, a clear picture of the state of the art and the different strengths and weaknesses of each type of strategy for a given process can be more easily perceived.

\footnotetext{
José Luis Mascareñas completed his $\mathrm{PhD}$ in the University of Santiago in 1988, and carried out postdoctoral studies at Stanford University (19891990) and Harvard University (1993 and 1995) He became full professor at the University of Santiago in 2005. He has published over 200 articles and supervised $36 \mathrm{PhD}$ theses. In 2014 was awarded with an ERC Advanced Grant for his project METBIOCAT (http://metbiocat.eu/) and,

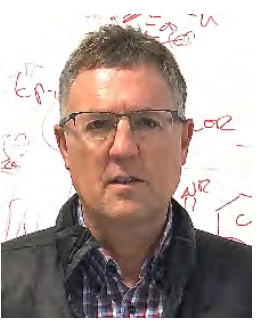
more recently, an ERC Proof of Concept (2020). He has been scientific director of CIQUS since 2014. In 2015 he received the Gold medal of the Spanish Society of Chemistry and in 2016, appointed as member of the European Academy of Sciences. His current research splits between a synthetic program aimed at discovering novel methods based on metal
} 
catalysis, and a chemical biology program focused on the development of synthetic tools for biological intervention.

Fernando López obtained his PhD in 2003 at the University of Santiago de Compostela (USC). He carried out predoctoral stays with Professors E. M. Carreira and J. F. Hartwig, and postdoctoral studies with Prof. B. L. Feringa. In 2006, he joined the USC as a "Ramón y Cajal" researcher. In 2008, he was appointed Tenured Scientist at the Spanish National Research Council (CSIC - IQOG) and, in 2018, he was promoted to Senior Research

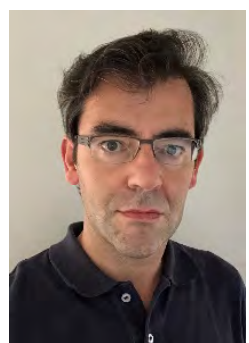
Scientist. From 2012, he is assigned as PI at the CiQUS (USC). His research lines are aimed at discovering efficient synthetic methods as well as novel biocompatible tools, both based on transition metal catalysis.

Paolo Destito studied Chemistry at Università della Calabria (Italy). He carried out a predoctoral stay at the I.M.S. of Aberdeen (Scotland) with Prof Matteo Zanda and obtained his PhD in 2019 under the supervision of Prof. J.L. Mascareñas and Dr. F. López working on new transition metal-promoted bioorthogonal transformations in biological media. Nowadays he is a research chemist at GalChimia.

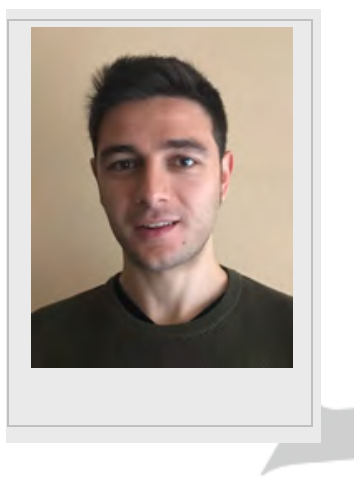

Cristian Vidal obtained his PhD in 2012 at the University of Oviedo about transition metal-mediated reactions in nonconventional solvents under the supervision of Dr. Joaquín García-Álvarez. Then, he moved to the group of Prof. Mascareñas as a Juan de la Cierva researcher at the University of Santiago de Compostela. During this time, he carried out a postdoctoral stay with Prof. Gerald Roelfes at the University of Groningen. He is interested in the translation of the ability of metal catalysis to biological complex media and living systems to achieve biological intervention.

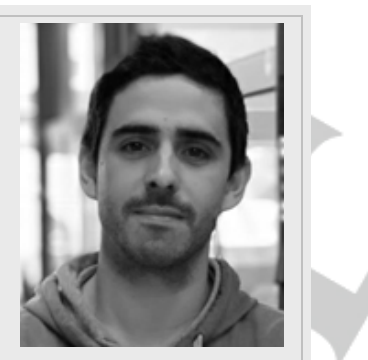

associated to the notion that metal reagents are incompatible with water and air, and can be readily deactivated in biological media, owing to the presence of components like glutathione (GSH), thiol-containing proteins, nucleobases, etc that can coordinate or decompose the metal complexes, and thereby decrease or cancel the catalytic activity.

In recent years there has been an increase number of reports demonstrating that, in contrast to previous beliefs, many organometallic transformations can tolerate the presence of bulk water. ${ }^{[13]}$ However, translating this chemistry to biological settings is far more challenging, and requires orthogonality and bioorthogonality, which means fast reaction rates and inertness toward a myriad of competing functionalities. Moreover, bouncing to living settings is even more complicated because in addition to these requirements, the transition metal has to react under very diluted conditions and, in many cases, be nontoxic, and cellpermeable. ${ }^{[15,16]}$

One of the earliest examples of a metal-catalyzed reaction in biological settings dates back to 1985, when a homogeneous water-soluble ruthenium complex incorporated into mesophyl protoplasts was shown to hydrogenate $\mathrm{C}-\mathrm{C}$ double bonds of fatty acids in the presence of hydrogen gas. ${ }^{[17]}$ However, there were few chemical details in the manuscript, and an extensive cell damage was observed after a one hour of exposure of the protoplasts to the catalyst and hydrogen.

It was not until 2002 when this field started to grow, with the discovery of the copper catalyzed azide-alkyne cycloaddition (CuAAC). ${ }^{[18]}$ This reaction had a tremendous impact in chemical biology and, in particular, in the field of bioconjugation, as it is compatible with water and highly chemoselective. In fact, it was used for the labelling of proteins, nucleic acids, and polysaccharides; ${ }^{[19]}$ as well as for modifying the outer, ${ }^{[20]}$ and inner ${ }^{[21]}$ surface of virus particles, bacteria, ${ }^{[22]}$ and even living mammalian cells (vide infra).

It is important to recall that the cycloaddition between azides and alkynes can be performed in the absence of the copper catalysts, however, it requires relatively harsh thermal conditions, and the products are obtained as mixtures of 1,4- and 1,5-regioisomers (Scheme 1, left). Conversely, the copper-catalyzed version affords the 1,4-disubstituted triazole with exquisite selectivity, in aqueous mixtures, with high reaction rates and at room temperature (Scheme 1, right).

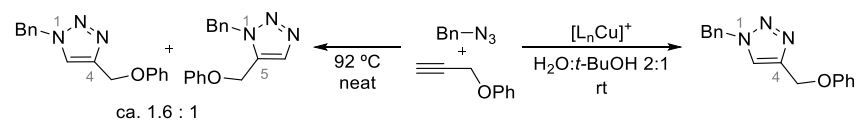

Scheme 1. Thermal and copper (I)-catalyzed assembly of triazoles

Nature has evolved to use enzymes and metalloenzymes to achieve very refined transformations in aqueous and living environments. Some of these reactions have been even transferred to the bench of synthetic chemists. Indeed, the field of biocatalysis has led to many important applications and continues to grow. ${ }^{[14]}$

Remarkably, the inverse process, namely the translation of the transformative power of metal catalysts to biological habitats has been almost completely overlooked. This might be in part
Another breakthrough in this field was reported in 2006 by Meggers and coworkers, and consisted of a $\mathrm{Ru}(\mathrm{II})$-catalyzed cleavage of $\mathrm{N}$-allylcarbamates. ${ }^{[23]}$ Following conditions previously studied by Kitamura and coworkers, the authors demonstrated that the deallylation reaction promoted by $\left[\mathrm{RuCp}^{*}(\mathrm{COD}) \mathrm{Cl}\right]$ (Ru1 ), which is accelerated by unnatural thiols, can be efficiently carried out in water, under air and, importantly, in the presence of 
living mammalian cells (Scheme 2). The generation of a fluorescent product such as rhodamine 110, resulting from the removal of the allylcarbamate in a protected precursor (profluorophore), was used to confirm the reactivity of the catalyst under dilute conditions, and also in HeLa cells. In the case of the cellular reactions, it is important to note that turnover was not demonstrated, not only in these reactions, but in most of those that will be discussed in the review.

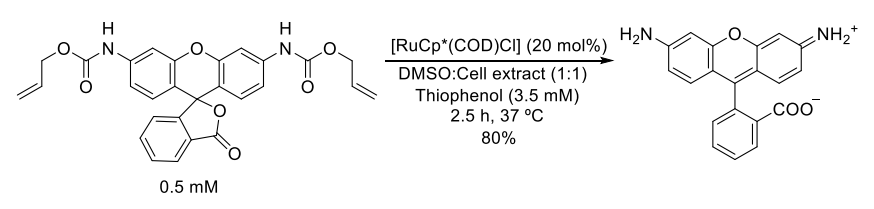

Scheme 2. Allyl carbamate cleavage in biological media.

The CuAAC and the Ru(II)-mediated $\mathrm{N}$-allyloxycarbonyl ( $\mathrm{N}$-alloc) removal confirmed the potential of transition metals to promote aqueous compatible, bioorthogonal transformations that do not occur in nature. After these seminal discoveries, an increasing number of transition metal complexes capable of promoting organometallic reactions in aqueous and biological media have been reported. ${ }^{[24]}$ In the following sections, we summarize some of the most relevant achievements. We have organized the reactions depending on whether the reactions involve the formation or the breaking of new bonds (Figure 1).
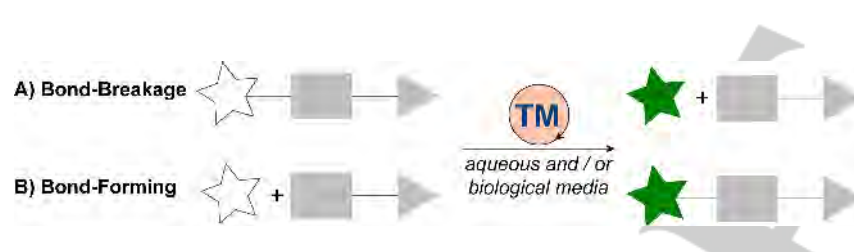

Figure 1. Bioorthogonal bond cleavage and bond-forming transformations mediated by transition metal complexes. TM = Transition Metal.

\section{Bioorthogonal bond forming-reactions}

\subsection{Copper(I)-promoted azide-alkyne cycloaddition (CuAAC)}

As mentioned above, since its discovery, the CuAAC has found a huge number of applications in bioconjugation, material chemistry and medicinal chemistry. Despite the mechanism of the cycloaddition is not fully established, it likely engages $\mathrm{Cu}(\mathrm{I})$ acetylide species bearing a $\pi$ complexed copper atom which reacts with the organoazide to form a bridging di-copper species. ${ }^{[18]}$

Despite the aqueous compatibility of the CuAAC, its translation to biological settings is not trivial, especially because of the oxidation sensitivity of $\mathrm{Cu}(\mathrm{I})$ ions, and the toxicity usually associated to this metal. Indeed, the catalytically active $\mathrm{Cu}(\mathrm{I})$ state is not stable under physiological conditions, as it reacts with oxygen or other oxidants with the consequent generation of reactive oxygen species (ROS). The generated peroxide or hydroxyl radicals can induce the degradation of amino acids and/or the cleavage of peptide chains, among other undesired processes. ${ }^{[25]}$ Generally, to produce and maintain the catalytically active $\mathrm{Cu}(\mathrm{I})$ oxidation state, sodium ascorbate or other reductants are needed. ${ }^{[26]}$ However, sodium ascorbate is not innocent, and, in its oxidized form (dehydroascorbate), it can also react with side chains of proteins (lysine and cysteine among others). ${ }^{[27]}$

In order to reduce cytotoxic effects and avoid the degradation of the copper (I) complexes, several groups have introduced specific coordinating ligands such as tris-triazoles (Figure 2, A). ${ }^{[28]}$ On the other hand, it has been shown that if the organic azide is linked to a pyridine ligand (Figure 2, B) there is an important increase in the rate and biocompatibility of the reaction, although in these conditions the copper turnover is compromised. With the indicated ligands it has been possible to use the CuAAC for different biological purposes, such as specific protein conjugations, or for the labeling of DNA or RNA. In some specific cases it has been shown that the CuAAC can be even performed in live cells. ${ }^{[29]}$
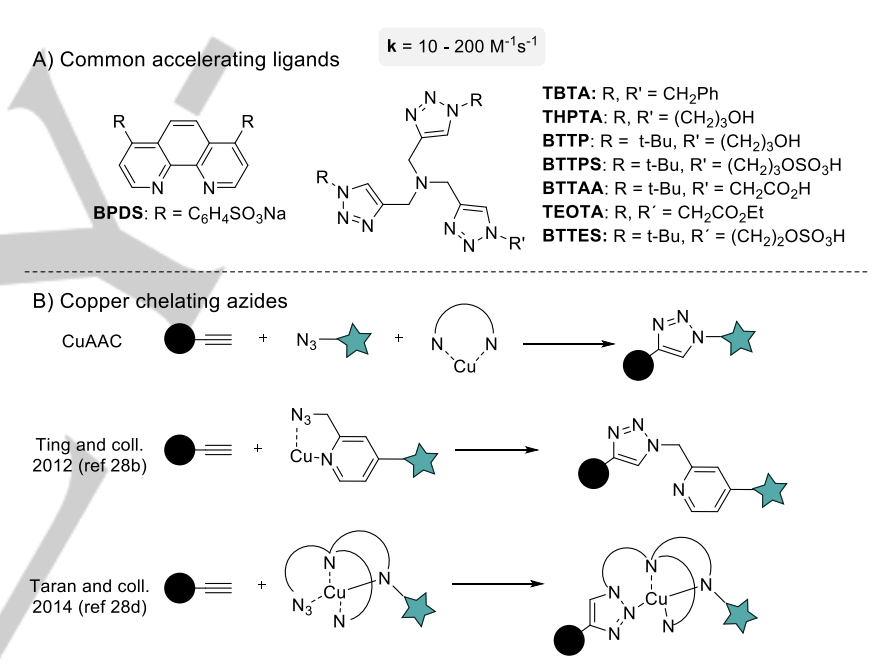

Figure 2. Commonly used ligands $(A)$ and chelating azides $(B$, reactions at the bottom).

The application of the CuAAC to perform bioconjugations in the complex environment of live entities dates back to 2003, when Tirrell and coworkers reported the metabolic incorporation of azidohomoalanine (as a methionine surrogate) into the outer membrane of protein C (OmpC) of E. coli (Figure 3, A) ${ }^{[30]}$ After incorporation of the azide, the cells were treated with $\mathrm{CuSO}_{4}(100$ $\mu \mathrm{M})$, tris (carboxyethyl)phosphine (TCEP, $200 \mu \mathrm{M})$, TBTA as ligand $(200 \mu \mathrm{M})$ and a biotinylated-alkyne $(1,50 \mu \mathrm{M})$ for $16 \mathrm{~h}$ at 4 ${ }^{\circ} \mathrm{C}$. The biotinylated cells were finally stained with fluorescent streptavidin facilitating in this way flow cytometric separation of labeled and unlabeled cells. Despite the labeling worked, the efficiency was modest (only $10-15 \%$ of all possible azide sites were tagged). Moreover, the translation of the strategy to mammalian cells is not straightforward due to the high amount of copper needed for the reaction to proceed $(100 \mu \mathrm{M})$, and the long reaction times $(16 \mathrm{~h})$. Interestingly, the same authors reported in 
2004 that the use $\mathrm{CuBr}(100 \mu \mathrm{M})$, instead of $\mathrm{CuSO}_{4}$, under otherwise identical reaction conditions, allowed for a 10-fold increase in the labelling efficiency of $E$. coli. ${ }^{[31]}$

In 2010, Finn and coworkers reported a rapid and efficient labeling of cell-surface glycans in mammalian cells using the CuAAC. ${ }^{[32]}$ By metabolic incorporation of an azide-containing $\mathrm{N}$ acetylmannosamine (Figure 3, B; Ac 4 ManNAz) and treatment with $\mathrm{CuSO}_{4}(50 \mu \mathrm{M})$, THPTA as copper ligand $(250 \mu \mathrm{M})$, sodium ascorbate (NaAsc, $2.5 \mathrm{mM})$, aminoguanidine $(1 \mathrm{mM})$ and an alkyne-bearing fluorophore $(2,25 \mu \mathrm{M})$, they were able to efficiently label the cell surface, as confirmed by confocal microscopy after cell fixation. Importantly, the reaction had to be carried out at $4{ }^{\circ} \mathrm{C}$, and cells were exposed to the reactants for only 5 minutes to avoid cytotoxic effects. The use of aminoguanidine was crucial to capture dehydroascrobate and its decomposition products

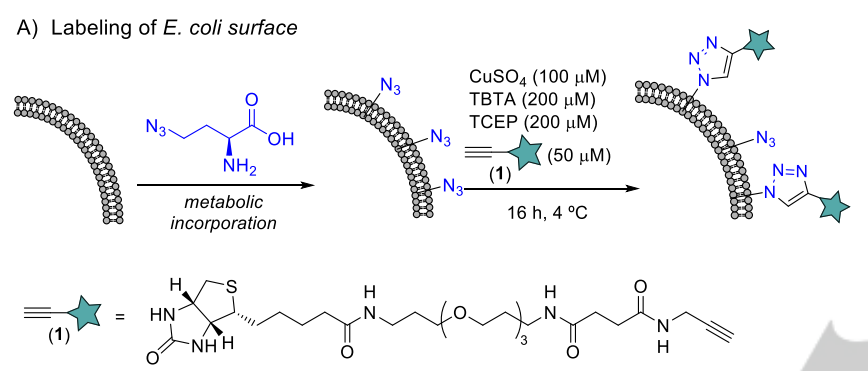

B) Mammalian Cell surface labeling of azido glycans

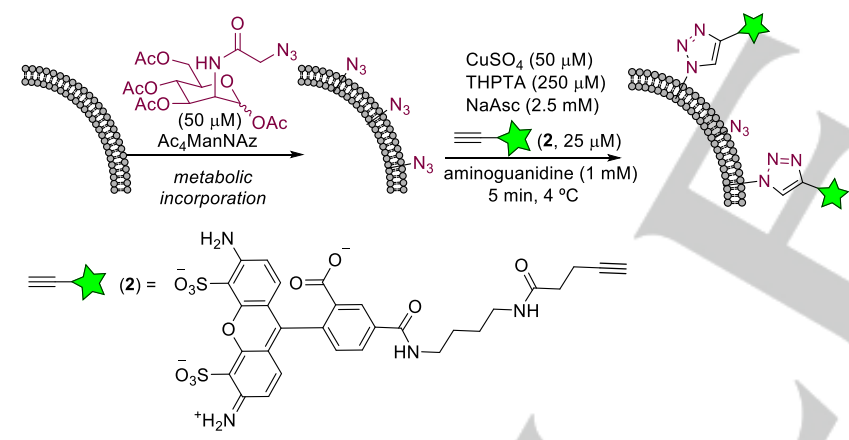

Figure 3. A) Labeling of E. coli surface and B) Mammalian Cell-Surface Labeling of Azido Glycans using CuAAC.

In an important advance, Zimmerman and coworkers reported in 2016 the synthesis of copper cross-linked single-chain nanoparticles (Cu-SCNPs) and their use to promote bioorthogonal azide-alkyne cycloadditions at low parts per million catalyst levels. Their first generation Cu-SCNPs (Cu-SCNP-1) are based on designed poly(norborneneimide) backbones that include alkyl imidazolium groups, and aspartate residues to effectively cross-link the polymer by coordinating copper(II) ions. This cross-linking eventually confers Cu-SCNP-1 a globular structure (Figure 4, A) ${ }^{[33]}$ Although the use of sodium ascorbate to generate the active $\mathrm{Cu}(\mathrm{I})$ containing SCNPs is required, this type of copper coordination seems to partially suppress the typical toxicity problems of discrete copper salts. Thus, the authors demonstrated the utility of these Cu-SCNPs to promote the CUAAC of a fluorogenic coumarin azide inside living mammalian cells (Figure $4, \mathrm{~B}$ ), as well as to synthesize, inside E. coli, an antimicrobial agent $(\mathrm{MIC}=11 \mu \mathrm{g} / \mathrm{mL}$ ) from two almost nontoxic substrates $(\mathrm{MIC}=300 \mu \mathrm{g} / \mathrm{mL}){ }^{[33]}$

In a subsequent paper, the same group reported a structure activity study which, together with kinetic analysis, NMR studies and computational simulations determined that the high catalytic activity of these Cu-SCNPs, which surpasses that of the most efficient discrete $\mathrm{Cu}$ catalysts, can be attributed to an enzyme-like substrate binding process. Thus, Cu-SCNP-1 binds both substrates in proximity to the metal center, so that the rate of the cycloaddition is eventually governed by the hydrophobic character of the substrates and the polymer, as well as by the charge complementarity. ${ }^{[34]}$

Remarkably, the same group showed that related Cu-SCNPs (Cu-SCNP-2) based on a polyacrylamide backbone and tris(triazolylmethyl)amine units for $\mathrm{Cu}(\mathrm{I})$ cross-linking (Figure 4, C), performs the above mentioned fluorogenic CuAAC significantly faster than Cu-SCNP-1, and many other previously developed $\mathrm{Cu}$ catalysts. Indeed, its reaction rate is 10 times faster than the most efficient small molecule catalyst (Cul-BTTAA). Moreover, CuSCNP-2 is extremely efficient promoting CuAAC on modified protein surfaces and surface glycans, with unprecedented rates. Combined experimental and computational studies indicated that a reversible binding of these Cu-SNCPs to the protein surfaces, through multiple hydrophobic and electrostatic contacts, is responsible for this excellent performance. ${ }^{[35]}$

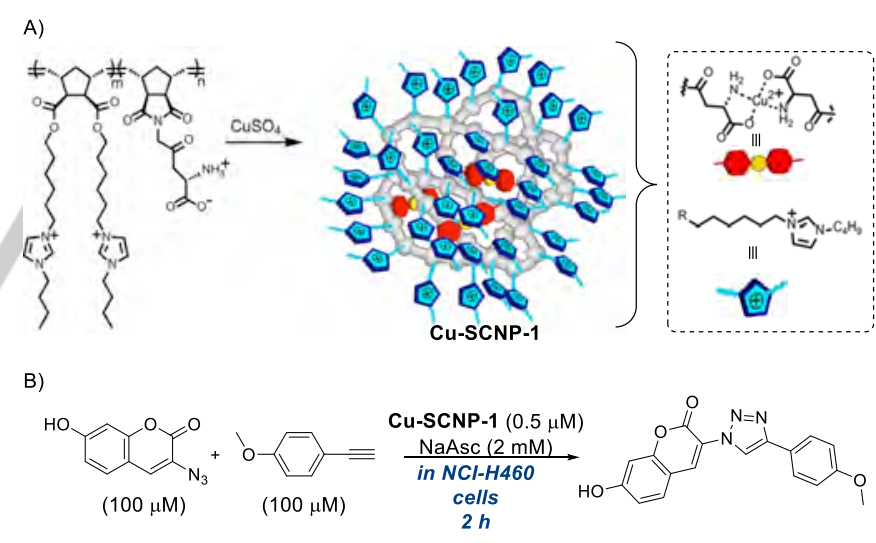

C)
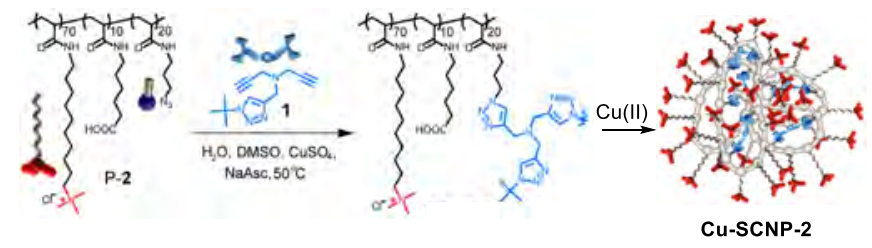

Figure 4. Cu-SCNPs by Zimmerman and coworkers.

In 2016, Bradley and coworkers described the synthesis of an alternative heterogeneous system for in vivo CuAACs which consist of copper nanoparticles $(\approx 50 \mathrm{~nm}$ ) embedded within a 
polymeric support (resin beads of $\approx 150 \mu \mathrm{m}$ ). These Cu-beads were shown to be biocompatible and can promote the in situ generation of a triazole-containing anticancer agent (a Combretastatin A4 analogue), from two non-toxic component halves. Although reactions take place in the extracellular media, due to the size of the heterogeneous construct, they were also shown to function as implantable devices into the yolk sac of zebrafishes, where they also proved to be active with no signs of toxicity (Figure $5, \mathrm{~A})$. $^{[36]}$

In an alternative strategy, the group of $\mathrm{Qu}$ developed various biocompatible heterogeneous $\mathrm{Cu}$ systems that are able to promote bioorthogonal CuAACs in vivo. Thus, in 2019, this group developed a catalyst based on a MOF support that holds and stabilizes ultrasmall copper $(0)$ nanoparticles at their inner cavities (5-10 wt\%). ${ }^{[37]}$ Interestingly, by decorating the resulting MOF-Cu particles with a triphenylphosphonium vector (MOF-Cu-TPP, Figure 5, B), the authors showed that they can preferentially accumulate in the mitochondria of living cells, wherein they remain active. As a result, this strategy allowed the mitochondrialocalized generation of a resveratrol-derived drug from their respective azide and alkyne precursors (Figure 5, B). The activity of these MOF-Cu-TPP nano-constructs was also tested in Caenorhabditis elegans, wherein the in situ synthesized resveratrol drug proved to have a better antitumor efficiency than the pre-synthesized molecule.

Despite the efficiency of this method, the use of Cu nanoparticles for CuAACs in living systems is not ideal, due to the inherent poor activity of $\mathrm{Cu}(0)$. In this regard, the same group also developed copper nanocatalysts based on mesoporous carbon nanospheres (MCNs) which, under NIR irradiation, generate reactive oxygen species (ROS) that effectively oxidizes $\mathrm{Cu}(0)$ to $\mathrm{Cu}(\mathrm{I})$ (Figure 5 , C). Thus, the CuAAC can be catalytically boosted. Moreover, the MCNs also transform NIR light into heat, increasing locally the temperature, resulting in an additional acceleration of the azidealkyne cycloaddition. ${ }^{[38]}$ The MCNs-Cu heterogeneous nanocatalyst $(\approx 50 \mu \mathrm{m})$ are highly stable, and biocompatible both inside HeLa cells (incorporated by endocytosis) as well as un $C$. elegans, where they can promote the in vivo synthesis of the above-mentioned drug.
A) Cu-beads promoted azide-alkyne cycloaddition by Bradley

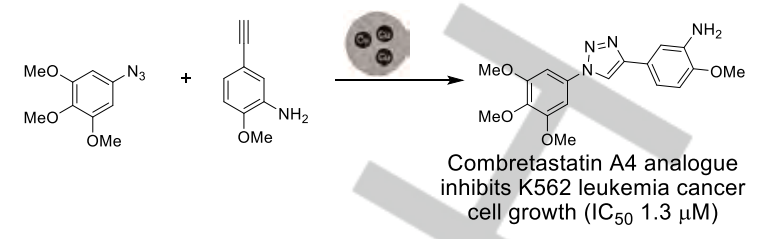

B) Biocompatible heterogeneous MOF-Cu nanosystems for CuAAC

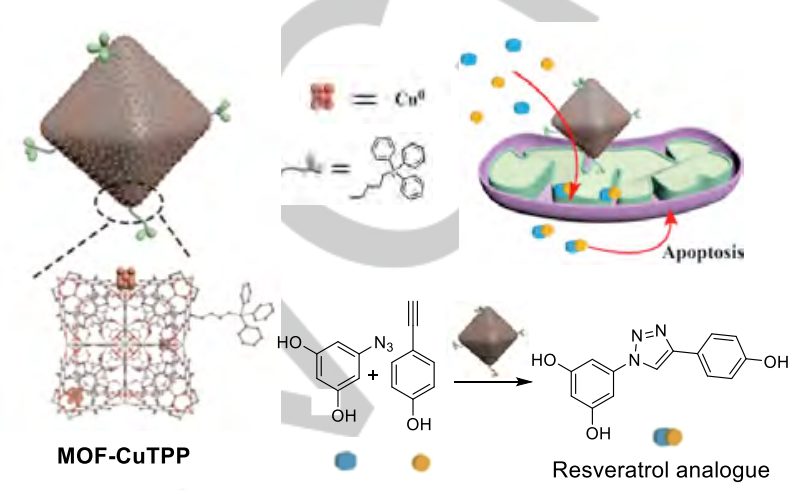

C) Near-infrared light dual-promoted heterogeneous $\mathrm{Cu}$ nanocatalyst

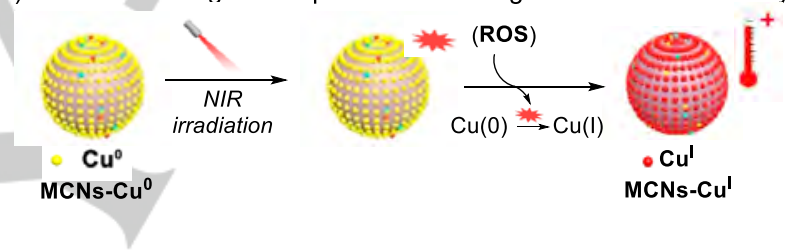

Figure 5. Heterogeneous Cu-based nanoconstructs for bioorthogonal CuAACs

Cai and coworkers reported a method to compare the efficiency of an intracellular CuAAC reaction (in the cytosol) to one occurring in the extracellular membrane. By tethering tris(triazolylmethyl)amine ligands (BTTAA-type derivatives) to positively charged cell penetrating peptides they observed intracellular reactions in OVCAR5 cancer cells. Additionally, they presented data suggesting that it is viable to perform an intracellular reaction on alkyne-containing proteins obtained by metabolic incorporation of homopropargylglycine (HPG) (Figure 6, A). Using LC-MS techniques, they found that while the extracellular reaction is relatively efficient, the intracellular process is almost negligible ( $0.8 \%$ yield). Nonetheless, this yield could be improved up to $15 \%$ yield by using $N$-ethylmaleimide to deactivate biothiols such as glutathione. ${ }^{[39]}$

In this context, Mascareñas and coworkers demonstrated that related preformed discrete $\mathrm{Cu}(\mathrm{I})$ complexes such as [Cu(BTTE)]PF 6 display excellent cellular uptake and can promote intracellular CuAAC annulations of small molecules (Figure 6, B). Thereby, some of the previous limitations of the intracellular CuAAC chemistry like the requirement of excess of ligands or the use of cytotoxic sodium ascorbate were partially solved. ${ }^{[40]}$ 


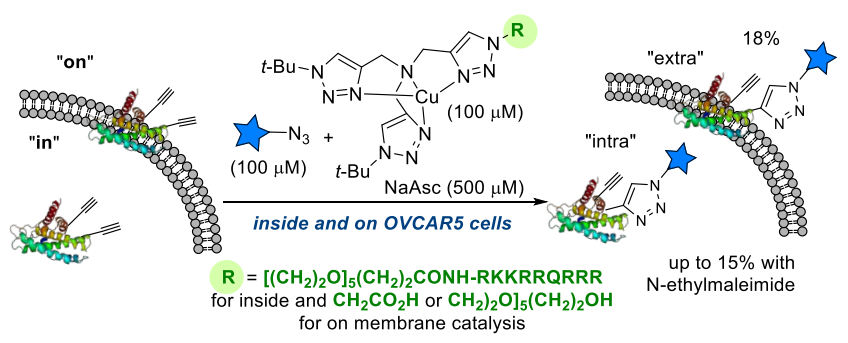

B) Azide-alkyne annulation using discrete $\mathrm{Cu}(\mathrm{I})$ complexes

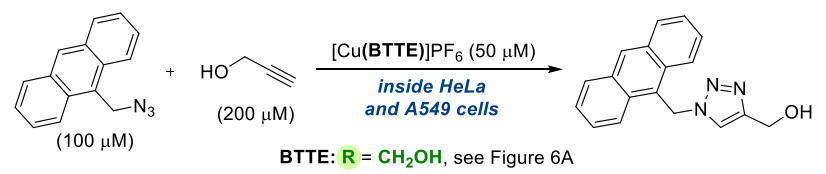

Figure 6. CuACC in live cells with homogeneous Cu catalysts.

The toxicity and lability of copper has led to an intensive search of alternative bioorthogonal annulations that can take place in the absence of the metal. These reactions are based on the use of strained reagents which exhibit an intrinsic tendency to react with azide partners in classical dipolar cycloaddition manner. This is for instance the case of the well-known azide-cycloalkyne cycloaddition (SPAAC) ${ }^{\left[{ }^{[1]}\right.}$ These types of reactions are very appealing for bioorthogonal chemistry, but also present limitations associated to the long-term stability and side reactivity of strained components like cycloalkynes (i.e. reaction with cellular nucleophiles such as glutathione or homo-trimerizations). In this context of strain-promoted process, the inverse demand Diels-Alder reaction is especially appealing, owing to its high rates and decent stabilities of the reactants. ${ }^{[42]}$

Despite the relevance of these transformations, using metals to promote bioorthogonal annulations continues to be highly attractive for several reasons which include the versatility with regard to the reactants, the relatively simple structure of the precursors, and the possibility of spatio-temporal control of the reactivity, as it is only triggered in the presence of the metal catalyst. Therefore, the development of alternatives to the CuAAC based on other metals that present better biocompatibility than copper(I) is a relevant goal.

In this regard, Mascareñas and coworkers reported in 2017 a ruthenium-catalyzed annulation between thioalkynes and azides (RuAtAC) that can be carried out in a biorthogonal manner, under mild aqueous conditions. The reaction, which is promoted by the ruthenium complex $\left[\mathrm{RuCp}^{*}(\mathrm{COD}) \mathrm{Cl}\right](\mathrm{Ru}-1)$, presents a wide scope, and the resulting triazoles are obtained with excellent regioselectivities in favor of the 1,5-disubstituted isomer (Figure 7, A) ${ }^{[43]}$ Interestingly, this methodology allows to perform both, a CUAAC and a RuAtAC in a mutually orthogonal manner (Figure 7, B).

Soon after this work was published, Song and coworkers demonstrated that the iridium(I) complex $[\mathrm{IrCl}(\mathrm{COD})]_{2}$ is also able to promote biocompatible annulations between azides and ynamides, instead of thioalkynes. In both cases, the reactions are fully regioselective, but $\mathrm{mM}$ concentrations of the reagents are required, which so far limits their use for chemical and cell biology applications. ${ }^{[44]}$

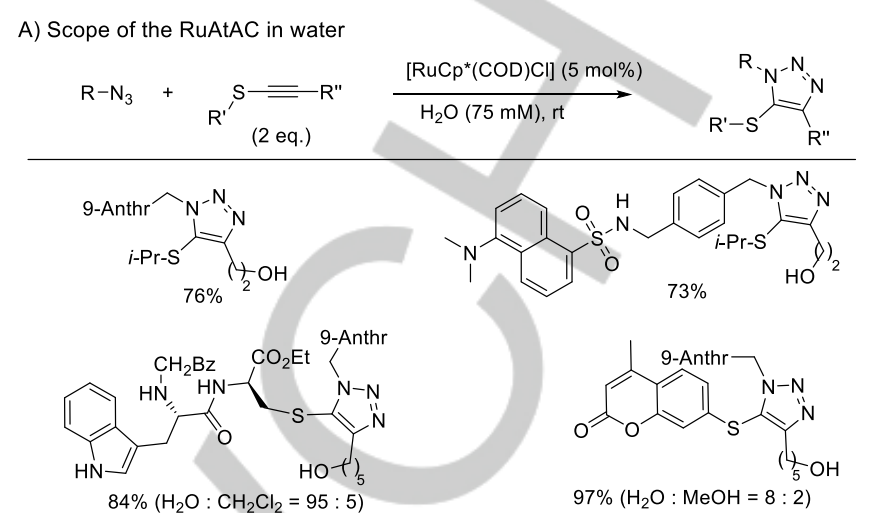

B) Mutually orthogonal CuAAC/RuAtAC

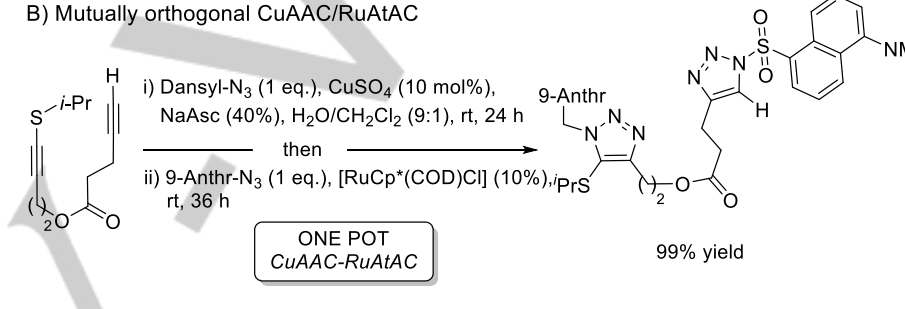

Figure 7. RuAtAC developed by Mascareñas and coworkers.

\subsection{Metathesis reactions}

Olefin cross metathesis is among the most relevant transformations for the formation of carbon-carbon bonds. Briefly, the reaction consists of the cleavage and reassembling of carbon-carbon double bonds so, formally, it allows the direct exchange of substituents between different alkene partners, in a catalytic manner (Figure 8). ${ }^{[45]}$

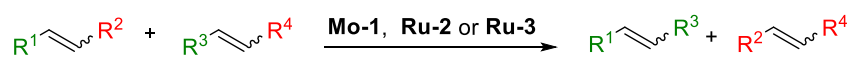

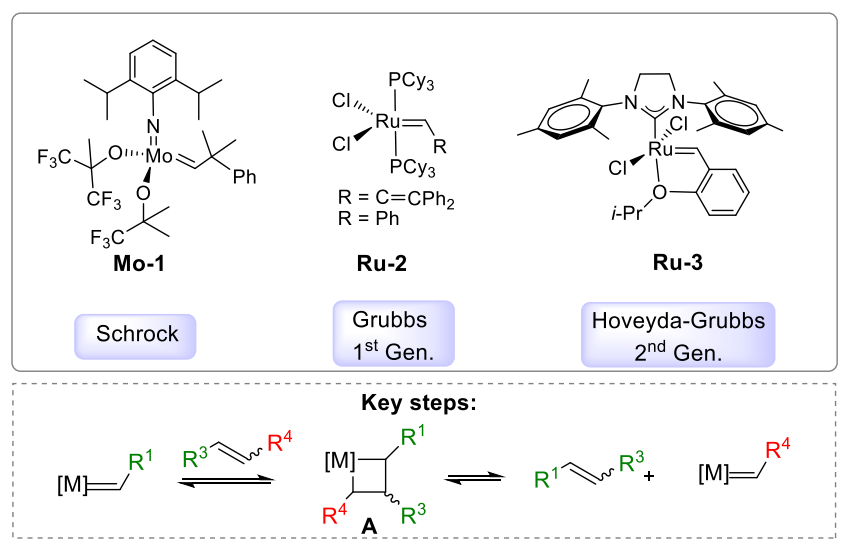

Figure 8. General scheme and catalysts for olefin metathesis. 
Mechanistically, the reaction involves a series of $(2+2)$ cycloadditions and cycloreversions between a transient metal carbene complex, usually a ruthenium or molybdenum species, and the alkene partners. An initial coordination of the olefin to the metal carbene triggers the first $(2+2)$ cycloaddition to form a metallacyclobutane intermediate $(\mathbf{A})$ that subsequently evolves to produce the alkenyl product and a new metal carbene complex that continues the catalytic cycle (Figure 8, Key steps). This mechanism includes reversible steps, so in order to avoid mixture of olefins, a shift in the proper direction to provide the desired product is crucial.As in many other cases, the reaction has been essentially investigated in organic solvents; ${ }^{[45 b-d]}$ however there are several studies reporting alkene metathesis processes in aqueous mixtures, some of them based on the use of watersoluble catalysts. ${ }^{[46]}$ Considering the stability of carbene-metal complexes, and that alkenes are excellent reactants for biorthogonal chemistry owing to their intrinsic inertness, it is not rare that some groups have investigated the use of metathesis reactions in chemical biology.

Davis and coworkers made impressive contributions in this topic. They demonstrated that it is possible to modify proteins featuring allyl-protected cysteines by cross metathesis with allylic alcohols, in the presence of the Hoveyda-Grubbs $2^{\text {nd }}$ generation catalyst (Ru-3, Figure 8). ${ }^{[47]}$ Apparently, the presence of the sulfur atoms benefits the reaction by working as a metal pre-coordinating motif. ${ }^{[48]}$ Indeed, the reaction was coined as sulfur-relay crossmetathesis. This methodology was applied by Davis for siteselective modification of the serine protease Subtilisin from Bacillus lentus (SBL). ${ }^{[49]}$ Importantly, addition of $\mathrm{MgCl}_{2}(100 \mathrm{mM})$ was found to be crucial, likely because it avoids a non-specific coordination of the catalyst to the protein, which would cancel the process (Figure 9). ${ }^{[49 b]}$

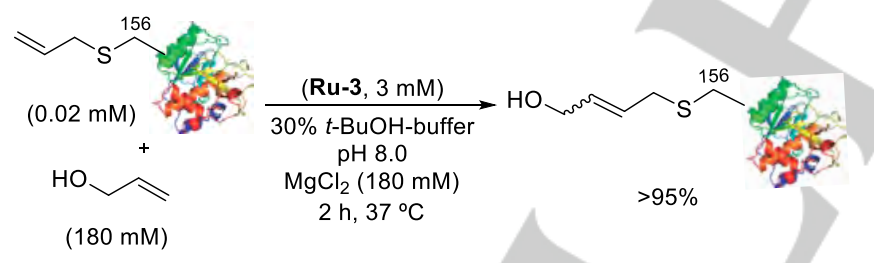

Figure 9. Cross-metathesis on SBL-156Sac.

A similar strategy was applied for the ring closing metathesis on the double O-crotylserine mutant on GFP (Figure 10, A) and Fmoc-1,6-Sac-oxytocin (Figure 10, B). ${ }^{[50,46 \mathrm{~b}]}$

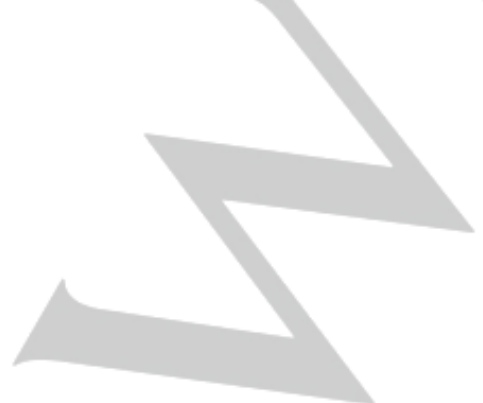

A)

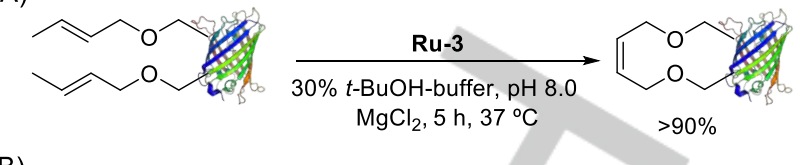

B)

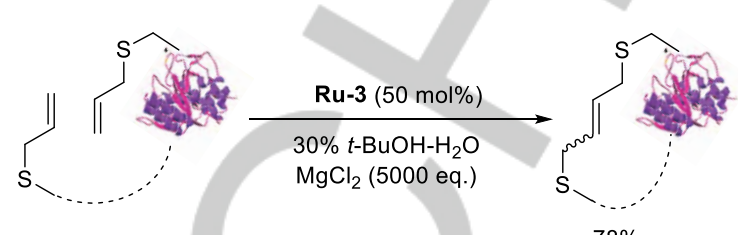

Figure 10. Application of ring-closing metathesis for the modification of proteins.

These advances demonstrated the compatibility of ruthenium metathesis catalysts with proteins and with aqueous media, an information that was likely very useful to Ward and coworkers in their work to perform metathesis reaction by artificial metalloenzymes developed by directed evolution. ${ }^{[51]}$ Thus, using the biotin-streptavidin (biot-SAV) technology developed by the group, ${ }^{[52]}$ they were able to create an artificial metalloenzyme featuring a Hoveyda-Grubbs $2^{\text {nd }}$ generation catalyst (Ru-4, Figure $11)$ in the periplasm of $E$. coli. This construct could promote a ring closing metathesis of substrate 3 , to give a fluorescent product (7hydroxycoumarin, 4, Figure 11). The authors found that the reaction is inhibited by thiols such as glutathione (GSH), and therefore needs to be performed in a thiol-free region, like the periplasm.

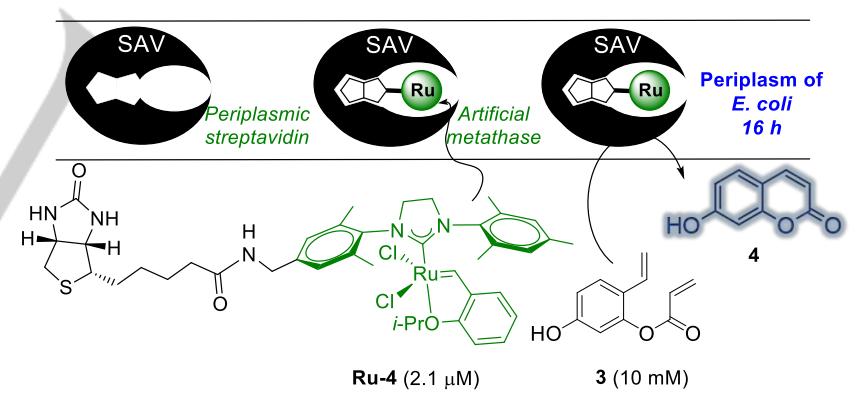

Figure 11. Biotin-Streptavidin (biot-SAV) based artificial metalloenzyme for a ring-closing metathesis.

In an interesting contribution in 2018, Michel and co-workers described the synthesis of the conjugate Ru-5, which features the Hoveyda-Grubbs $2^{\text {nd }}$ generation catalyst tethered to a BODIPY moiety. ${ }^{[53]}$ Interestingly, the fluorescence of BODIPY is quenched in Ru-5. However, upon a metathesis reaction with a suitable olefin, a fluorescent BODIPY-derived product is released. They used this approach to detect exogenous ethylene in HEK239T cells. The cells were exposed to ethylene gas or vapor from a ripe banana and mango and then were treated with $2 \mu \mathrm{M}$ of complex Ru-5 and, after $15 \mathrm{~min}$, they observed the formation of the fluorescent product 5 (Figure 12). 


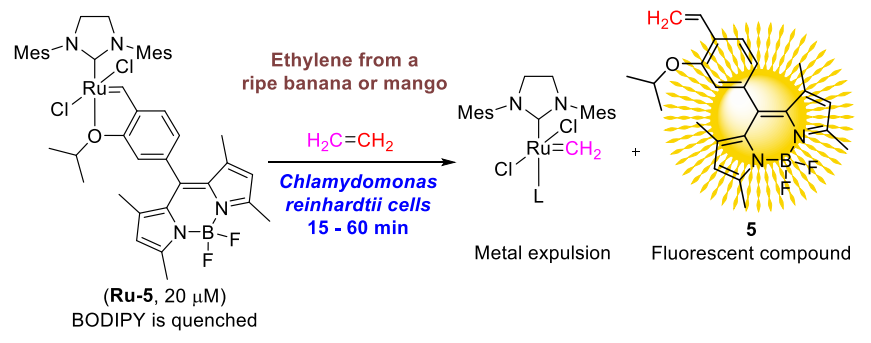

Figure 12. Olefin metathesis for the detection of ethylene in live cells.

Recently, Tanaka and coworkers reported the assembly of a human serum albumin protein (HSA) derivative embedding a Hoveyda-Grubbs $2^{\text {nd }}$ generation complex within the hydrophobic pocket of the protein (HSA-Ru-6), and found that the resulting metalloprotein can promote alkene metathesis reactions under live settings. ${ }^{[54]}$ They tested the ability of this artificial metalloenzyme in ring-closing and ene-yne cross-metathesis reactions, under diluted aqueous conditions. Due to the protecting lipophilic environment provided by the HSA, both reactions could be carried out even in the presence of glutathione (GSH), a common deactivation reagent, without affecting the TON of the reactions. As a potential drug therapy, this study shows that the artificial ruthenium metalloenzyme can induce the production of the anticancer agent umbelliprenin from a prodrug, using a ruthenium-promoted ring-closing metathesis reaction (Figure 13). Moreover, by introducing designed N-glycans $[\alpha(2,3)$-linked sialic acid] to the ruthenium-bound albumin proteins, the resulting metalloenzymes can be preferentially accumulated to cancer cell lines that overexpress galectin-8, a known receptor of $\alpha(2,3)$ linked sialic acid. Thus, the prodrug activation can be triggered locally, in the vicinity of the targeted cells, inducing a significant decrease in their growth.

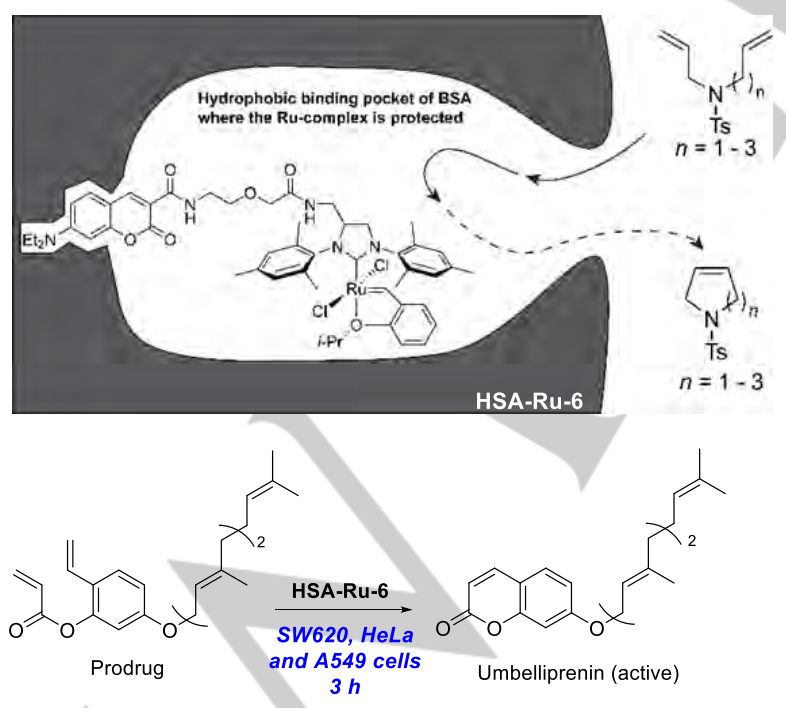

Figure 13. Ring-closing reaction promoted by an artificial metalloenzyme.

\subsection{Pd-catalyzed Suzuki-Miyaura cross-couplings}

Cross-coupling reactions hold a prime position in the toolbox of a synthetic chemist. This type of transformations consists of a metal promoted coupling between organic electrophiles and nucleophiles, and include several variants such as the Stille, Suzuki, Negishi or Sonogashira couplings, among others. ${ }^{[5]}$ All of them, involve a relatively complex mechanistic scenario engaging several elementary steps, such as oxidative additions, transmetalations and reductive eliminations. This mechanistic complexity, together with the air-sensitivity of many transition metal complexes and intermediates, led to the initial conviction that these reactions should be barely compatible with aqueous media, and thus they were mainly studied in organic solvents under inert atmospheres. However, pioneering work independently disclosed by Casalnuovo and Genet in the nineties, confirmed that some of these couplings could be carried out in aqueous mixtures, provided that an appropriate water-compatible catalyst is used. ${ }^{[56]}$ Since then, and throughout the last decades, the Suzuki-Miyaura cross-coupling has been the most studied cross-coupling process under aqueous conditions, probably due to its mild reaction conditions, excellent functional group tolerance and the availability and low-cost of aryl halides and boronic acids. ${ }^{[57]}$

Despite these favorable winds, it was not until 2009 when Davis and co-workers found the possibility of carrying out this reaction in biological settings. ${ }^{\left[{ }^{[8]}\right.}$ In particular, they reported an effective way of achieving Suzuki-Miyaura cross-couplings in water, by using palladium complexes featuring 2-aminopyrimidines as added ligands. ${ }^{[59]}$ The model reaction shown in Figure $14 \mathrm{~A}$ was carried out in buffered water at $37{ }^{\circ} \mathrm{C}$ with $1 \mathrm{~mol} \%$ of the $\mathrm{Pd}$ catalyst (Pd-1) formed by mixing $\mathrm{Pd}(\mathrm{OAc})_{2}$ and the sodium salt of 2-aminopyrimidine-4,6-diol. Using these conditions, good yields of the corresponding cross-coupling products between phenyl boronic acid and 4-bromo or 4-iodophenylalanine were obtained (95\% and $98 \%$ respectively), whereas 4-chlorophenylalanine did not react under otherwise identical reaction conditions. Importantly, thiols were again detrimental for the reaction; in fact, addition of one equivalent of glutathione showed complete passivation of the catalyst, which represents an important limitation in terms of transferring this reaction to biological settings. ${ }^{[60]}$

Notably, the methodology was used for the modification of an appropriately engineered serine protease that holds a modified cysteine featuring a phenyl iodide moiety (SBL-156Arl). The reaction was efficiently carried out in short reaction times when using 50 equiv. of the palladium complex and 500 equiv. of phenyl boronic acid (Figure 14, B). The reaction did not require the use of an external base as the phosphate buffer solution employed $(\mathrm{pH} \approx 8)$ is basic enough to allow the key transmetallation step. Interestingly, the same group has also shown that these $\mathrm{Pd}$ complexes can also promote Suzuki reactions at the cell surface of $E$. coli, provided that a genetically modified transmembrane protein (i.e. $\mathrm{OmpC}$ ), with the unnatural amino acid $p$ iodophenylalanine, is used. ${ }^{[61]}$ 
A) Suzuki coupling in aqueous media

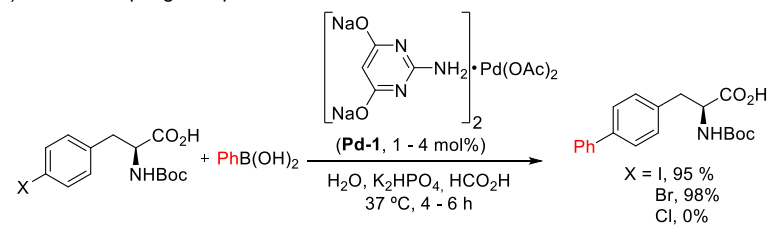

B) Protein SBL-156Arl labeling
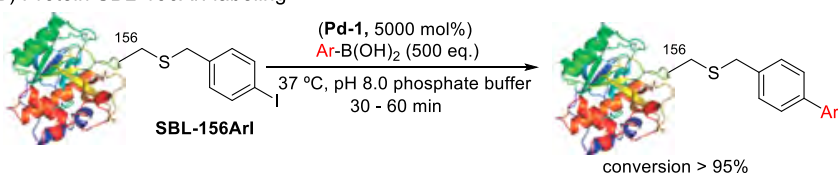

Figure 14. A) Suzuki coupling in aqueous media and B) Protein SBL-156Arl labelling.

While achieving palladium-promoted Suzuki couplings in cells doesn't seem obvious, in 2011 Bradley, Unciti-Broceta and coworkers claimed the development of such intracellular Suzuki reaction using palladium nanoparticles trapped within polystyrene microspheres (Figure 15, Pd-2). ${ }^{[62]}$ In particular, they reported that a triflate derivative of the methyl-fluorescein (6) can be coupled to a triphenylphosphonium-bearing pinacol boronate 7 at $37^{\circ} \mathrm{C}$ in different reaction media such as PBS, RPMI media, cell extract or DMF, to give the cross-coupled product 8 with yields up to $22 \%$, using catalytic amounts of Pd. They also indicated that incubation of HeLa cells with $\mathbf{P d - 2}$ followed by treatment with non-fluorescent triflate $\mathbf{6}$ and the alkylaminophenylboronate 7 , produced a mitochondrial fluorescent signal, detected by confocal

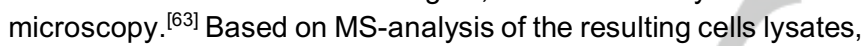
the authors suggested that this fluorescent signal is due the formation of the cross-coupled product 8.
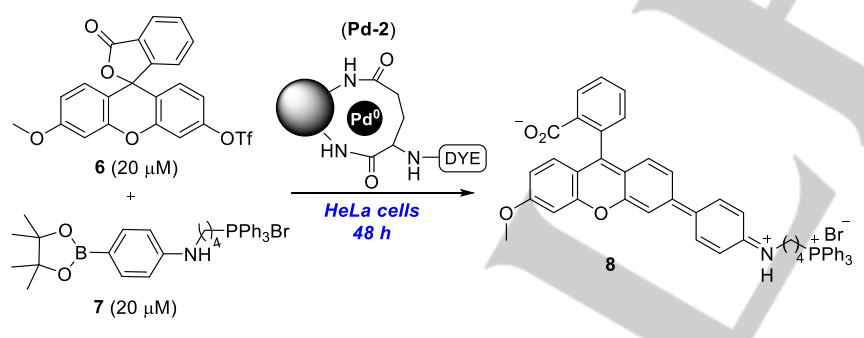

Figure 15. Suzuki-Miyaura cross coupling to generate anthofluorescein derivative $\mathbf{8}$.

Bradley and coworkers developed alternative heterogeneous nanostructures $(\mathbf{P d}-3)$ based on Pd nanoparticles $(9.2 \pm 1.5 \mathrm{~nm}$ size) entrapped within larger modular polymeric networks (sintered aminomethyl polystyrene resin beads of macroscopic size, $9.0 \times 7.5 \mathrm{~mm}$, see Figure $16, \mathrm{~A}){ }^{[64]}$ Their performance was evaluated in water-ethanol mixtures, $5 \%$ fetal bovine serum (FBS) as well as in cell lysates, for the cross-coupling between the fluorogenic bis-iodo-BODIPY 9 and the boronic acid 10, to yield the corresponding fluorescent bis-thienyl BODIPY 11 (Figure 16, A). An evident drop of the reactivity was observed in FBS, probably because of the binding of thiols to the Pd nanoparticles, which might poison the catalytic activity. Interestingly, this modular palladium catalyst (Pd-3) was also used for the in situ extracellular synthesis of the cytotoxic agent PP-121, which induced localized cytotoxicity and early apoptosis on PC-3 cancer cells (Figure 16, B).

The same cytotoxic drug (PP-121, Figure 16, B) was synthesized by Bradley and coworkers using smaller heterogeneous $\mathrm{Pd}$ catalysts consisting of Pd-nanoparticles entrapped in polystyrene fluorescent microspheres functionalized with a targeting vector, such as the cyclic peptide cRGDfE (Pd-4, Figure 16, B). By using this vector, the nanoparticles accumulated selectively in brain cancer cells (glioblastoma) maintaining their activity. ${ }^{[65]}$

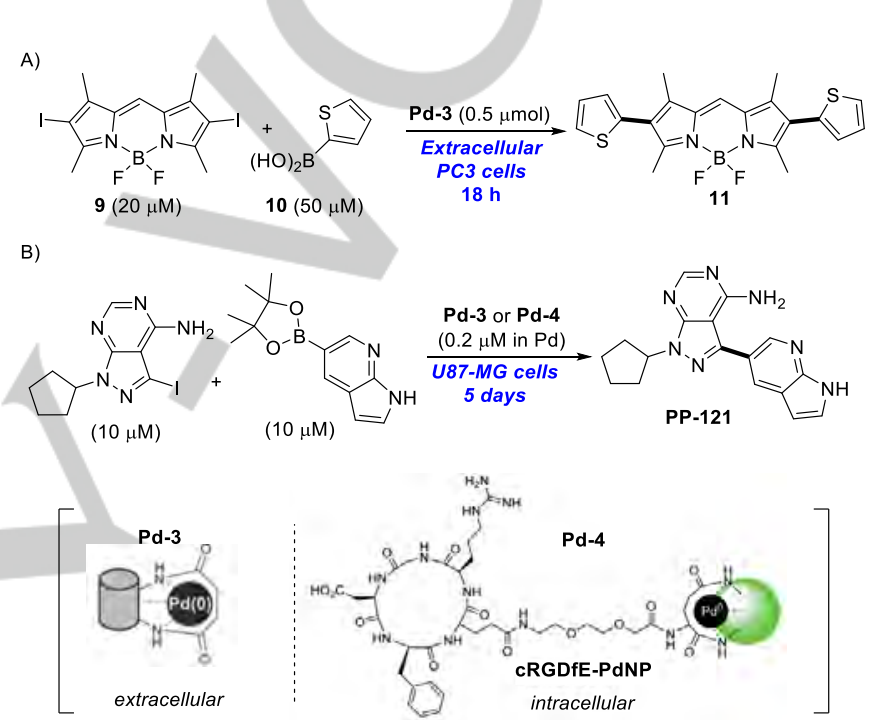

Figure 16. Catalytic activity of Pd-3 (A) and in situ generation of PP-121 with Pd-3 and Pd-4 (B).

The group of $\mathrm{Qu}$ has recently reported another example of a Suzuki reaction in biological settings, using a switchable device to control the catalytic process (Figure 17). ${ }^{[6]}$ In particular, their strategy was based on the synthesis of $\mathrm{Pd}$ nanoparticles embedded in macroporous silica nanostructures functionalized with an azobenzene switch (Figure 17, A). These azobenzenes, when exhibiting a trans-configuration, can insert into cyclodextrin hosts (Figure 17, B), and hence preclude the access of substrates to the palladium core. Upon UV light irradiation and concomitant isomerization of the azo moiety to the cis form, the cyclodextrin blocker is released, enabling the catalytic activity of the $\mathrm{Pd}$ nanoparticles (Figure 17, C). They demonstrated the value of the strategy to control the Suzuki-Miyaura coupling of fluoresceinderived triflate 6 and the alkylaminophenylboronate 7 (Figure 15). They also tested the process inside HeLa cells; incubation of the cells with the cyclodextrin-capped nanostructures, followed by the substrates and UV light irradiation, produced an intense green fluorescence in mitochondria of cells, which was suggested to correlate with the formation of the product. 
A) Azobenzene isomerization

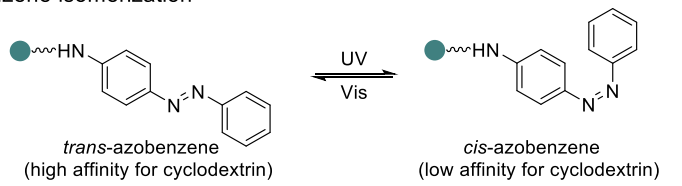

B) Activation of the catalyst

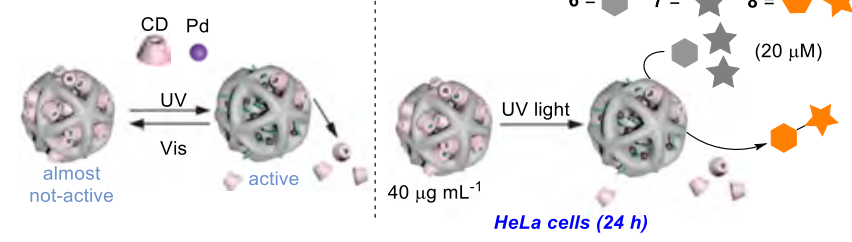

C) Catalytic activity

Figure 17. Photo-activatable bioorthogonal system for the Suzuki coupling between 6 and 7 (see Figure 15). CD = cyclodextrin.

In 2019, Mascareñas and coworkers in collaboration with CorreaDuarte demonstrated that porous hollow microspheres consisting of mesoporous silica nanoshells equipped with palladium nanoparticles at the internal surface (Pd-Cap1) could be used as nanoreactors for $\mathrm{Pd}$-catalyzed Suzuki reactions in water, as well as in complex biorelevant media (Scheme 3 ). The success of these nanocatalysts stems from the protected environment offered by the shell, which avoids the deactivation of the palladium by biomolecules. ${ }^{[67]}$ Thus, the cross coupling between thiophen2 -ylboronic acid and $p$-iodobenzaldehyde can be carried out in PBS at $37{ }^{\circ} \mathrm{C}$ with good yields without the requirement of any external base $(65 \%$ yield after $3 \mathrm{~h})$; moreover, the reaction was also carried out in the presence of biologically relevant molecules, and is quite insensitive toward the presence of added amino acids. Unfortunately, the reaction was inhibited by biorelevant thiols such as glutathione and do not proceed in cell lysates, likely due to the mechanistic complexity of the bimolecular process and the lateral reactivity of the some of the transient palladium intermediates with thiols.

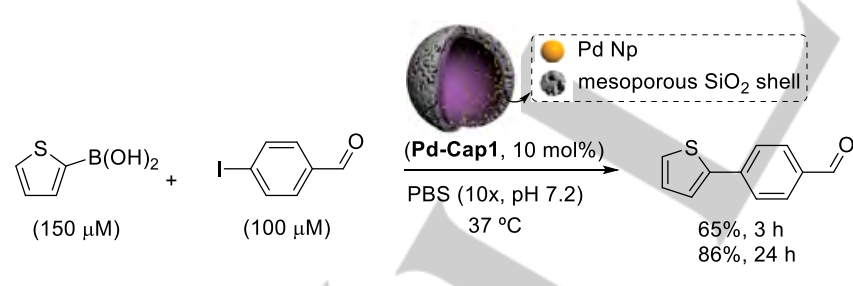

Scheme 3. Suzuki-Miyaura reaction promoted by mesoporous silica nanoshells equipped with Pd-nanoparticles at the internal surface (Pd-Cap1)

\subsection{Pd-catalyzed Sonogashira cross-couplings}

The Sonogashira reaction consists of the cross coupling of terminal alkynes to aryl halides (or pseudohalides) in the presence of a Cu(I) salt, ${ }^{[68]}$ and a palladium catalyst. ${ }^{[69]}$ The first application of this reaction for the modification of proteins was reported by Tachibana and coworkers, ${ }^{[70]}$ and consisted of a coupling between a biotinamide bearing a terminal alkyne and an iodophenyl-containing Ras protein. The reaction was carried out in aqueous media containing DMSO $(18 \%)$, in the presence of $\mathrm{Pd}(\mathrm{OAc})_{2}(15 \mathrm{mM})$, a sodium triphenylphosphine trisulfonate ligand (TPPTS), copper(I) triflate $(0.7 \mathrm{mM})$, sodium ascorbate $(0.2$ $\mathrm{mM})$, and excess of alkyne $(15 \mathrm{mM})$. The desired product was formed in $25 \%$ yield after 80 min of reaction at $6^{\circ} \mathrm{C}$, using $1.4 \mathrm{mM}$ of peptide (Figure 18, A). These conditions are not very biocompatible, since copper(I) salts and sodium ascorbate have cytotoxic effects, as discussed before, and the palladium loading is significantly high.

The Lin's group used a slightly modified version of the Davis's catalysts (Pd-5), to perform a copper-free Sonogashira crosscoupling (Heck-Cassar coupling) of an homo-propargylglycineencoded ubiquitin protein (HPG-Ub) and a wide range of aryl iodides, in aqueous media (Figure 18, B). ${ }^{[71]}$ For this purpose, the authors treated a $5-10 \mu \mathrm{M}$ solution of the protein with the palladium complex $(1 \mathrm{mM})$ and the aryl iodide $(0.1 \mathrm{mM})$, which led to the coupled products in short reaction times $(30-240 \mathrm{~min})$ and yields between 50 and $90 \%$. This methodology was also successfully applied by Lin and coworkers to label proteins in mammalian cell surfaces. ${ }^{[72]}$ Moreover, the reaction could also be performed inside E. coli.

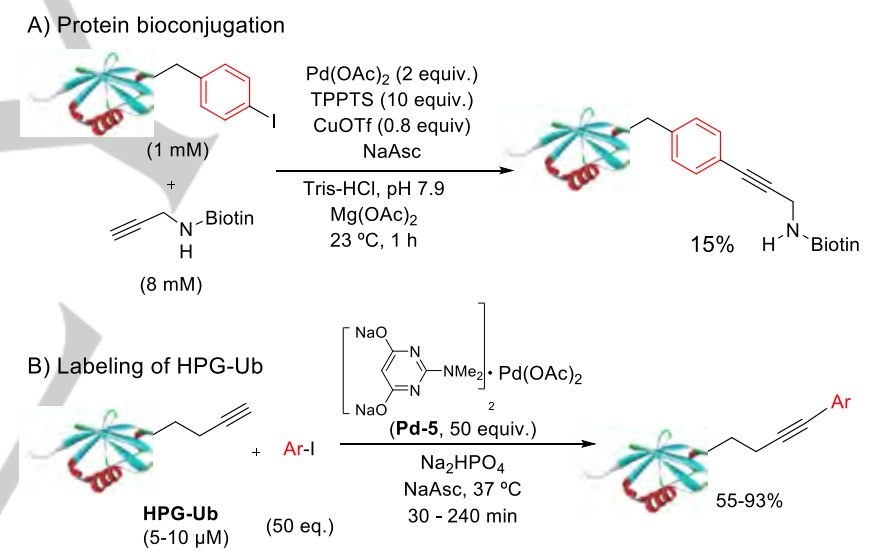

Figure 18. Pioneer developments (A) in protein bioconjugations using Sonogashira couplings, and selective labelling of the homopropargyl glycinencoded ubiquitin (HPG-Ub).

Interestingly, a copper and ligand-free version of the Sonogashira reaction (Heck-Cassar coupling) was developed by Chen's group using small-sized Pd complexes. ${ }^{[73]}$ In particular, these authors showed that a terminal alkyne-modified green-fluorescent protein (GFP-N149, $10 \mu \mathrm{M}$ ) can be coupled with a fluorophore bearing an aryl iodide $(100 \mu \mathrm{M})$ in the presence of a suitable Pd complex (100 $\mu \mathrm{M})$ and sodium ascorbate $(1 \mathrm{mM})$ at $\mathrm{rt}(1 \mathrm{~h})$. The most efficient results were obtained employing $\mathrm{Pd}\left(\mathrm{NO}_{3}\right)_{2}$ and $\mathrm{Na}_{2} \mathrm{PdCl}_{4}$ as $\mathrm{Pd}$ reagents $(95 \%$ and $90 \%$ yield of the product, respectively, Figure 19 ), whereas Lin's complex (Figure 18, B) afforded the product in $53 \%$ yield. Remarkably, this reaction was used for site-specific protein labelling inside pathogenic Gram-negative bacterial cells. It is important to highlight that $\mathrm{Pd}\left(\mathrm{NO}_{3}\right)_{2}$ and $\mathrm{Na}_{2} \mathrm{PdCl}_{4}$ are indeed precursors of the active species, since, in the presence of an 
electron donor agent like sodium ascorbate, these complexes are readily reduced to $\operatorname{Pd}(0)$ nanoparticles, which are suggested by the authors to be the real reagents. ${ }^{[74]}$

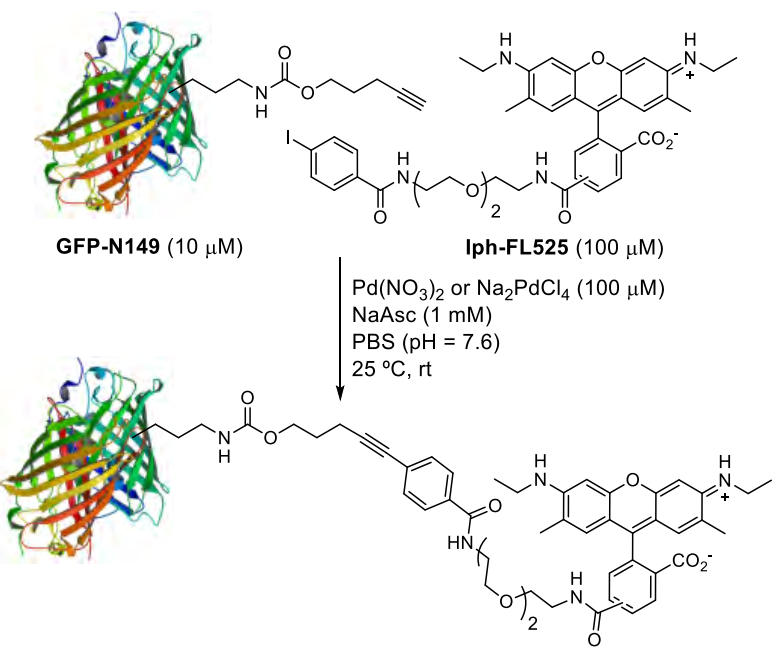

Figure 19. Heck-Cassar reaction by Chen's group using discrete Pd catalysts.

\section{5. $\mathrm{Pd}(\mathrm{II})$ and $\mathrm{Au}(\mathrm{I} / \mathrm{III})$ catalyzed $\mathrm{C}-\mathrm{S}, \mathrm{C}-\mathrm{N}$ and $\mathrm{C}-\mathrm{C}$ bond formations}

Due to its distinctive nucleophilicity, cysteine is one of the most useful handles for bioconjugation. Generally, $S_{N} 2$ substitutions with alkyl halides and Michael additions to $\alpha, \beta$-unsaturated compounds (e.g. maleimide) are the most common reactions to introduce diversity at these protein residues. On the other hand, arylation of cysteine remained challenging because of the issues associated with the development of a mild nucleophilic aromatic substitution reactions with sulfur-based nucleophiles.

In this context, Wong and coworkers reported in 2014 a cyclometallated gold(III) complex [Au(bpy)msen] (Au-1, Figure 20) for the chemoselective cysteine modification of peptides and proteins based on a ligand exchange reaction and reductive elimination. ${ }^{[5]}$ This strategy was used for the stoichiometric modification of small peptides in aqueous mixtures with remarkable yields $(67-99 \%$, Figure $20, \mathrm{~A})$, and also for the arylation of bovine serum albumin (BSA) with the dansyl-based gold complex Au-2 (Figure 20, B).

Unfortunately, the need of an arylpyridine moiety in the cyclometalated gold reagent represents an important limitation of the methodology in terms of versatility. Moreover, the unfavorable reaction kinetics due to a slow reductive elimination step from intermediates, makes necessary to heat at $37^{\circ} \mathrm{C}$ for a prolonged time, which facilitates the degradation of the proteins under these conditions.

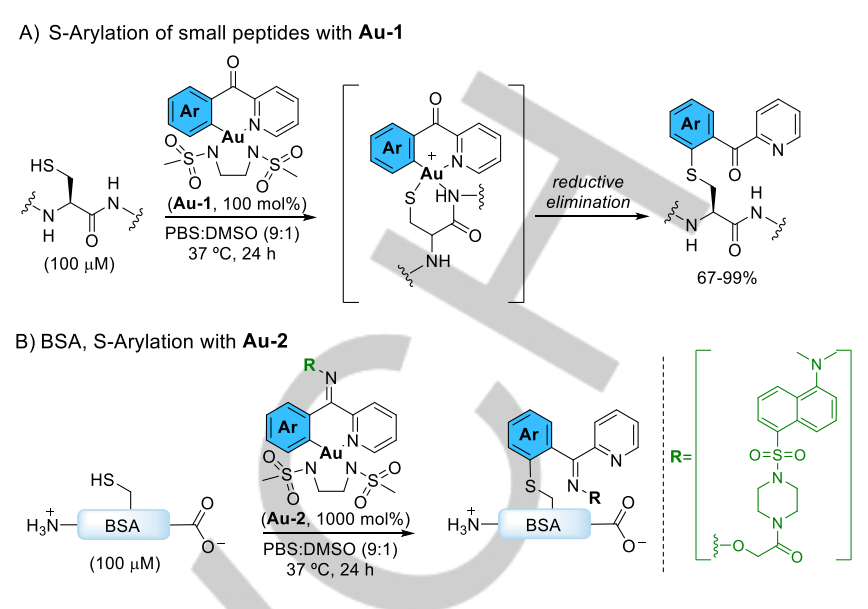

Figure 20. Cysteine-residue arylation mediated by $\mathrm{Au}$ (III) complex.

In 2015, Buchwald, Pentelute and coworkers introduced a related organometallic approach to arylate cysteines in peptides and proteins based on the use of air stable aryl palladium(II) reagents. ${ }^{[6]}$ Notably, although the presence of thiols had been long considered to inhibit palladium-catalyzed cross-coupling reactions on peptides, these authors demonstrated that a careful choice of ligands at palladium allows the soft nucleophilic thiol of cysteine to react, selectively, with certain aryl palladium(II) species. Thus, in the case of peptides, full conversions and high selectivities towards cysteine arylations were obtained within minutes using the RuPhosPd(II) aryltriflate complex Pd-6 (Figure $21, A){ }^{[77]}$ Remarkably, while the conjugates typically obtained from the reaction of thiols with maleimide usually show poor stability in the presence of external bases or thiol nucleophiles, ${ }^{[78]}$ the hybrids obtained from this Pd-promoted $S$-arylation presented excellent stability towards acids, bases and external thiols.

Moreover, the synthesis of bis-palladium reagents like Pd-7 from commercially available aryl or biaryl dihalides allowed the macrocyclization of peptides containing two cysteine residues to occur with excellent selectivity (Figure 21, B).

$$
\text { A) S-arylation }
$$

B) Macrocyclization

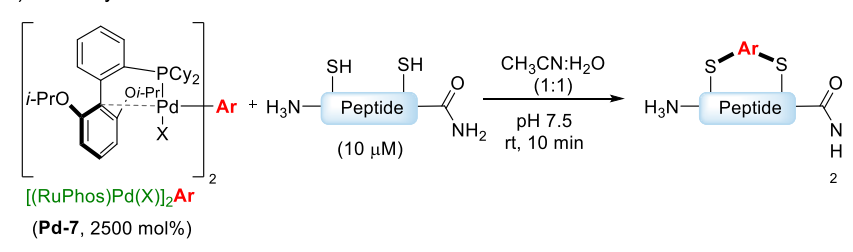

Figure 21. Pd-promoted cysteine arylation reactions in peptides and proteins. 
Mechanistically, the reaction can be considered to involve two main steps (Scheme 4), nucleophilic attack on the pre-formed palladium(II) complex, deprotonation and reductive elimination to give the arylated product containing the C-S bond.

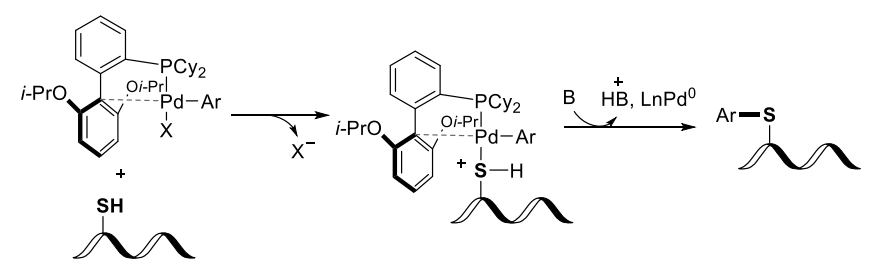

Scheme 4. Elementary steps in C-Nu bond formation.

A catalytic version of this method was reported by Messaoudi and coworkers in 2016. ${ }^{[79]}$ Using XantPhos-based aminobiphenyl mesylate palladium pre-catalysts (Pd-8) and aryl iodides, they were able to transform short unprotected peptides into the corresponding S-arylated products (Scheme 5). The reactions were carried out at room temperature in a water:tetrahydrofuran (2:8) mixture, using $2 \mathrm{~mol} \%$ of the Pd catalyst, and provided the products with yields above $90 \%$. Even though this catalytic reaction has been shown to be robust and quite general, their effectivity has been only demonstrated for the arylation of small peptides in highly concentrated $(0.25 \mathrm{M})$ aqueous THF solutions. The palladium-promoted coupling strategy was used for the labeling of the monoclonal antibody Trastuzumab. In this case, excess of the Pd complex (Pd-8) (1.25 eq. for each of the eight free-cysteine residues) and of a fluorescent aryl iodide derivative (2.5 eq. for each cysteine) were used, and the corresponding fluorophore to antibody ratio was estimated to be of three ${ }^{[79]}$ Not surprisingly, a side product due to the transfer of the 2-amino biphenyl moiety of the complex Pd-8 was also detected. Therefore, for applications under more challenging conditions, a further optimization of the process is compulsory to improve efficiency and chemoselectivity.

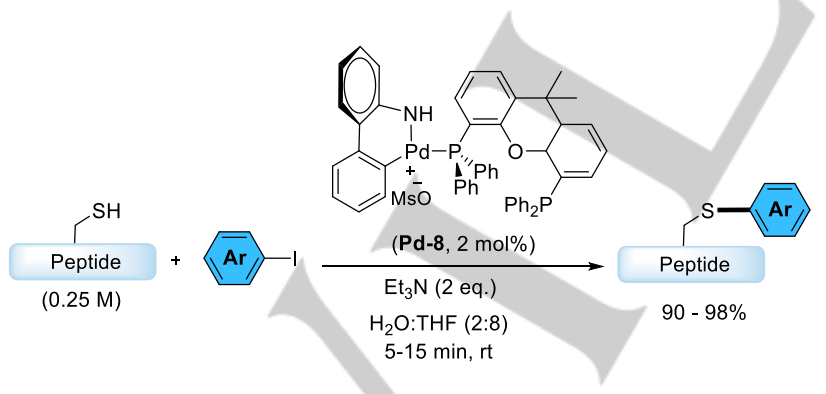

Scheme 5. Pd-8 complex for catalytic cysteine arylations.

More recently, Buchwald and Pentelute have also reported the arylation of amine groups in lysine residues (Figure 22). ${ }^{[80]}$ In this case, the reaction showed to be more challenging than that of cysteines, because of the less nucleophilic nature of the amine. Moreover, due to the lower acidic nature of the putative palladiumamine complex intermediate, the use of an external base is mandatory. Moreover, to facilitate the desired $\mathrm{C}-\mathrm{N}$ reductive elimination in preference to other Pd-mediated bond forming processes, an appropriate selection of the palladium ligand becomes crucial. The best results for these processes were obtained with the very bulky BrettPhos family of ligands (Figure 22).

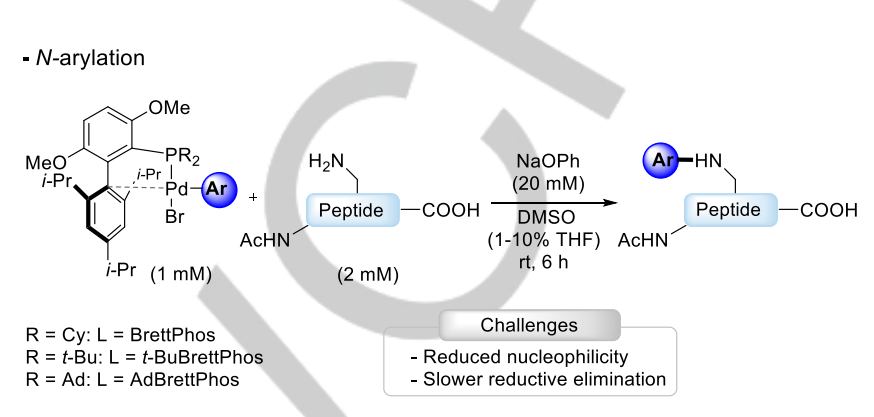

Figure 22. $\mathrm{C}-\mathrm{N}$ bond formation: $\mathrm{N}$-arylation of lysine residues.

Finally, in 2018, Spokoyny and coworkers introduced a gold(III) complex (Au-3) for cysteine arylations. ${ }^{[81]}$ The reaction showed almost the same kinetic and chemoselectivity profile than the palladium-based one, leading to full conversions in few minutes and being compatible with a wide pHs (from 0.5 to 14). But importantly, in a competition experiment between the gold and palladium arylating-reagents Au-3 and Pd-9, the gold complex showed a higher reactivity towards glutathione (GSH) (Scheme $6)$.
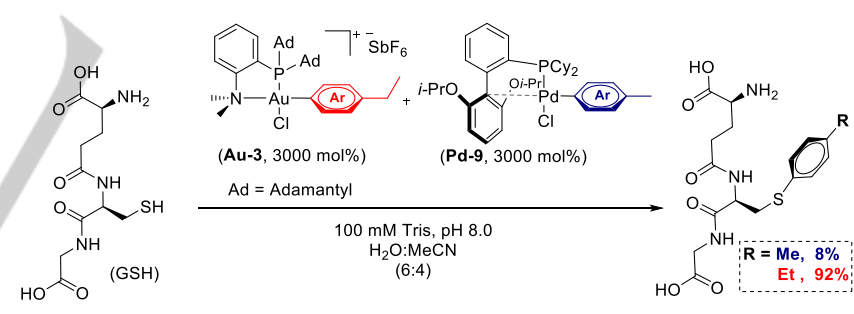

Scheme 6. Competitive glutathione (GSH) arylation with Au-3 and Pd-9.

Despite these advances, until now, there are not reports on the use of this type of couplings in living environments. However, several groups have developed fluorogenic probes that undergo fluorescent turn-on responses upon $\mathrm{Au}^{3+}$-promoted cyclizations, even in cellular contexts. ${ }^{[82]}$

Tae and coworkers reported the synthesis of a chemosensor for $\mathrm{Au}^{3+}$ ions based on a rhodamine amide tethered to an alkyne (12, Figure 23) that undergoes a fluorescent turn-on upon irreversible $\mathrm{Au}^{3+}$-promoted cyclization to generate the product (13). ${ }^{[82 \mathrm{a}]}$ The reaction was carried out in PBS buffer and was used for the fluorogenic detection of $\mathrm{Au}^{3+}$ ions in fixed HeLa cells. Related approaches were reported by Yoon, ${ }^{[82 b, c]}$ Ahn and coworkers, ${ }^{[82 d]}$ for the fluorogenic detection of $\mathrm{Au}^{+}$and $\mathrm{Au}^{3+}$ salts (Figure 23). 
A) General strategy for the development of gold ion chemosensors

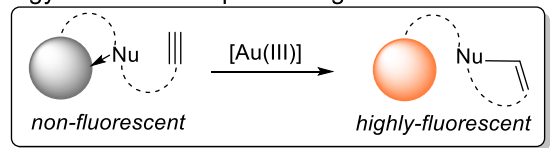

B) Rhodamine-amide chemosensor for $\mathrm{Au}^{+3}$ ions

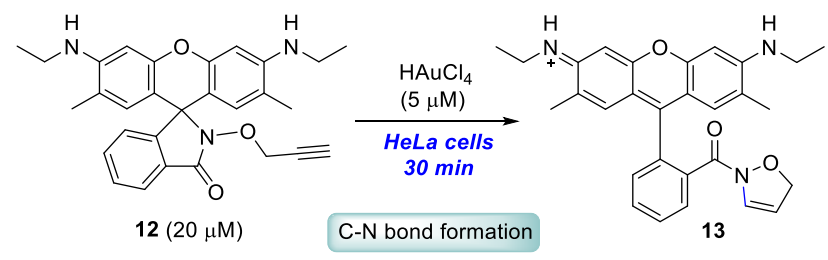

Figure 23. Chemosensor for $\mathrm{Au}^{3+}$ ions.

Another strategy to detect gold ions was reported by Patra and coworkers, ${ }^{[82 h]}$ and is based on a gold-promoted release of a fluorophore. The probe was made by linking a fluorescein derivative to 2-ethynylbenzoic acid. Upon addition of $\mathrm{Au}^{+}$or $\mathrm{Au}^{3+}$ salts, the substrate undergoes an intramolecular cyclization to produce an isochromene derivative 15 , while releasing a methylfluorescein dye (Figure 24). This approach was used to detect $\mathrm{Au}^{+}$ions even inside $\mathrm{A} 549$ cells, albeit the study was very preliminary.
Then, these preformed Glyco-Au complexes were intravenously introduced into live nude mice and after a rapid glycan-directed organ accumulation, a pro-fluorescent propargyl ester was injected. Based on fluorescence and imaging studies, the authors proposed that the reaction took place on surface proteins of the liver (using disialoglycoalbumin, Sia) or intestine (using galactosylglycoalbumin, Gal). This work showed, for the first time, that a gold(III) metal complex can be used in vivo to promote a synthetic transformation, opening in this way new avenues for biomedical applications. Although the requirement of a propargyl ester for an efficient amidation strongly suggests that the ester moiety is activated through a gold-alkyne coordination, deeper mechanistic studies are needed.

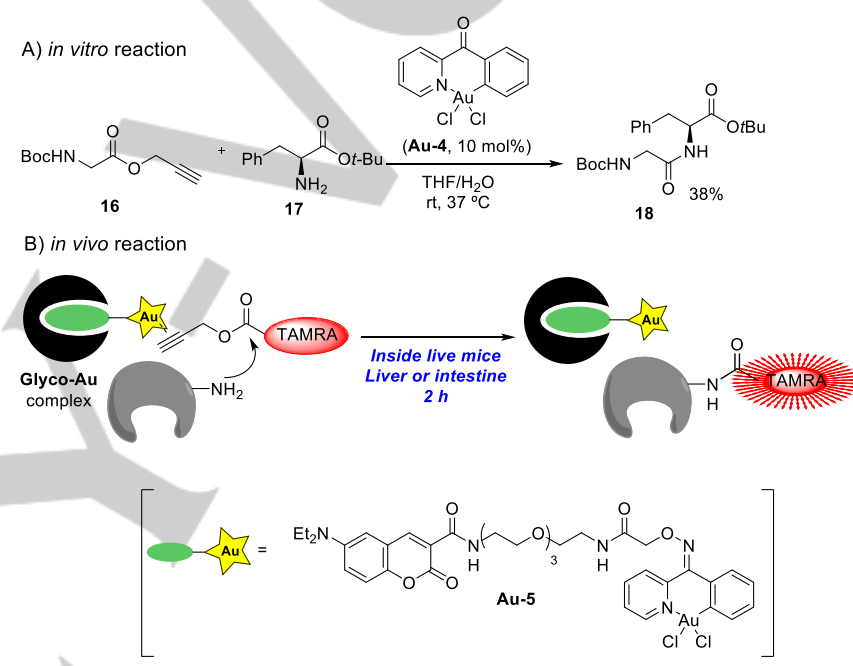

Figure 25. Gold-promoted amide bond formation in aqueous media (A) and in live mice (B)

Finally, Mascareñas and coworkers reported in 2018 a catalytic hydroarylation promoted by $\mathrm{Au}(\mathrm{I})$ complexes that take place not only in bio-relevant complex media but also inside living mammalian cells. ${ }^{[84]}$ Initially, the hydroarylation process was explored in a water-acetonitrile mixture using $5 \mathrm{~mol} \%$ of the gold(I) complex Au-6, providing the expected product in excellent yield (Figure 26, A). The authors demonstrated that water acts not only as solvent but also a chloride scavenger, that is essential to generate the catalytically active gold species. After these results, the reaction was explored in complex biological media, such as PBS (phosphate buffer saline solution), DMEM (media for the cell growth), and HeLa cell lysates, observing yields between moderate and good. This reasonable bioorthogonal profile prompted the authors to translate the reaction to the interior of living cells. The results confirmed that the $\mathrm{Au}(\mathrm{I})$ complex Au-6 can promote hydroarylation reactions inside living mammalian cells without affecting the cell viability during the required reaction times. Also important, they demonstrated for the first time the possibility of combining in a mutually orthogonal manner, an intracellular ruthenium-mediated $\mathrm{N}$-alloc removal (see section 4.1, Figure 35 for the development of this Ru-promoted uncaging) and 
the above gold promoted $\mathrm{C}-\mathrm{C}$ bond forming process (Figure 26, B). This represents a pioneering step in the future development of artificial metabolic networks based on transition metal catalysis.

A) Gold(I) catalyzed hydroarylation inside living cells

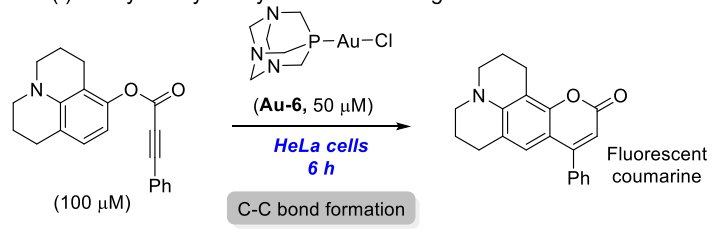

B) Dual metal mediated reaction in living cells

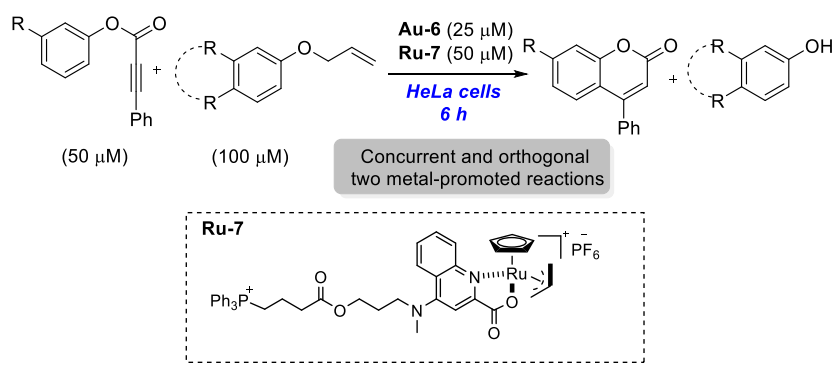

Figure 26. Gold(I) catalyzed hydroarylation reaction inside living HeLa cells (A), and $\mathrm{Au}$ and $\mathrm{Ru}$ complexes working in a concurrent and orthogonal manner inside living cells.

\subsection{Reactions with metal-hydride complexes}

The reduction of unsaturated systems using metal-hydride complexes, also known as metal catalyzed transfer hydrogenation, has also been explored in the context of bioorthogonal chemistry in aqueous media. Mechanistically, metal-catalyzed transfer hydrogenations generally proceed through the in situ generation of a metal-hydride species by reaction with a hydride donor (e.g NADH). The transient metal hydride species could then transfer the hydride to a proton source generating hydrogen gas (Figure 27, A, eq 1), or directly reduce a carbonyl moiety through an inner-sphere mechanism (Figure 27, A, eq. 2). ${ }^{[85]}$ Sadler and coworkers demonstrated in 2012 that cationic organometallic $\mathrm{Ru}(\mathrm{II})$ and $\operatorname{Ir}(\mathrm{III})$ complexes such as $\mathbf{R u}-\mathbf{8}$ and Ir-1 (Figure 27, B) can be used for the stoichiometric reduction of pyruvate to lactate in water, using NADH as a hydride source. ${ }^{[86]}$ In particular, the reaction of the complex Ir-1 with $\mathrm{NADH}$ in a 9:1 $\mathrm{H}_{2} \mathrm{O} / \mathrm{MeOH}$ mixture generates a Ir-hydride complex Ir-2 (rate limiting), which promotes the reduction of pyruvate to afford lactate in $30 \%$ yield.

In 2018, the same group reported an asymmetric transfer hydrogenation of pyruvate to generate $D$-lactate in the interior of cells by using an osmium (II) complex (Figure 27, C). ${ }^{[87]}$ Although the transformation in the aqueous media take place at very low yield $(\sim 1 \%)$ using sodium formate as hydride source, the reaction was enantioselective. On these bases, the authors explored the enantioselective hydrogenation of pyruvate to produce $D$ or $L$ lactate in cells. Due to $L$-lactate is formed naturally by the reduction of pyruvate by the enzyme lactate dehydrogenase $(\mathrm{LDH})$, they studied the formation of the $D$-lactate, also present in the cells but at lower concentration. These results represent the first demonstration of the enantioselective reduction of pyruvate by a synthetic catalyst taking place inside cells (Figure $27, \mathrm{C}$ ).

A) General mechanistic scenarios for metal-catalyzed transfer hydrogenations

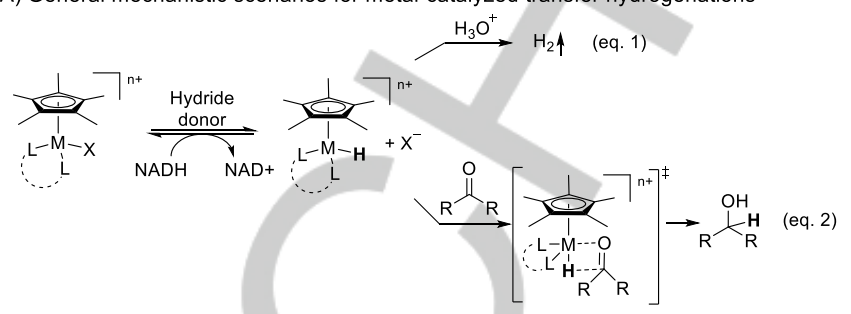

B) Example developed by Sadler

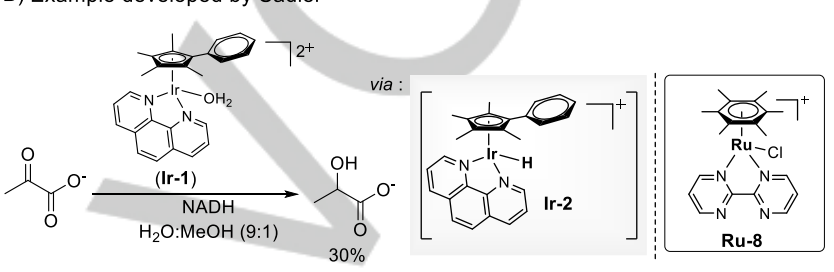

C) Intracellular asymmetric transfer hydrogenation mediated by an Os(II) complex
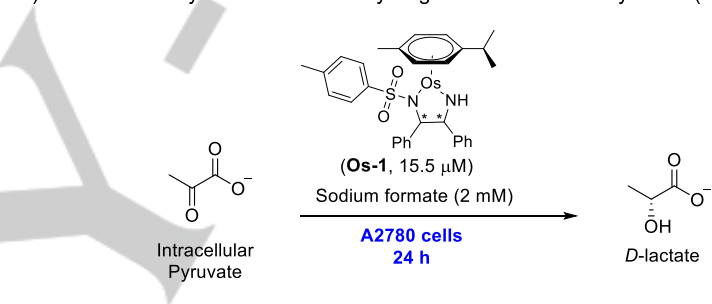

Figure 27. Metal-mediated transfer hydrogenation.

Along the same lines, the Do's group developed an interesting iridium-mediated reduction of aldehydes such as benzaldehyde (among others) in alcoholic PBS and biological media, using $\mathrm{NADH}$ as a hydride transfer agent (Figure $28, \mathrm{~A}){ }^{[88]}$

A) Benzaldehyde reduction
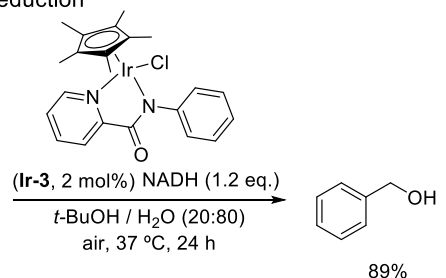

$89 \%$

B) Cytotoxic enal reduction
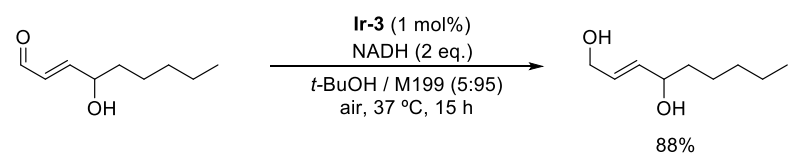

Figure 28. Iridium-promoted transfer hydrogenation in biological media.

The reaction was carried out in $\mathrm{t}-\mathrm{BuOH}: \mathrm{PBS}(2: 8)$ mixtures, under air, at $37^{\circ} \mathrm{C}$ and also in the presence of biologically relevant 
molecules (like amino acids and GSH). The Cp*Ir complex Ir-3, bearing a N-phenyl-2-pyridinecarboxamidate derivative as ligand, was found to be the most active catalyst. Interestingly, this method allowed the conversion of cytotoxic enals to more biocompatible alcohol derivatives in complex media (M199), just as an enzyme mimic for aldehyde detoxification (Figure 28, B). Additionally, Do and coworkers exported this chemistry to living cells (Scheme 7). ${ }^{[89]}$ In particular, they treated NIH-3T3 mouse embryo fibroblast cells with Bodipy- $\mathrm{CHO}$ (19), an aldehyde that features a fluorogenic BODIPY probe, and the Ir complex Ir-3. After $2 \mathrm{~h}$, they observed, by confocal fluorescence microscopy, a slight fluorescence enhancement, suggesting that the reduction of Bodipy-CHO to Bodipy-OH (20) was taking place.
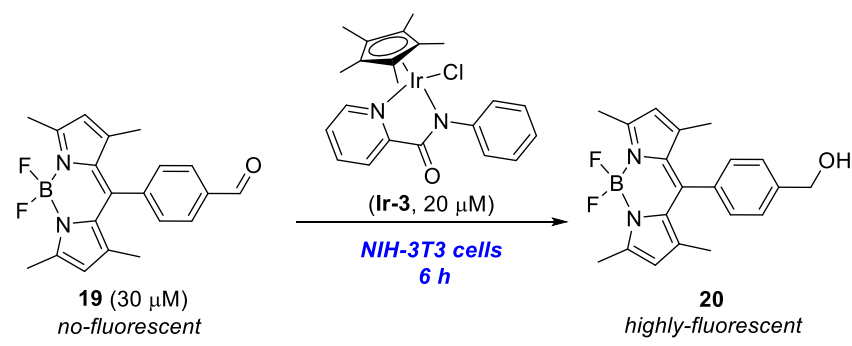

Scheme 7. Intracellular aldehyde reduction by Do and coworkers.

A related example involving ruthenium hydride intermediates was reported by Mascareñas and coworkers based on the redox neutral isomerization of allylic alcohols using a ruthenium (IV) complex (Ru-9). ${ }^{[90]}$ Considering previous contributions with related reactions in water, ${ }^{[91]}$ they questioned whether this type of isomerizations could be achieved in biological media (Figure 29, A). The reaction proceeds efficiently in water and in other biological media, such as PBS, DMEM or HeLa cells lysates with very good yields and with a broad scope, and it can also be carried out inside HeLa cells. They designed a fluorogenic probe that showed green emission after the isomerization reaction, so this signal could be observed in all cell lines tested after only $30 \mathrm{~min}$ of incubation (Figure 29, A). Moreover, the authors also made the first quantitative calculation of an intracellular turnover number (TON), demonstrating that this transformation takes place in a catalytic manner. The reaction was also used to generate glutathione depleting agents by isomerization of bis-allyl alcohols to the corresponding $\alpha, \beta$-unsaturated compounds (Figure 29, B).

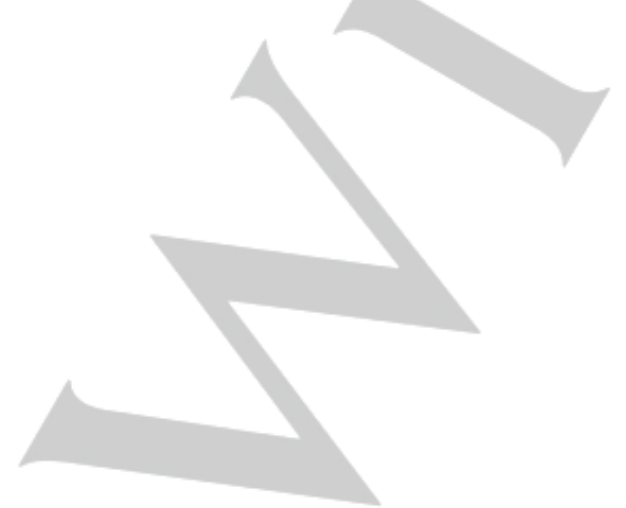

A) Ru-catalyzed bioorthogonal isomerization of allylic alcohols

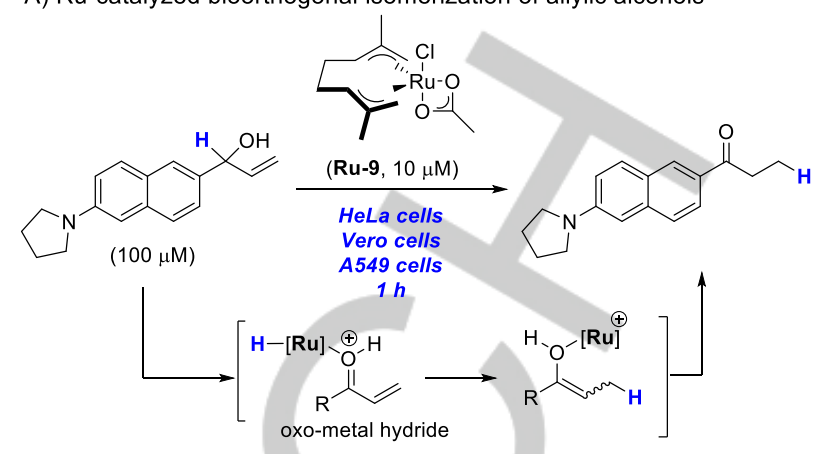

B) Strategy to reduce the levels of the GSH inside living cells

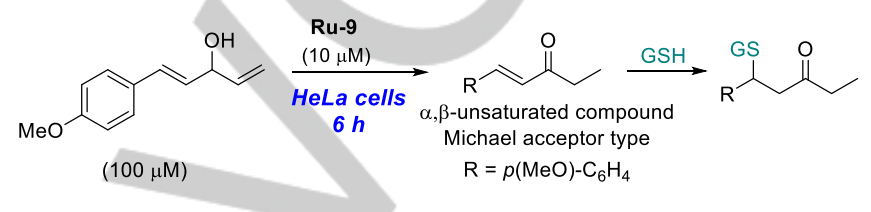

Figure 29. Ru-catalyzed isomerization of allylic alcohols in biological media.

Finally, it is worth highlighting a very recent example by Qu and coworkers describing chiral-modified $\mathrm{Pd}$ catalysts that can promote asymmetric transfer hydrogenation reactions using sodium formate as the biocompatible reductant. As a proof of concept, the chiral model drug ibuprofen was prepared from its corresponding dehydrogenated precursor in living cells as well as mice, observing the desired anti-inflammatory action. ${ }^{\text {[92] }}$

\section{Bond cleavage reactions}

In this section, we include transition metal promoted bioorthogonal reactions in which existing bonds are broken and therefore there is a concomitant release of molecular entities.

\subsection{Cleavage of $N$-Allyloxycarbonyl (alloc) and $O$-allyl groups}

It is well known that allylic compounds can react with carbon or heteroatom nucleophiles in presence of transition metal catalysts. As early as in 1965, Tsuji demonstrated that an electrophilic palladium-allyl complex, bound in $\eta^{3}$ fashion, reacts in a stoichiometric manner with carbon nucleophiles generating a new C-C bond (Figure 30, A) ${ }^{[93]}$ Hata and Atkins reported the first catalytic versions, in which allyl alcohols and derivatives were used as precursors of transient $\pi$-allyl $\mathrm{Pd}$ complexes that eventually react with nucleophiles (carboxylates, alcohols, amines etc.) to deliver the corresponding products (Figure 30, B; nucleophile $\left.=\mathrm{Et}_{2} \mathrm{NH}\right) \cdot{ }^{[94]}$ 
A) Tsuji (1965)

$$
1 / 2\left[\left\langle(-\mathrm{PdCl}]_{2}+\mathrm{EtO}_{2} \mathrm{C} \widehat{\mathrm{CO}_{2} \mathrm{Et}} \frac{\mathrm{NaH}}{\mathrm{DMSO}} \underset{\mathrm{EtO}_{2} \mathrm{C}}{\stackrel{\mathrm{CO}}{\mathrm{Et}}}\right.\right.
$$

B) Atkins (1970)

$$
\begin{aligned}
& \begin{array}{ccc}
\mathrm{X}+\mathrm{NHEt}_{2} & \mathrm{Pd}(\mathrm{AcAc})_{2}(0.5 \mathrm{~mol} \%) \\
\mathrm{P}=\mathrm{OH}, \mathrm{OPh},-\mathrm{OC}(\mathrm{O}) \mathrm{R} & 50^{\circ} \mathrm{C}, 0.5 \mathrm{~h}
\end{array} \mathrm{NEt}_{2}
\end{aligned}
$$

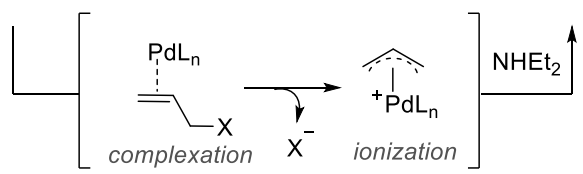

Figure 30. Pioneering examples of Pd-promoted allylic substitutions.

This type of reactivity with Pd catalysts is now very well developed, thanks in part to the relevant contributions disclosed by the group of Trost throughout these decades. Moreover, metal-catalyzed allylic substitutions have been developed with transition metals others than palladium, such as ruthenium, iridium, molybdenum, cobalt or rhodium, both in a racemic and enantioselective manner. ${ }^{[95]}$

Importantly, the nucleophilic substitution can also be carried in substrates featuring allyloxycarbonyl (alloc) instead of allyl groups, like carbamates or carbonates, reactions that convey the release of amines and alcohols as secondary products. Thus, the reaction of an allyl carbamate (or carbonate) with the metal complex generates a $\pi$-allyl metal intermediate of type I with concomitant decarboxylation and release of $\mathrm{CO}_{2}$ and the free amine (or alcohol). Interception of this allylic species by a sacrificial nucleophile $(\mathrm{NuH}$, e.g. water) regenerates the catalyst (Scheme 8).

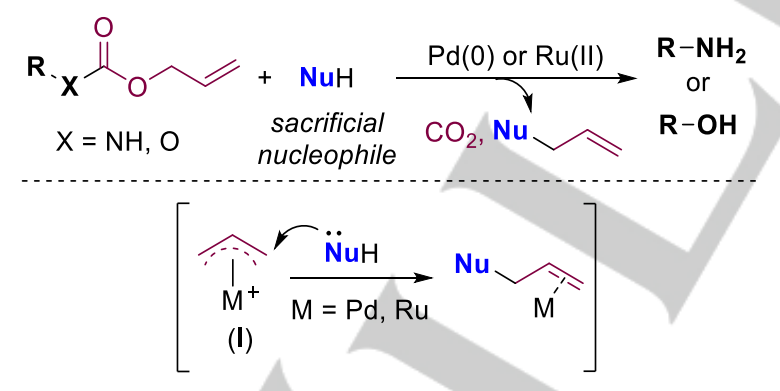

Scheme 8. Cleavage of allyloxycarbonyl-protected amines and alcohols.

As already commented in the introduction (Scheme 2), Meggers et al. demonstrated in 2006 that $\mathrm{N}$-alloc-protected amines such 21 can react with catalytic amounts of [RuCp*(COD)Cl] (Ru-1), in aqueous buffers, in the presence of excess of thiophenol $(\mathrm{PhSH}$, 5 eq.), to release the $p$-toluidine (Figure 31 ). Interestingly, the reaction could also be carried out inside HeLa cells using a caged rhodamine 110 as fluorogenic probe which, upon alloc removal, generates the highly fluorescent rhodamine 110 (Scheme 2, page
3). Although the authors did not investigate the process in detail, it constitutes the first demonstration of the utility of ruthenium complexes as bioorthogonal catalysts in mammalian cells. ${ }^{[23]}$

This type of ruthenium-promoted deprotection was further developed by Meggers in 2012 using the photoactivable halfsandwich ruthenium pyrene (Pyr) complex $\left[\operatorname{RuCp}^{*}\left(\mathrm{Pyr}_{\mathrm{r}}\right) \mathrm{PF}_{6}\right.$ (Figure 31). ${ }^{[96]}$ This inert complex, upon photoactivation (5 min. at $\lambda \geq 330 \mathrm{~nm}$ ), is transformed into a catalytically active ruthenium species (by $\eta^{6}$-pyrene displacement) that is able to carry out the uncaging of several alloc protected amines under mild conditions (DMSO, rt, under air), albeit the presence thiophenol as nucleophile is still required. Likewise, the deprotection reaction could also be performed in live cells using the $\mathrm{N}$-alloc-protected rhodamine 110 as substrate. The possibility to activate the catalyst in the presence of UV light augurs well for its use in applications that require spatial and temporal control, albeit further studies are needed to demonstrate the potential of the technology since the requirement of an excess of thiophenol $(\mathrm{PhSH})$ and the use of DMSO as solvent limits its bioorthogonal potential.
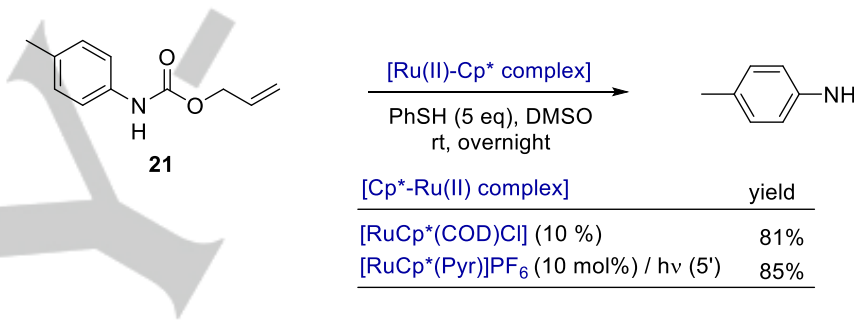

Figure 31. Ru(II) catalyzed cleavage of allyloxycarbonyls.

In this context, Mascareñas and coworkers reported in 2014 the first example of a Ru(II)-catalyzed uncaging of $\mathrm{N}$-alloc protected DNA-binding agents in complex aqueous media (e.g. DAPI, Figure 32, A) and inside living mammalian cells (e.g. ethidium bromide, Figure 32, B). ${ }^{[97]}$ In particular, while $\mathrm{N}$-alloc-protected 4,6-diamidino-2-phenylindole (DAPI) and ethidium bromide show poor ability to interact with DNA, upon treatment with $\left[\mathrm{RuCp}^{*}(\mathrm{COD}) \mathrm{Cl}\right]$ for alloc removal, the parent DNA binding species are released.

When Vero cells were treated with $\mathrm{N}$-alloc protected DAPI $(2.5$ $\mu \mathrm{M})$, this was evenly distributed between cytoplasm and cell nuclei. However, upon addition of the ruthenium complex [RuCp*(COD)Cl] $(2.5 \mu \mathrm{M})$ and thiophenol $(100 \mu \mathrm{M})$ its location changed, leading to a clear redistribution of the emission into the cell nuclei, as a consequence of the release of uncaged DAPI, and its affinity towards nuclear DNA. Similar effects were observed when CEF primary cells were treated with $\mathrm{N}$-alloc caged ethidium bromide $(10 \mu \mathrm{M})$, which showed a preferential accumulation into the cytoplasm. However, after addition of the ruthenium complex $(20 \mu \mathrm{M})$ and thiophenol $(100 \mu \mathrm{M})$ it accumulated into the nuclei and nucleoli, which show a strong red emission (Figure 32, B). 


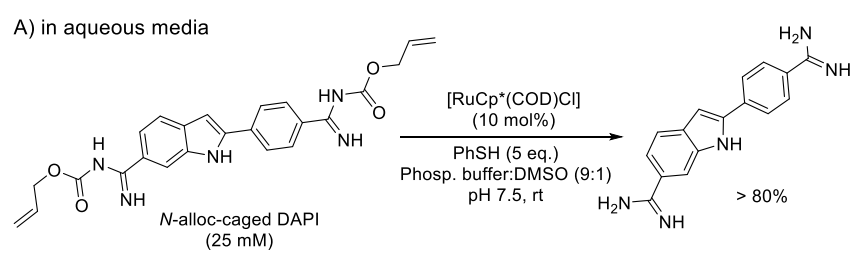

B) in living cells

$$
\begin{gathered}
\begin{array}{c}
\text {-alloc-caged ethidium bromide }(10 \mu \mathrm{M}) \\
\text { (reduced DNA-binding ability) }
\end{array} \\
\begin{array}{c}
\text { in CEF cells } \\
\text { (high affinity for } \\
\text { nuclei and nucleoli) }
\end{array}
\end{gathered}
$$

Figure 32. Generation of the DNA-binding agents by Ru-promoted $\mathrm{N}$-alloc cleavage

An important limitation of the above-described methods is the need of cytotoxic thiophenol as sacrificial nucleophile for the $\pi$ allyl cleavage. In this regard, Meggers and coworkers, after a screening of a set of catalysts that were known to be highly active in the Ru-catalyzed Tsuji-Trost reaction, found that a modified version of the Kitamura catalyst (Ru-10, Figure 33, A) displayed high efficiency in presence of bioavailable glutathione (GSH), instead of thiophenol, as sacrificial nucleophile (Figure 33, B). ${ }^{[8,99]}$ Having established the superior performances of these catalysts, Meggers and coworkers showed that it was possible to activate chemotherapeutic agents inside living cells. Using a similar strategy to that proposed by Mascareñas and coworkers, the wellknown anticancer agent doxorubicin was masked using an $\mathrm{N}$ alloc protecting group, disabling in this way its cytotoxic effect. Incubation of HeLa cells with the masked doxorubicin $(100 \mu \mathrm{M})$ and the ruthenium catalyst Ru-12 $(5 \mu \mathrm{M})$ produces a substantial decrease in cell viability due to the efficient uncaging reaction that release the cytotoxic doxorubicin (Figure 33, C).
A) Kitamura's Ru-catalyzed allylic etherification with Ru-10

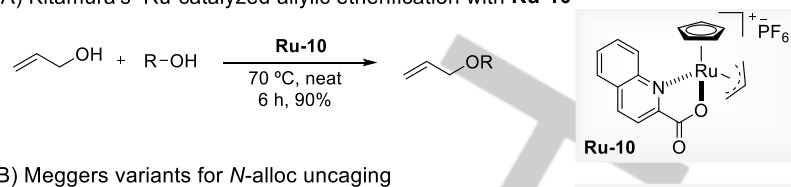

B) Meggers variants for $\mathrm{N}$-alloc uncaging<smiles></smiles>

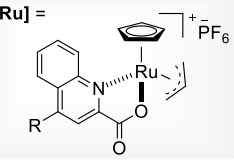
\begin{tabular}{cc} 
[Ru $]$ & TON \\
\hline Ru-10,R=H & 90
\end{tabular} $\mathrm{Ru}-11, \mathrm{R}=\mathrm{OMe} 150$ $\mathrm{Ru}-12, \mathrm{R}=\mathrm{NMe}_{2} 270$

C) Doxorubicin uncaging in living HeLa cells

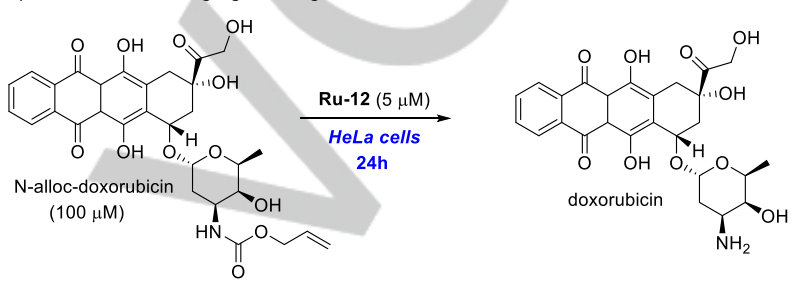

Figure 33. Ru-promoted cleavage of allylcarbamates in aqueous and biological media.

Mechanistically, it was proposed that the $\mathrm{Ru}(\mathrm{II})$ intermediate (Figure 34, I) undergoes ligand exchange with the olefin to generate intermediate II. Then, the ruthenium(IV) $\pi$-allyl complex III would be formed, with concomitant release of the free amine and carbon dioxide. Finally, a nucleophilic attack on this $\pi$-allyl complex generates the Ru(II) intermediate IV which, after ligand exchange, restores the catalytically active species (II). The reaction follows a zero-order dependence on glutathione (GSH), and this suggests that the catalytic performances are not affected by the high concentrations of thiols in biologically relevant conditions or in living cells, avoiding in this way a rapid passivation of the catalyst. These evidences are crucial to understand the catalytic behavior of this family of catalysts; in fact, millimolar concentration of thiols in living cells do not diminish the catalytic activity but instead enable a fast reaction rate since the allylation step is now not rate limiting So, in the presence of strong nucleophiles like glutathione, the uncaging step (formation of III from II) becomes rate determining, whereas in presence of soft nucleophiles like alcohols, the rate determining step shifts towards the allylation (formation of IV from III). 


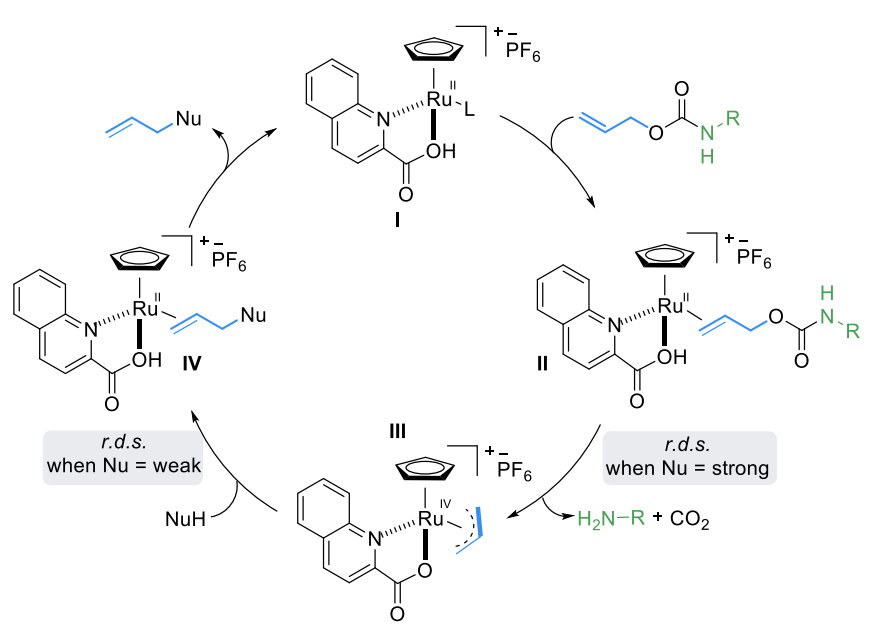

Figure 34. Mechanistic proposal for the allyloxycarbonyl removal using ruthenium catalysts.

In 2016, Wender, Waymouth and coworkers reported an analytical method for the real-time evaluation of the catalytic activity of the Ru catalyst Ru-11 using bioluminescence. ${ }^{[100]}$ Using a $\mathrm{N}$-alloc-protected aminoluciferin (22) they were able to show the extracellular uncaging of this probe to produce a real time bioluminescence readout (Figure 35, A). After a detailed investigation of the catalytic activity in complex aqueous mixtures, in consonance with Meggers results, they found that the presence of thiols like cysteine are crucial to achieve high reactivity and selectivity. However, in absence of thiols several side products were formed.

In the same year, Mascareñas and coworkers reported the synthesis of Ru-13, a Ru(IV)Cp complex functionalized with an aryl phosphonium moiety which exhibits high affinity for the mitochondria of mammalian cells. ${ }^{[101]}$ To test the intracellular catalytic activity of this complex, alloc protected rhodamine 110 was used as fluorogenic probe. Thus, after addition of the ruthenium compound to cells followed by the probe, an intense fluorescent signal $\left(\lambda_{\mathrm{em}}=521 \mathrm{~nm}\right)$ was observed, confirming the intracellular uncaging. The affinity of the catalyst for the mitochondria, associated with the subcellular reactivity was used for the localized generation of the protonophore 2,4-dinitrophenol (DNP, 24), known to decrease the mitochondrial membrane potential and switch off the ATP production (Figure 35, B). Accordingly, albeit the caged allyl-DNP derivative (23) did not show any biological effect, even at high concentrations (500 $\mu \mathrm{M})$, the addition of the caged-DNP to HeLa cells previously treated with the ruthenium catalyst showed a rapid decrease in the mitochondrial membrane potential (indicative of an intense DNP uncaging).

It is important to highlight that treatment of the cells with the ruthenium complex lacking the phosphonium unit only produced a very weak depolarization effect, demonstrating in this way that the subcellular reaction is much more effective in promoting the desired depolarization effect. Moreover, the localized generation of the DNP required lower concentration of the active drug for a reproducible damaging effect, confirming again the effectiveness of the compartmentalized catalysis. ${ }^{[102]}$

A) Bioorthogonal catalytic activation of cellular bioluminiscence

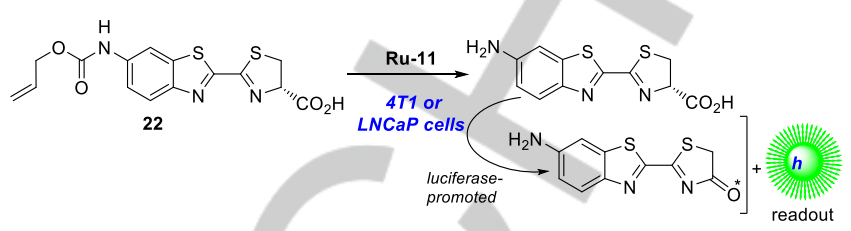

B) DNP-uncaging

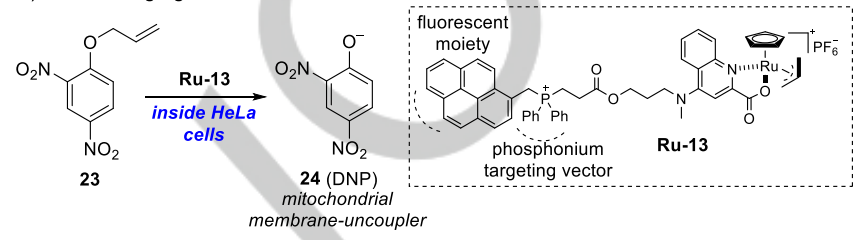

Figure 35. A) Extracellular uncaging of $\mathrm{N}$-alloc-protected aminoluciferine and B) generation of 2,4-dinitrophenol (DNP) inside the mitochondria of HeLa cells

In a series of recent papers, Rotello and coworkers have demonstrated that hydrophobic transition metal catalysts can be encapsulated in water soluble nanoparticles. The resulting nanoconstructs -coined as nanozymes due to their size-similarity with many typical enzymes $(\sim 8 \mathrm{~nm})$ consist of a gold core surrounded by an aliphatic shell, which creates the hydrophobic pockets for catalyst encapsulation/protection, and a polar surface (ammonium groups) that provides the overall aqueous solubility. ${ }^{[103]}$ Following this strategy, in their initial report, this group encapsulated [RuCp*(COD)Cl] (Figure 36, A), and demonstrated that the resulting nanozyme (Ru-Nz-1) was effective for in situ uncaging of $\mathrm{N}$-alloc rhodamine 110 , also in living cells (Figure 36, B).
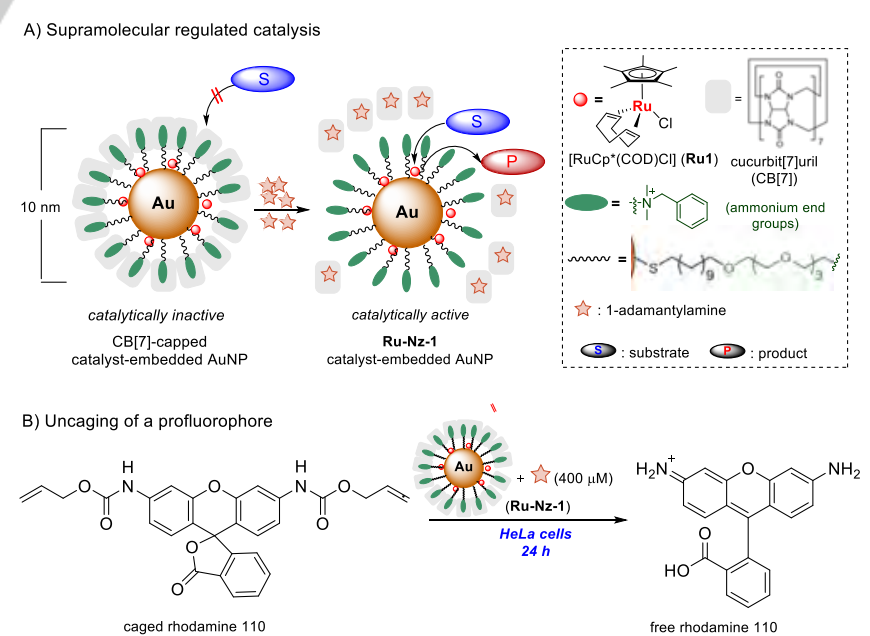

Figure 36. Supramolecular regulation of ruthenium accessibility to the reactants with protein-sized bioorthogonal ruthenium nanozymes. 
Remarkably, the authors showed that by adding curcubituril (CB[7]), which effectively coordinates the ammonium groups, the nanozyme remains inactive whereas, upon addition of 1adamantylamine, the curcubituril caps are released (due to the higher affinity), delivering the active nanozymes. Interestingly, this process proved to be reversible, mimicking the allosteric regulation of enzymes. In subsequent years, the same group developed related nanoenzymes with different properties. ${ }^{[104-107]}$ For instance, surface engineering was used to dictate either extraor intra-cellular localization of the nanozymes. Thus, surface functionalization with zwitterionic sulfobetaine moieties (Ru-Nz-2) limits the Ru-promoted uncaging of pro-Rhodamine and proresorufin to the extracellular space (Figure 37, A). On the contrary, the use of cationic (ammonium) residues at the nanoenzyme surface (Ru-Nz-3) enables their cell-penetration and subsequent intracellular catalysis. The enhanced therapeutic efficacy observed with the cationic nanozymes was attributed by the authors to the stronger impact of intracellular drug activation coupled with a somewhat higher catalytic rate, which was observed with these systems (Figure 37, A).

More recently the same type of surface functionalization was also applied to modulate the generation of protein coronas on these nanoparticles in serum media. Those nanozymes bearing zwitterionic sulfobetaine moieties provide corona-free NPs, whereas those bearing positively charged quaternary ammonium terminal groups, interact with proteins generating soft corona. Moreover, the hard or soft nature of the corona can be modulated by ligand design. For instance, nanozymes having the hydrophobic segment but lacking the PEG-fraction lead to protein denaturation and irreversible protein adsorption (hard corona, Figure $37, \mathrm{~B})$. Nonetheless, the catalytic activity in these passivated particles can be restored upon proteolysis of the protein corona with endogenous proteases such as trypsin. ${ }^{[106,107]}$

A)
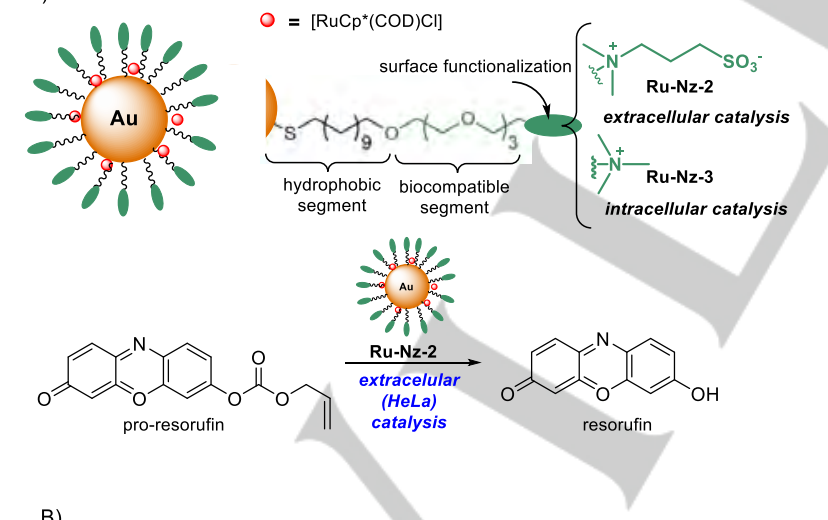

B)

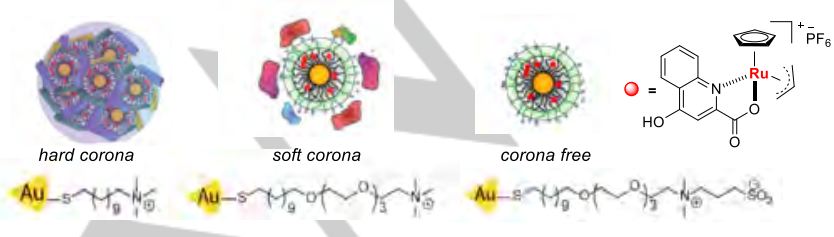

Figure 37. Regulation of intra- or extracellular nanozyme catalysis by surface engineering $(A)$, and regulation of protein coronas $(B)$.
Allyloxycarbonyl groups can also be cleaved using the $\mathrm{Pd}$ microspheres developed by Bradley and Unciti-Broceta (Pd-2, see Figure 15). In particular, this group showed the deprotection of $N$-alloc caged rhodamine $110(30 \mu \mathrm{M})$ in HeLa cells (incubation time 24h). ${ }^{[62]}$ Then, to expand the scope of the in cellulo uncaging strategy, they performed a preliminary cytotoxicity study using alloc-protected amsacrine (Figure 38). ${ }^{[108]}$ As usually, the caged drug showed a relatively lower cytotoxic effect than the parented drug. However, treatment of the cells with the Pd microspheres led to a 7-fold increment of the cytotoxicity, which is proposed to be the consequence of the release of the cytotoxic agent amsacrine, indicating that the masking strategy was suboptimal.

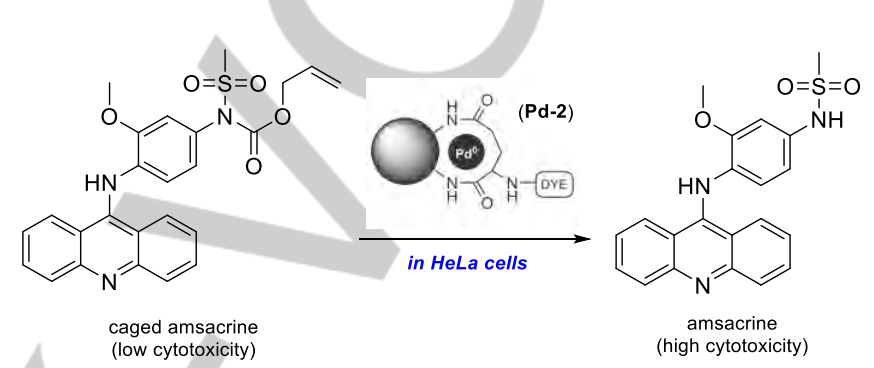

Figure 38. Palladium-promoted Amsacrine uncaging in living cells.

In 2017, a relevant example of in vivo prodrug activation mediated by a palladium deallylation step was reported by Miller, Weissleder and coworkers. ${ }^{[109]}$ After an extensive screening of $\mathrm{Pd}(0)$ and $\mathrm{Pd}(\mathrm{II})$ catalysts either in aqueous buffer or in cell culture media, they found that the trisfuryl phosphane derivative $\mathrm{PdCl}_{2}$ (TFP) $)_{2}$ was particularly active promoting the uncaging of the $\mathrm{N}$-alloc-protected rhodamine 110, providing an 85\% yield after 12 $\mathrm{h}$ at $37^{\circ} \mathrm{C}$ in Hank's Balanced Salt Solution (HBSS).

In general, this palladium complex $\left[\mathrm{PdCl}_{2}(\mathrm{TFP})_{2}\right]$ showed excellent performances for the stoichiometric uncaging under physiological conditions. However, its limited stability in biologically complex media such as FBS, significantly reduced its efficiency. This observation, together with its high lipophilic nature ( $c \log P$ of 7 ), led the authors to encapsulate the palladium complex in a biocompatible poly(lactic-co-glycolic acid)- $b$ polyethyleneglycol platform [(PLGA-PEG)-NP's] (Pd-10, Figure $39, A)$. This not only improved stability and biocompatibility, but it also allowed a precise in vivo delivery of the trisfuryl phosphane $\mathrm{Pd}$ complex, with the possibility to efficiently accumulate into tumors of live mice. The presence of free carboxylic acids on the PEG chains increases the water solubility and improves tumor accumulation. Moreover, after implantation of the $\mathrm{Pd}$ nanoparticles (Pd-10) in mice bearing subcutaneous human fibrosarcoma tumors, biodistribution experiments using ICP-MS allowed them to confirm that the palladium complex was not only able to reach the tumor, but it was also partially released from the nanoparticles (after $20 \mathrm{~h} 50 \%$ of release was observed in vitro). This approach allowed to uncage nanoencapsulated $\mathrm{N}$-alloc doxorubicin in a locally constrained manner, minimizing systemic exposure and toxicity (Figure 39, B). ${ }^{[110]}$

To allow the introduction of more potent cytotoxic agents, such as monomethyl auristatin $\mathrm{E}$ (MMAE), the same group recently 
reported an improved method for the nanoencapsulation of the prodrug, based on a caging strategy that couples bioorthogonal $\mathrm{N}$-alloc cleavage with a self-immolative linker (based on 4aminomandelic acid) and an aliphatic anchor (C16 chains) to tune hydrophobicity. This aliphatic anchor promotes micelle selfassembly and enables $>90 \%$ nanoencapsulation efficiency of the prodrug within PGLA-PEG-NPs. Moreover, upon prodrug activation with $\mathbf{P d}-\mathbf{1 0}$, a $10^{4}$-fold increased cytotoxicity is observed (Figure 39, C). Thus, under combined administration to mice of the nanoencapsulated MMAE prodrug and Pd-10, tumor (HT1080) growth was safely blocked, especially when combined with a local radiation therapy to improve permeability and retention effects. ${ }^{[110 b]}$

A) Synthesis and nanoencapsulation of $\mathrm{PdCl}_{2}(\mathrm{TFP})_{2}$
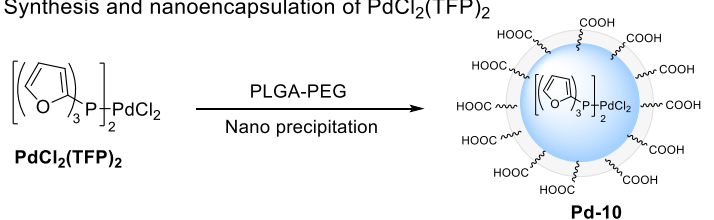

B) Doxorubicin activation
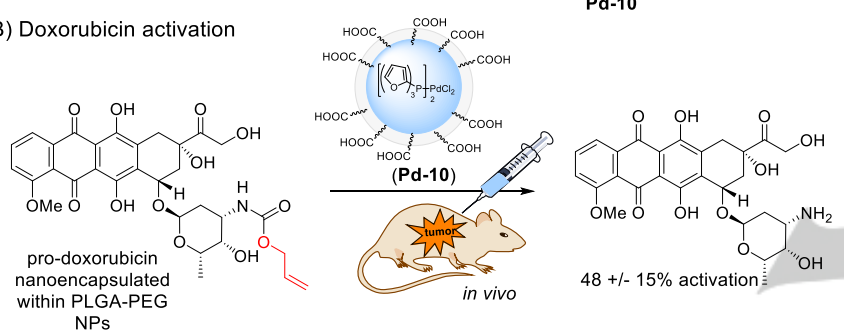

C) MMAE self-immolative alloc uncaging inside living mice

$$
\text { (n) }
$$

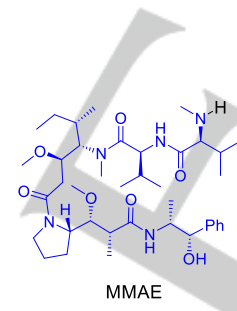

Figure 39. Nanoencapsulation of $\mathrm{PdCl}_{2}(\mathrm{TFP})_{2} \quad$ (A); N-alloc-Doxorubicin uncaging inside living mice; Mice treated with $50 \mathrm{mg} \cdot \mathrm{kg}^{-1} \mathrm{Pd}-10$, followed $(5 \mathrm{~h}$ later) by $16 \mathrm{mmol} \cdot \mathrm{kg}^{-1}$ treatment with fluorescently-labelled pro-doxorubicin PLGA-PEG NPs. [tumor = OVCA and fibrosarcoma tumors] (B); MMAE selfimmolative drug uncaging inside living mice (C).

The above-mentioned results suggest that nanoencapsulation of discrete palladium complexes might be required for their use in complex biological media and in living cells, in order to avoid fast deactivation of the catalyst. However, the use of small-sized nonencapsulated discrete homogeneous palladium complexes might allow for an easier tuning of the ancillary ligands, which eventually might help to modulate solubility, stability, reactivity and even the cell transport and intracellular targeting. Mascareñas and coworkers addressed this challenge and developed discrete palladium complexes with designed phosphine ligands that can promote $\mathrm{N}$-alloc cleavage reactions in cell lysates, and even in living mammalian cells (e.g. $\mathrm{N}$-alloc rhodamine and related fluorophores). ${ }^{[111]}$ Importantly, appropriate engineering of the ligand allows subcellular targeting and catalysis. In particular, using a phosphine ligand tethered to phosphonium and hydrophobic pyrene groups, the palladium complex presents a preferential accumulation in mitochondria, wherein it remains active (Figure 40).

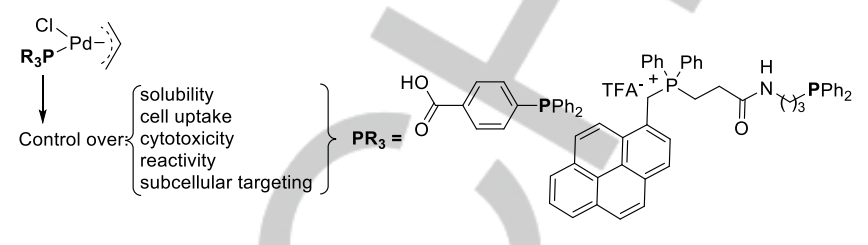

Figure 40. Discrete Pd-complexes introduced for $\mathrm{N}$-alloc uncaging of allocRhodamine, by Mascareñas and coworkers.

All the above systems rely on discrete metal complexes or metal nanoparticles for intracellular activities. Nature manages to perform catalytic processes inside cells using enzymes and metalloenzymes, and with impressive results in terms of rate and selectivity. Therefore, it is remarkable that artificial metalloenzymes capable of promoting bioorthogonal reactions in mammalian cells had not been developed until 2018, when Matile, Fussenegger, Ward and coworkers described the design and synthesis of a Streptavidin-based artificial ruthenaenzyme. This artificial metalloenzyme has cell penetrating capabilities and performs a $\mathrm{N}$-alloc uncaging reactions in live cells. The strategy capitalizes on the homotetrameric nature of streptavidin, which holds four biotin-binding sites, to incorporate both a biotinylated cell-penetrating poly(disulfide) and a biotinylated ruthenium(II) complex (Figure 41, A). The resulting metalloenzyme is taken up into mammalian cells and induces the uncaging of an allylcarbamate-protected thyroid hormone, triiodothyronine (Figure 41, B). ${ }^{[112]}$ This bioorthogonal reaction causes the upregulation of a gene circuit which eventually leads to the expression of a potent bioluminescence reporter protein, a nanoluc-luciferase

A) Cell-penetrating artificial Streptavidin-based metalloenzime for N-Alloc cleaveage

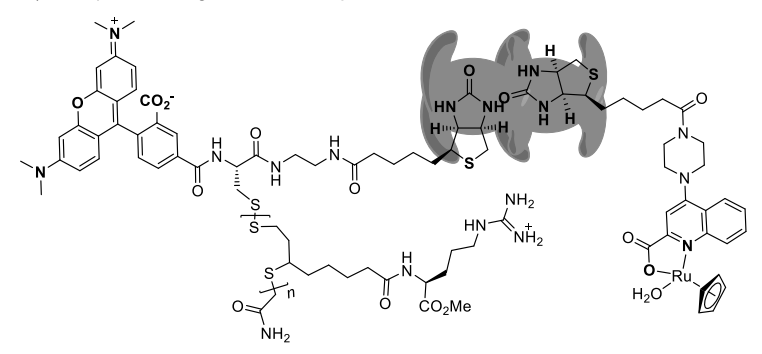

B) Intracelular uncaging of triiodothyronine to trigger a intracellular reaction cascade

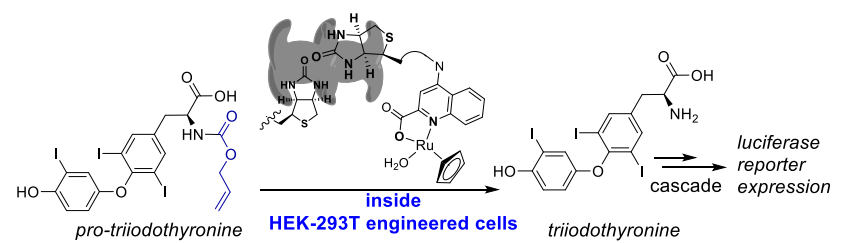

Figure 41. A cell penetrating artificial metalloenzyme in a mammalian cell. 
To conclude, this "unmasking" strategy, promoted by transition metals, is one of the most successfully employed bioorthogonal technologies, as it allows both the in situ generation of an active drug and the signal amplification of imaging probes.

\subsection{Cleavage of $O$-propargyl and $N$-propargyloxycarbonyl (poc)}

Propargyl-protected amines or alcohols can also be cleaved using transition metals complexes of $\mathrm{Pd}(0), \mathrm{Pd}(\mathrm{II})$ or even $\mathrm{Pd}(\mathrm{IV})$, as well as $\mathrm{Au}(\mathrm{I})$ (Scheme 9).

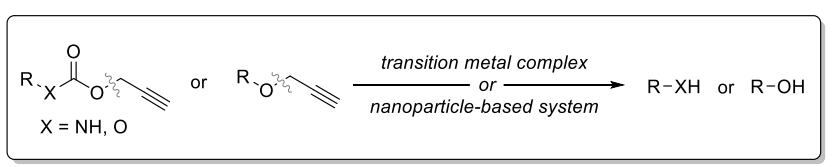

Scheme 9. Propargyl group removal promoted by a transition metal complex

Even though the mechanisms of these reactions have not been thoroughly studied, it is commonly accepted that they depend on the oxidation state of the metal. Thus, employing $\operatorname{Pd}(0)$ reagents, the reaction might start by formation of an allenyl-palladium species (I), which would subsequently undergo nucleophilic attack by water at the central sp-carbon of the allene, leading to the enol intermediate II and its tautomeric keto-derivative III (Figure 42). ${ }^{[113,114]}$ At this point, the $\alpha$-Pd carbonyl intermediate (III) hydrolyses and regenerates the active $\mathrm{Pd}(0)$ species. If $\mathrm{Pd}(\mathrm{II})$ or $\mathrm{Pd}(\mathrm{IV})$ are used, the proposed mechanism could start by electrophilic activation of the alkyne and addition of water to give the enol intermediate l', which tautomerizes to the $\alpha$-Pd-aldehyde intermediate II'. Finally, hydrolysis of this intermediate (II') affords the free alcohol 3-hydroxypropanal (III') and restores the catalytically active species.

It is important to highlight that $\mathrm{Pd}(\mathrm{II})$ or $\mathrm{Pd}(\mathrm{IV})$ species in aqueous or biological media shows generally poor stability, and the formation of palladium nanoparticles is very likely, so that the $\mathrm{Pd}(0)$-path cannot be completely ruled out (Figure 42).

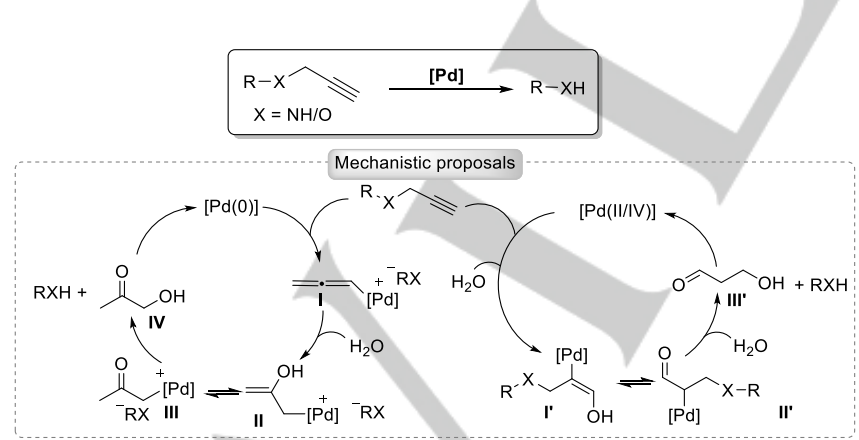

Figure 42. Mechanistic proposals for the N/O-propargyl group removal by $\mathrm{Pd}(0)$ and $\mathrm{Pd}(\mathrm{II}) / \mathrm{Pd}(\mathrm{IV})$ complexes.

The first example of a propargyl uncaging reaction under biologically relevant conditions was reported by Chen and coworkers. ${ }^{[115]}$ In particular, they screened several $\operatorname{Pd}(0), \operatorname{Pd}(I I)$ and $\mathrm{Pd}(\mathrm{IV})$ reagents for the deprotection of the $\mathrm{N}$ propargyloxycarbonyl (poc) protected rhodamine 110 (Figure 43, A). Even though the results did not follow a clear trend, in some cases $\mathrm{Pd}(\mathrm{dba})_{2}$ and $[\mathrm{PdCl}(\text { allyl })]_{2}$ showed the highest reactivities, whereas with an $\mathrm{N}$-propargyloxycarbonyl coumarin derivative, freshly-synthesized palladium nanoparticles seemed to provide better results. In this regard, the authors comment that the palladium nanoparticles need to be used within the first 30 seconds after preparation, to avoid their passivation, which emphasizes undoubtedly one key challenges that need to be addressed when using this type of nanoparticles.

On the other hand, the same authors also evaluated a palladiumpromoted activation of proteins with lysines protected with $\mathrm{N}$ propargyloxycarbonyl groups (Figure 43, B).

Chen and coworkers also reported that $\left[\mathrm{PdCl}(\text { allyl) }]_{2}\right.$ allows the intracellular decaging of $\mathrm{N}$-propargyloxycarbonyl modified proteins and enzymes, such as green fluorescent protein (GFPN149-ProcLys) or the phospho-threonine lyase OspF. This approach involves the site-specific biosynthetic incorporation of a \&-propargyloxycarbonyl protected Lys-residue into the biomolecule of interest. The intracellular uncaging of the phospho-threonine lyase (OspF-K134-ProcLys) allowed to elucidate its role as a virulence factor (Figure 43, C) ${ }^{[114]}$ A similar strategy, employing freshly prepared palladium nanoparticles, was used for the in situ generation of neuramic acid (Neu) on cellsurface glycans. ${ }^{[116]}$

A)

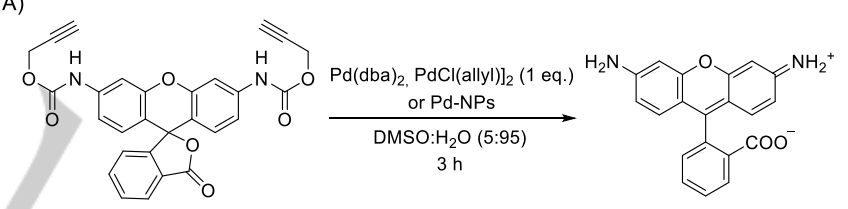

B)

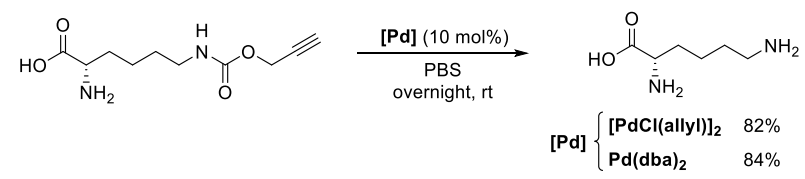

C)

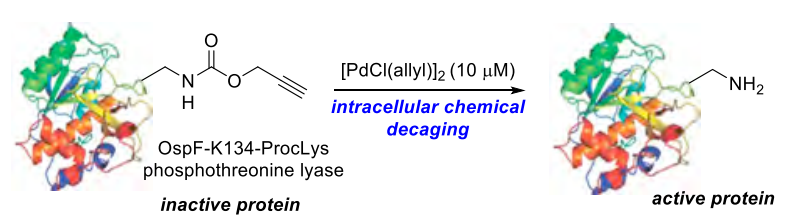

Figure 43. Pd-promoted $N$-propargyloxycarbonyl (poc) removal in aqueous enviroment from pro-fluorophores $(A)$, caged lysines $(B)$ and intracellular protein activation by $\mathrm{Pd}$-promoted lysine uncaging $(\mathrm{C})$.

Unciti-Broceta and coworkers have shown that their extracellular Pd-containing microspheres (aprox. $150 \mu \mathrm{m}$ in diameter, larger than human cells) are also able to perform depropargylation processes.[117] In particular, 5-fluorouracil was generated 
extracellularly from a $N$-propargyl protected precursor $(0.3-100$ $\mu \mathrm{M}$, Figure 44$)$, by treatment with $0.66 \mathrm{mg} / \mathrm{mL}(133 \mu \mathrm{M})$ of $\mathrm{Pd}-$ microspheres (Pd-2), achieving in this way comparable antiproliferative effects to those of the unmodified drug. A similar strategy was used by Unciti-Broceta and coworkers for the uncaging of $\mathrm{N}$-propargyl gemcitabine, ${ }^{[118]}$ vorinostat derivative,${ }^{[119]}$ and doxorubicin inside cells. ${ }^{[120]}$

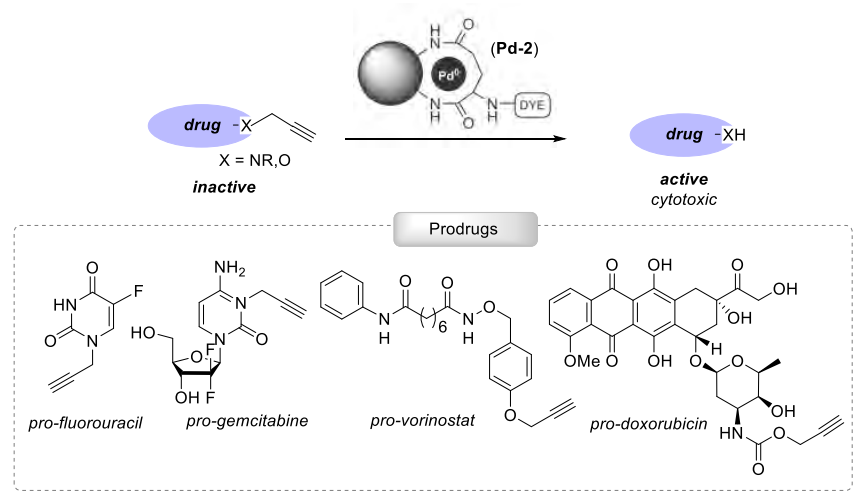

Figure 44. Prodrugs activation using Pd-microspheres.

Rotello and coworkers reported that their supramolecularly regulated nanozyme based on curcubit[7]uril / 1-adamantylamine (ADA) host-guest interactions were not only suitable for stabilizing and controlling the bioorthogonal reactivity of ruthenium complexes inside cells (see Ru-Nz-1, Figure 36), but also for $\mathrm{Pd}(\mathrm{II})$ bisphosphine complexes like $\mathrm{Pd}(\mathrm{dppf}) \mathrm{Cl}_{2}$ (Figure 44, A). This supramolecular system was used for the conditional synthesis of the chemotherapeutic drug 5 -fluorouracil inside HeLa cells from its $\mathrm{N}$-propargyl derivative $(0.05-1 \mathrm{mM}$ ) (Figure 45 , B). ${ }^{[103]}$
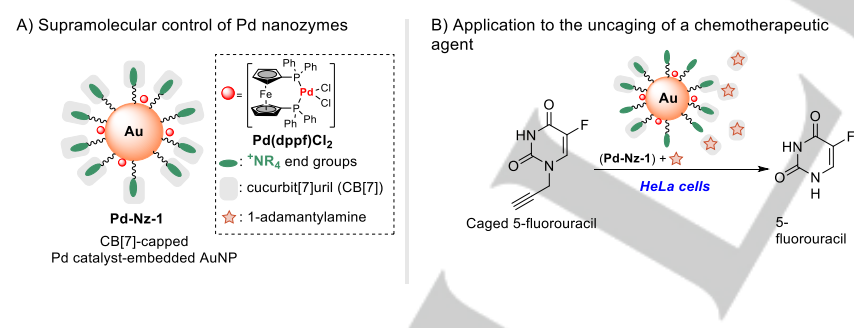

Figure 45. Bioorthogonal nanozyme design and reactivity.

On the other hand, hollow palladium-containing nanoreactors developed by Mascareñas and coworkers also showed good catalytic performances under highly diluted conditions (50-100 $\mu \mathrm{M})$ for the propargyl group removal in fluorogenic probes, showing an overall remarkable biocompatibility. Additionally, uncaging can also be carried out in the presence of excess of a protein such as BSA $(100-600 \mu \mathrm{M})$, owing to the filtering capabilities of the nanocapsule. Standard homogenous $\mathrm{Pd}$ complexes were less active under these conditions because of the passivation of the palladium. The low toxicity of the Pd- nanoreactors enable the efficient uncaging of a propargylprotected probe in the presence of Hela mammalian cells (Figure 46). ${ }^{[67]}$

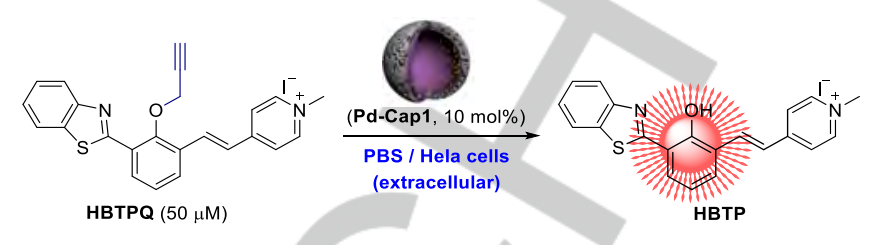

Figure 46. Palladium-based hollow nanoreactors for in vivo propargyl uncaging

In a recent tour the force, Unciti-Broceta, Santamaría and coworkers have demonstrated that cancer-derived exosomes bearing ultrathin $\mathrm{Pd}$ nanosheets in their interior can be used to deliver selectively these metal nanostructures into designated cancer cells, allowing the Pd-triggered prodrug activation. ${ }^{[121]}$ In particular, the authors showed that the preferential tropism of these bio-artificial exosomes for their progenitor cells, can be used to achieve a cell-specific uncage and release of an anticancer drug such as panobinostat, a pan-histone deacetylase (HDAC) inhibitor that is currently used to treat multiple myeloma and in clinical trials for several other tumors. The Pd-promoted uncaging reaction consists of a depropargylation of the $p$ (propargyloxy)benzyl hydroxamate derivative of the drug (Figure 47). ${ }^{[122]}$

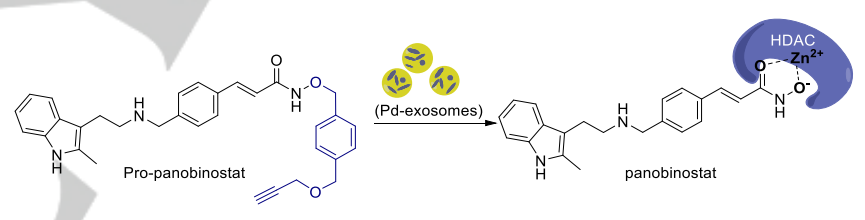

Figure 47. Prodrug activation using cancer derived Pd-loaded exosomes.

In 2018, Bernardes and coworkers reported the development of a bifunctional linker bearing a propargyl carbamate and a substituted thioether which allows for both stereospecific protein modification and a palladium triggered uncaging of a specific drug. NMR experiments confirmed the critical role of the thioether, as its ulfur atom coordinates the palladium center directing the cleavage of the proximal propargyl carbamate. ${ }^{[123]}$ The $\mathrm{Pd}(\mathrm{II})$ complex $\mathrm{Pd}(\mathrm{COD}) \mathrm{Cl}_{2}$ provided the best results in vitro. Interestingly, the authors prepared an antibody drug conjugate by cysteine selective conjugation of an anti-HER2 based nanobody with a PEGylated thioether propargyl carbamate doxorubicin derivative. Treatment of this nanobody prodrug conjugate with 10 fold excess of $\mathrm{Pd}(\mathrm{COD}) \mathrm{Cl}_{2}$ in sodium phosphate buffer $(\mathrm{pH} 7.0$ at $37^{\circ} \mathrm{C}$ ) allowed the complete decaging of the doxorubicin in just 2 hours, as determined by LC-MS (using 3-mercaptopropionic acid as palladium scavenger to improve resolution). Moreover, this transformation could be performed in cell culture using the HER2 positive cell line MCF-7. The toxicity of doxorobucin $(1 \mu \mathrm{M})$, measured as cell viability (\%), turned out to be equivalent to that observed from the treatment of the nanobody prodrug conjugate 
$(1 \mu \mathrm{M})$ with a non-toxic $10 \mu \mathrm{M}$ concentration of the $\mathrm{Pd}$ complex $\mathrm{Pd}(\mathrm{COD}) \mathrm{Cl}_{2}$ (Figure 48).

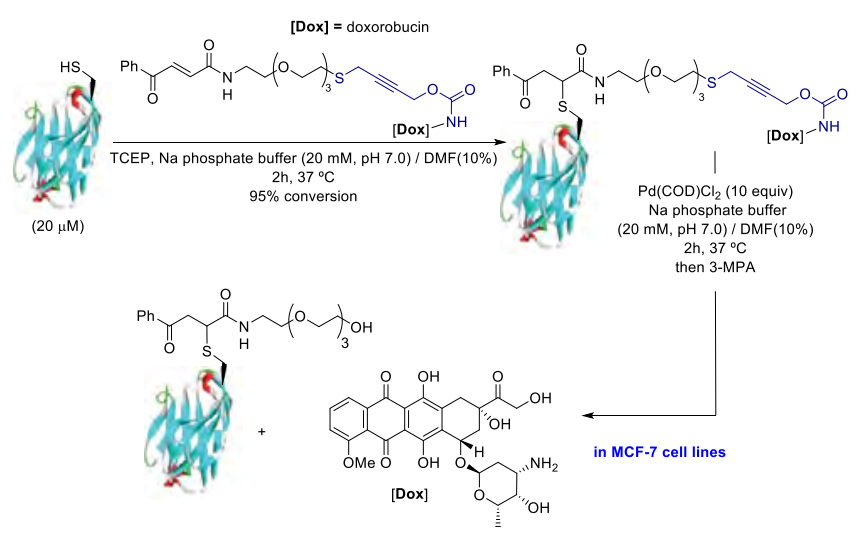

Figure 48. Thioether-directed Pd-catalyzed decaging of a bifunctional propargyl carbamate.

Very recently, Mascareñas and coworkers showed two different strategies for performing Pd-promoted poc-removal inside living cells. Mascareñas and del Pino demonstrated that watercompatible core-shell Pd/ZIF-8 nanocomposites, featuring single $\mathrm{Pd}$ nanocube cores (the catalyst) and a porous nanometric ZIF-8 shell (the filter), equipped with an amphiphilic polymer (PMA: poly [isobutylene-alt-maleic anhydride]-graft-dodecyl) to provide aqueous stability, are capable of working as efficient, and longlasting bio-orthogonal heterogeneous $\mathrm{Pd}$ nanoreactors for $\mathrm{O}$ propargyl and $N$-propargyloxycarbonyl removal of profluorophores (e.g. cresyl violet). Importantly, the ZIF-8/PMA architecture not only protects the $\mathrm{Pd}$ nanocatalyst from deactivation, leaking, and aggregation, but its porosity allows a diffusion-controlled flow of reactants within the core reaction chamber (Figure 49, A). As a result, these constructs can be used as efficient metallo-nanoreactors (NRs) in complex aqueous media and inside living mammalian cells. Moreover, tissue-like 3D spheroids containing the nanoreactors were also shown to promote the uncaging reaction in a recurrent manner. ${ }^{[124]}$

On the other hand, Mascareñas and coworkers also demonstrated in 2020 how small peptides such as brHis2 (Figure 49 , B), consisting of the basic domains of bZIP transcription factors mutated to include two histidine residues (at $i$ and $i+4$ positions), react with palladium(II) sources to generate catalytically active, stapled pallado-miniproteins..$^{[125]}$ Importantly, while the peptide precursor brHis2 failed to translocate across cell membranes on its own, the stapled pallado-protein undergoes efficient cell internalization into living mammalian cells (mediated by integrin receptors), ${ }^{[126]}$ where it performs palladium-promoted depropargylation reactions without cellular fixation (Figure 49, B). The effectiveness of the approach is likely associated to a synergistic beneficial effect of the conformational constrain introduced by the metal bridge, and a protective role of the peptide scaffolding, which avoids a rapid deactivation of the metal catalyst (Figure 49, C).
A) Pd/ZIF-8 nanoreactors for propargyl uncaging

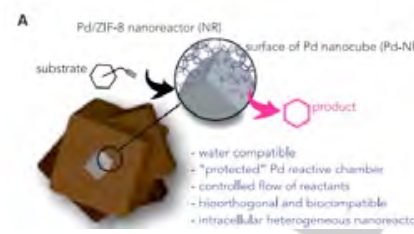

B) Catalytically active, stapled pallado-miniproteins $\left(\right.$ brhis $\left._{\mathbf{2}}-\mathbf{P d}\right)$

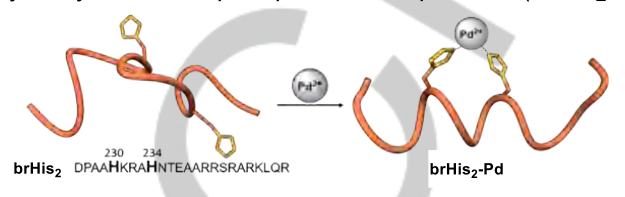

C) Uncaging of cresyl violet with $\mathbf{P d} / \mathbf{Z I F}-\mathbf{8}$ nanoreactors and brhis $\mathbf{2}_{\mathbf{2}}-\mathbf{P d}$

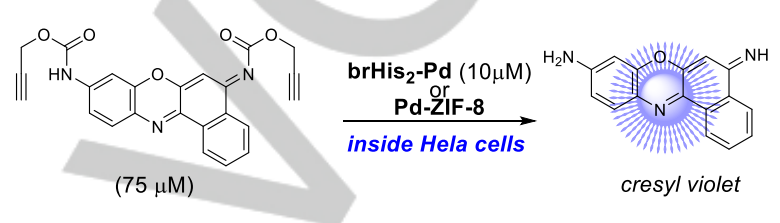

Figure 49. $\mathrm{Pd} / \mathrm{ZIF}-8$ nanoreactors $(\mathrm{A})$, metallopeptide made from brHis2 and $\mathrm{PdCl}_{2}(\mathrm{COD})(\mathrm{B})$ and uncaging reaction of cresyl violet with both systems inside HeLa cells $(C)$.

Notably, gold is also able to promote the bioorthogonal removal of propargyl protecting groups in biological media, as recently shown by Unciti-Broceta and coworkers (Figure 50, A). ${ }^{[127]}$ To protect the gold from the deactivating thiols, the authors needed to develop specific heterogeneous catalysts consisting of gold nanoparticles appropriately embedded within a polyethylene glycol (PEG)-grafted low-cross-linked polystyrene matrix (75 microns in diameter). Curiously, they observed an enhanced reactivity in serum, compared to PBS, which was rationalized on the basis of a superior performance of the gold-resin in the presence of small molecular weight nucleophiles, which are part of the serum. Moreover, they found that the addition of glutathione (GSH) as additive, up to $50 \mu \mathrm{M}$, was crucial for a good reactivity in PBS (Figure 50, B). ${ }^{[128]}$ Mechanistically, they propose a coordination of the thiol group of the glutathione (GSH) to the gold nanoparticles, activation of the triple bond by the gold with concomitant nucleophilic attack from the amine group of the glutathione to the terminal carbon atom of the alkyne, to afford a vinyl gold intermediate species like $\mathbf{2 4}$ (Figure 50, C). Eventually, this intermediate undergoes an elimination to afford the free amine (or alcohol derivative, $\mathrm{R}-\mathrm{XH}$ ), together with an allenic product and the active gold catalyst. The same group has also used this new platform for the activation of $\mathrm{N}$-propargyl gemcitabine, vorinostat, and doxorubicin in A549 cancer cell culture. Moreover, using the same strategy they also achieved the first intracranial uncaging of a poc-protected rhodamine 110 in zebrafish.

Cho and Lee have shown that by using plasmonically integrated nanoreactors with strong and tunable IR absorption in the visible to NIR, they can dramatically accelerate intracellular depropargylation reactions. ${ }^{[129]}$ 
A)

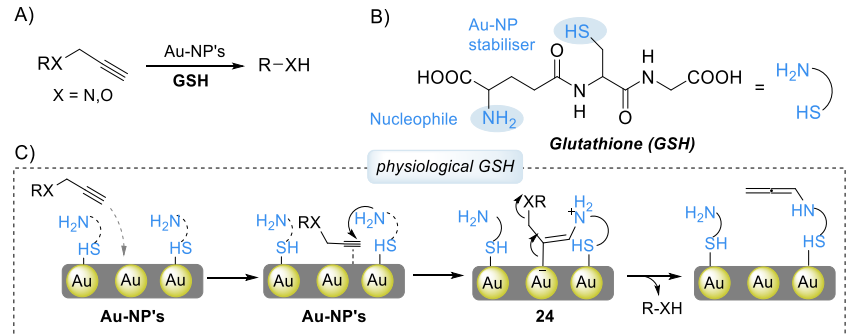

Figure 50. Gold nanoparticle promoted propargyl uncaging.

In a recent article, Brik and coworkers demonstrated the viability of uncaging propargylated peptidesunder mild aqueous conditions, using AuCl. ${ }^{[130 a]}$ The method might be applicable in biological environments. On the other hand, Oliveira, Fior and Bernardes have very recently demonstrated that platinum complexes such as $\mathrm{K}_{2} \mathrm{PtCl}_{4}$ or cisplatin can be used to decage $\mathrm{N}$ propargyl and $\mathrm{N}$-pentynoyl tertiary amides, in biological media,. Cytotoxic drugs such as fluorouracil could be decaged in the presence of HeLa cells, as well as in a colorectal zefrafish xenograft model, leading to a reduction in the tumor size. ${ }^{[130 b]}$

The bioorthogonal removal of O-propargyl and $\mathrm{N}$ propargyloxycarbonyl groups can also be carried out with copper complexes. In particular, Chen and coworkers have recently shown that the complex $\mathrm{Cu}(\mathrm{I})$-BTTA, originally developed for azide-alkyne biocompatible cycloadditions, is also able to promote the bioorthogonal cleavage of O-propargyl and $\mathrm{N}$-Poc groups that hold a second alkyl substituent at the propargylic position. ${ }^{[131 a]}$ The method constitutes the first examples of a copper-catalyzed biorthogonal cleavage reaction and was applied to the release of drugs bearing a phenol or a primary amine moiety, such as the anticancer agents doxorubicin (Figure 51, A). Moreover, the strategy was also applied to release these drugs on live cell membranes, by anchoring them to affibodies (antibody mimetics like ZHER2), which binds with high affinity to HER2 receptors of cancer cell lines SKBR-3. Thus, the addiction of $\mathrm{Cu}(\mathrm{I})-\mathrm{BTTA}$ allows to generate a drug such as etoposide at the membrane of a desired tumor cell that overexpresses these receptors (e.g. SKBR-3, Figure 51, B). From a mechanistic perspective, the authors suggest the formation of an intermediate copper vinylidene species with concomitant release of the cargo (Figure 51, C).

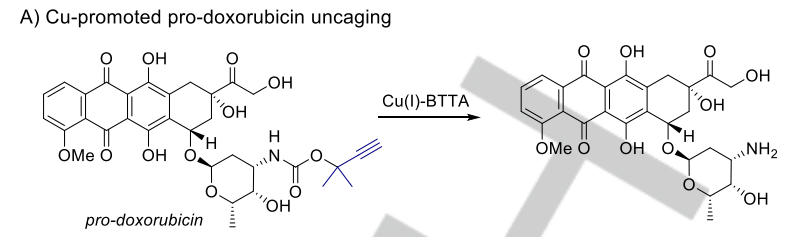

B) Cu-promoted pro-etoposide uncaging

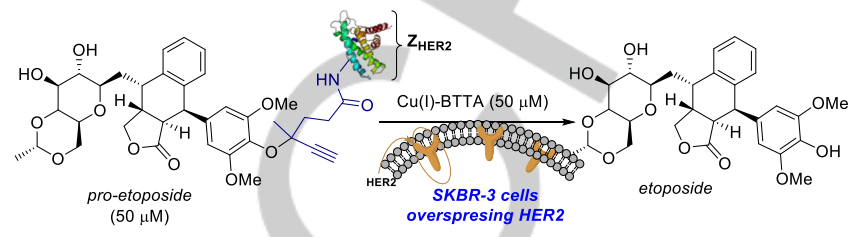

C) Mechanistic proposal

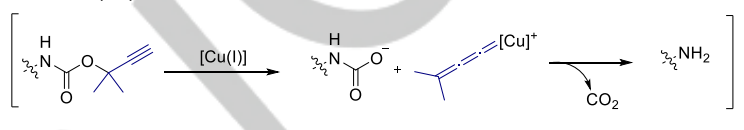

Figure 51. $\mathrm{Cu}(\mathrm{I})$-catalyzed activation of prodrugs.

\subsection{Cleavage of $O$-allenyl groups}

In 2016, Chen and coworkers reported an intracellular palladium mediated allene tyrosine decaging strategy (Figure 52, A). ${ }^{132]}$ Three different allene-derivatives were synthesized and their stabilities and reactivity in cell lysates were analyzed in comparison with a propargylic derivative (Figure 52, B). On average, in the presence of a palladium complex (Pd-11-14, Figure 52, C), the reactivity of 1,2-allenyl group 25 resulted to be superior to that of 2,3-allenyl system $\mathbf{2 6}$ and of the propargyl probe 27. Among all the complexes used, the best results in PBS were obtained with the $\operatorname{Pd}(0)$ complex bearing a 1,3,5-triaza-7phosphaadamantane ligand.

The methodology has been successfully applied to unmask enzymatic tyrosine sites and for the post-translational tyrosine modification site in vitro and in live cells.

A) Pd-mediated allene uncaging

$$
\mathrm{RO}_{(100 \mu \mathrm{M})}=\frac{\mathrm{Pd} 11-14(100 \mu \mathrm{M})}{\mathrm{PBS}, 37^{\circ} \mathrm{C}, 5 \mathrm{~min} .} \quad \mathrm{R}-\mathrm{OH}
$$

B) Order of reactivity based on Relative Fluorescence Intensity (R.F.I.)

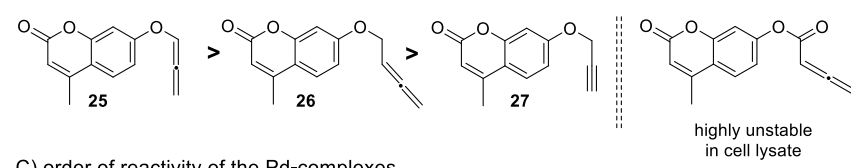

C) order of reactivity of the Pd-complexes

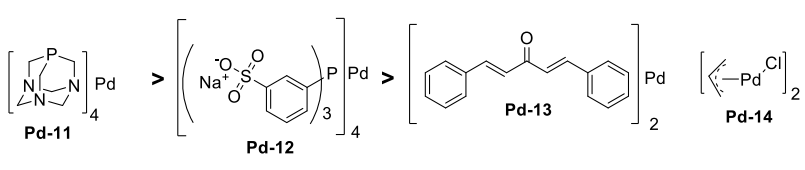

Figure 52. Pd-mediated allene uncaging.

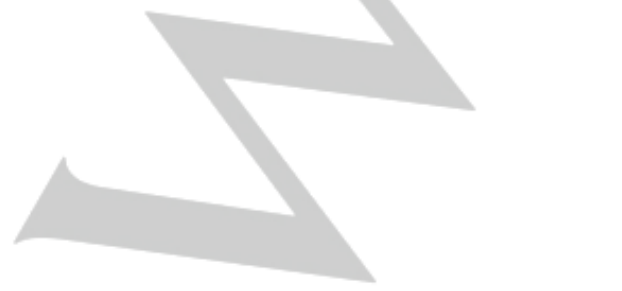

Figure 52. Pd-mediated allene uncaging. 


\subsection{Photoreductive uncaging}

In 2018, Winssinger and coworkers developed an alternative type of bioorthogonal uncaging reaction. In particular, these authors demonstrated that bioluminescence resonance energy transfer (BRET) from a luciferase (NanoLuc) could be employed to activate a ruthenium-based photocatalyst $\left[R u(b p y)_{2}\right.$ phen] that subsequently uncages a fluorophore or small molecule drugs such as ibrutinib and duocarmycin, at biologically effective concentrations. Interestingly, instead of a propargyl-based or $\mathrm{N}$ alloc caging group, the authors made use of a pyridinium linker that is reductively cleaved by the Ru complex. The precise design of a luciferase-based indicator of drugs (LUCID), involving a SNAP protein, the luciferase and a receptor protein that binds the caged drug, is key for the success of the strategy, since the luciferase, ruthenium complex and the caged molecule need to be in close proximity. ${ }^{[133]}$

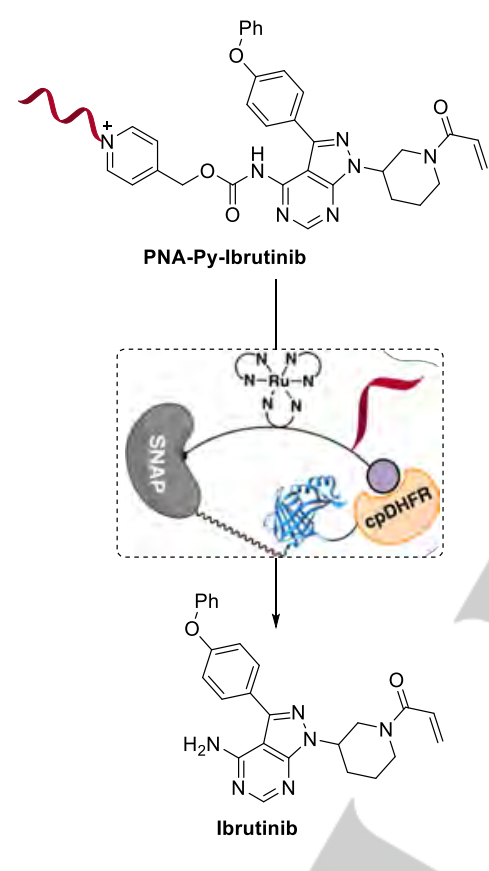

Figure 55. Bioluminescence resonance energy transfer (BRET) from a luciferase to a Ru-based photocatalyst for the uncaging of fluorophores or small molecule drugs (e.g. PNA-Py-lbrutinib)

\subsection{Tandem azide reduction and cleavage}

In 2020, Rotello and coworkers developed a new variant of their nanozymes constructs based on self-assembled polymer nanoparticles engineered to encapsulate lipophilic TMCs within a protective hydrophobic environment. In these case, the authors encapsulate an iron tetraphenyl porphyrine complex $[\mathrm{Fe}(\mathrm{TPP})] \mathrm{Cl}$ which is able to promote the reduction of azides to the corresponding amines in presence of thiols (i.e. glutathione). Interestingly, the cationic nature of the encapsulating polymer facilitates penetration of the resulting particles (size $\sim 50 \mathrm{~nm}$ ) into bacterial biofilms. Accordingly, these nanosystems exhibited excellent catalytic efficiency for the activation of fluoroquinolone pro-drugs such as pro-moxifloxacin or pro-ciprofloxacin within biofilms of $E$ coli or $P$ aeruginosa. The high antimicrobial activity is achieved at concentrations that do not compromise the fibroblast cell viability. ${ }^{[134]}$

A)

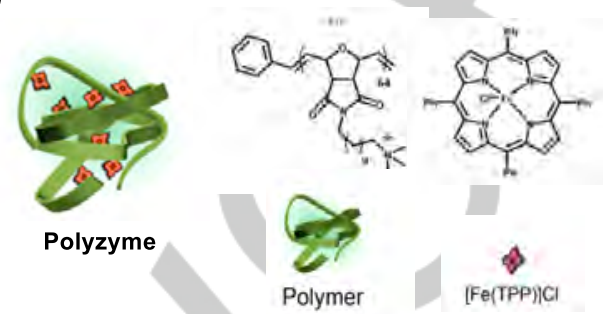

B)

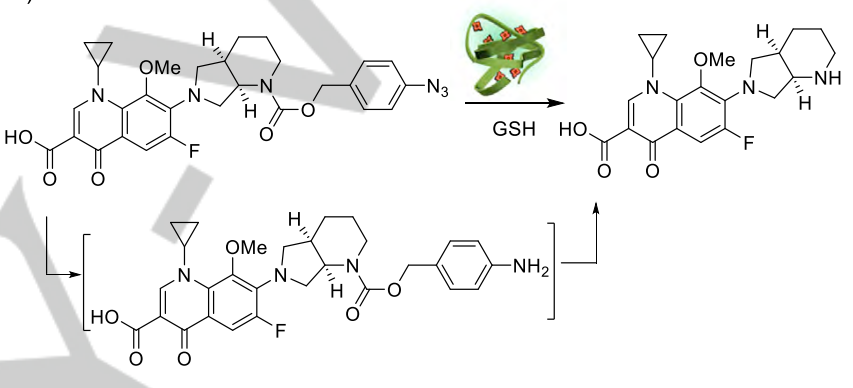

Figure 55. Tandem azide reduction and cleavage

\section{Summary and Outlook}

When chemists started to report organometallic reactions in aqueous media, especially using transition metals catalysts, it could not be envisioned that these discoveries could impact areas other than sustainable chemistry. In this context, it is also worth to note that the pioneering report of Meggers in 2006 on the ruthenium-promoted removal of alloc protecting groups in the presence of live cells went by almost unnoticed for several years. However, the subsequent demonstration by several groups that ruthenium and palladium complexes can promote other biorthogonal deprotection reactions, and that the reactions can raise biological activities, demonstrated that this research topic is much more than a mere curiosity.

Indeed, along the last 5 years a number of groups have joined the wave and are demonstrating impressive inventions and applications in this field of biorthogonal transition metal catalysis, which is clearly growing. However, in order for organometallic catalysis to be fully harnessed for biological applications, there are many problems that need to be overcome. Especially important is the development of catalytic systems that show good rates and clear turnovers under dilute aqueous conditions, and in complex biological settings. Bioorthogonality and biocompatibility 
are also parameters that need to be substantially improved if these reactions are to be used for biomedical or biotechnological applications.

\section{Acknowledgements}

We would like to acknowledge financial support from Spanish grants (SAF2016-76689-R, CTQ2017-84767-P and ORFEOCINQA network CTQ2016-81797-REDC), the Consellería de Cultura, Educación e Ordenación Universitaria (2015-CP082, ED431C-2017/19 and Centro Singular de Investigación de Galicia accreditation 2019-2022, ED431G 2019/03), the European Union (European Regional Development Fund-ERDF corresponding to the multiannual financial framework 2014-2020), and the European Research Council (Advanced Grant No. 340055). DFF thanks Xunta de Galicia for his postdoctoral fellowship (ED481B2019-005). C.V. thank the Ministerio de Economía y Competividad for the Juan de la Cierva-Formación fellowship (FJCl-2017-33168).

Keywords: Biological chemistry, organometallic catalysis, biocatalysis, cellular chemistry, aqueous catalysis

[1] A. Chanda, V. V. Fokin, Chem. Rev. 2009, 109, 72.

[2] U. M. Lindstrm (Ed); Organic Reactions in Water, Blackwell Publishing Ltd, 2007.

[3] F. Q. Wöhler, Sci. Lit. Art. 1828, 491.

[4] A. Baeyer, V. Villiger, Ber. Dtsch. Chem. Ges. 1899, 32, 3625.

[5] A. W. Hofmann, Chem. Ber. 1881, 14, 2725.

[6] a) N. Kishner, Russ. Phys. Chem. Soc. 1911, 43, 582; b) L. Wolff, Liebigs Ann. Chem. 1912, 394, 23.

[7] E. Buchner, T. Curtius, Chem. Ber. 1885, 18, 2371.

[8] E. L. O. Sauer in Green Organic Chemistry in Lecture and Laboratory (Eds.: A. P. Dicks), CRC Press, Boca Raton, 2012, pp. 103-130.

[9] R. Breslow, D. Rideout, J. Am. Chem. Soc. 1980, 102, 7816.

[10] S. Narayan, J. Muldoon, M. G. Finn, V. V. Fokin, H. C. Kolb, K. B. Sharpless, Angew. Chem. Int. Ed. 2005, 44, 3275; Angew. Chem. 2005, 117, 3339.

[11] a) H.C. Hang, C. Yu, D. L. Kato, C. R. Bertozzi, Proc. Natl. Acad. Sci. U. S. A. 2003, 100, 14846; b) C. R. Bertozzi. Acc. Chem. Res. 2011, 44 651; c) E. M. Sletten, C. R. Bertozzi, Angew. Chem. Int. Ed. 2009, 48, 6974; Angew. Chem. 2009, 121, 7108.

[12] P. T. Anastas, J. C. Warner in Green Chemistry Theory and Practice, Oxford, University Press, Oxford, 1998; b) A. S. Matlack in Introduction to Green Chemistry, M. Dekker, New York, 2001; c) J. H. Clark, D. J. Macquarrie in Green Chemistry and Technology, Blackwell Publishing, Abingdon, 2002; d) M. Poliakoff, J. M. Fitzpatrick, T. R. Farren, P. T. Anastas, Science 2002, 297, 807.

[13] a) N. Pinault, D. W. Bruce, Coord. Chem. Rev. 2003, 241, 1; b) A. D. Phillips, L. Gonsalvi, A. Romerosa, F. Vizza, M. Peruzzini, Coord. Chem. Rev. 2004, 248, 955; c) B. Cornils, W. A. Herrmann in Aqueous-Phase Organometallic Catalysis, 2nd ed.; Wiley-VCH, Weinheim, 2004; d) J. Bravo, S. Bolaño, L. Gonsalvi, M. Peruzzini, Coord. Chem. Rev. 2010 254, 555; e) M. Zablocka, A. Hameau, A.-M. Caminade, J.-P. Majoral, Adv. Synth. Catal. 2010, 352, 2341; f) P. Dixneuf, V. Cadierno in MetalCatalyzed Reactions in Water, Wiley-VCH Weinheim, 2013; f) B. H. Lipshutz, S. Ghorai, M. Cortes-Clerget, Chem. Eur. J. 2018, 24, 6672. g) B. H. Lipshutz, Curr. Opin. Green Sus. Chem. 2018, 11, 1-8. h) B. H. Lipshutz, Chem 2018, 4, 2004.
[14] a) K. Drauz (Ed), H. Waldmann (Ed), Enzyme Catalysis in Organic Synthesis, Wiley-VCH Verlag GmbH, 2002; b) W. D. Fessner (Ed), T. Anthonsen (Ed), Modern Biocatalysis, Wiley-VCH Verlag GmbH \& Co. KGaA, 2008; c) N. J. Turner, L. Humphreys in Biocatalysis in Organic Synthesis: The Retrosynthesis Approach. Royal Society of Chemistry, 2018.

[15] Y. Bai, J. Chen, S. C. Zimmerman, Chem. Soc. Rev. 2018, 47, 1811.

[16] a) J. J. Soldevila-Barreda, P. J. Sadler, Curr. Opin. Chem. Biol. 2015, 25, 172; b) A. H. Ngo, S. Bose, L. H. Do, Chem. Eur. J. 2018, 24, 10584; c) C. S. McKay, M. G. Finn, Chem. Biol. 2014, 21, 1075; d) M. MartínezCalvo, J. L. Mascareñas, Coord. Chem. Rev. 2018, 359, 57.

[17] L. Vigh, F. Joó, Á. Cséplö, Eur. J. Biochem. 1985, 146, 241.

[18] V. V. Rostovtsev, L. G. Green, V. V. Fokin, K. B. Sharpless, Angew. Chem. Int. Ed. 2002, 41, 2596; Angew. Chem. 2002, 114, 2708. b) H. C Kolb, M. G. Finn, K. B. Sharpless, Angew. Chem. Int. Ed. 2001, 40, 2004; Angew. Chem. 2001, 113, 2056. c) C. W. Tornøe, C. Christensen, M. Meldal, J. Org. Chem. 2002, 67, 3057. For mechanistic studies on CuAAC, see: d) L.Zhu, C. J. Brassard, X. Zhang, P. M. Guha, R. J. Clark, Chem. Rec. 2016, 16, 1501. See also: e) B. T. Worrell, J. A. Malik, V. V. Fokin, Science 2013, 340, 457

[19] J. E. Moses, A. D. Moorhouse, Chem. Soc. Rev. 2007, 36, 1249.

[20] a) P. S. Banerjee, P. Ostapchuk, P. Hearing, I. Carrico, J. Am. Chem. Soc. 2010, 132, 13615; b) P. S. Banerjee, P. Ostapchuk, P. Hearing, I. S. Carrico, J. Virol. 2011, 85, 7546.

[21] a) M. J. Abedin, L. Liepold, P. Suci, M. Young, T. Douglas, J. Am. Chem. Soc. 2009, 131, 4346; b) M. L. Hovlid, J. L. Lau, K. Breitenkamp, C. J. Higginson, B. Laufer, M. Manchester, M. G. Finn, ACS Nano 2014, 8, 8003.

[22] a) A. Deiters, T. A. Cropp, M. Mukherji, J. W. Chin, J. C. Anderson, P. G. Schultz, J. Am. Chem. Soc. 2003, 125, 11782; b) C. C. Liu, P. G. Schultz, Ann. Rev. Biochem. 2010, 79, 413.

[23] C. Streu, E. Meggers, Angew. Chem. Int. Ed. 2006, 45, 5645; Angew. Chem. 2006, 118, 5773.

[24] a) J. J. Soldevila-Barreda, P. J. Sadler, Curr. Opin. Chem. Biol. 2015, 25, 172; b) A. H. Ngo, S. Bose, L. H. Do, Chem. Eur. J. 2018, 24, 10584; c) C. S. McKay, M. G. Finn, Chem. Biol. 2014, 21, 1075; d) P. K. Sasmal, C. N. Streu, E. Meggers, Chem. Comm. 2013, 49, 1581; e) M. MartínezCalvo, J. L. Mascareñas, Chimia, 2018, 72, 791. For a recent review on in vivo metal catalysis with a particular focus on living biological systems, see: f) Vong, K. and Tanaka, K. in Handbook of In Vivo Chemistry in Mice: From Lab to Living System, (Eds K. Tanaka and K. Vong). WileyVCH 2020, Chapter 11, pp. 309-353.

[25] C. S. McKay, M. G. Finn, Chem. Biol. 2014, 21, 1075.

[26] C. Kennedy, C. S. McKay, M. C. B. Legault, D. C. Danielson, J. A. Blake, A. F. Pegoraro, A. Stolow, Z. Mester, J. P. Pezacki, J. Am. Chem. Soc. 2011, 133, 17993.

[27] V. Hong, N. F. Steinmetz, M. Manchester, M. G. Finn, Bioconjugate Chem. 2010, 21,1912.

[28] a) K. Lang, J. W. Chin, ACS Chem. Biol. 2014, 9, 16; b) C. Uttamapinant, A. Tangpeerachaikul, S. Grecian, S. Clarke, U. Singh, P. Slade, K. R. Gee, A. Y. Ting, Angew. Chem. Int. Ed. 2012, 51, 5852; Angew. Chem. 2012, 124, 5954. c) C. Uttamapinant, M. I. Sanchez, D. S. Liu, J. Z. Yao, A. Y. Ting, Nat. Protoc. 2013, 8, 1620; d) V. Bevilacqua, M. King, M. Chaumontet, M. Nothisen, S. Gabillet, D. Buisson, C. Puente, A. Wagner, F. Taran, Angew. Chem. Int. Ed. 2014, 53, 5872; Angew. Chem. 2014, 126, 5982; e) C. Wang, D. Wang, S. Yu, T. Cornilleau, J. Ruiz, L. Salmon, D. Astruc, ACS Catal 2016, 6, 5424.

[29] L. Li, Z. Zhang, Molecules 2016, 21.

[30] A. J. Link, D. A. Tirrell, J. Am. Chem. Soc. 2003, 125, 11164

[31] A. J. Link, M. K. S. Vink, D. A. Tirrell, J. Am. Chem. Soc. 2004, 126, 10598.

[32] V. Hong, N. F. Steinmetz, M. Manchester, M. G. Finn, Bioconjugate Chem. 2010, 21, 1912. 
[33] Y. Bai, X. Feng, H. Xing, Y. Xu, B. K. Kim, N. Baig, T. Zhou, A. A. Gewirth, Y. Lu, E. Oldfield, S. C. Zimmerman, J. Am. Chem. Soc. 2016, 138, 11077.

[34] J. Chen, J. Wang, Y. Bai, K. Li, E. S. Garcia, A. L. Ferguson, S. C. Zimmerman, J. Am. Chem. Soc. 2018, 140, 13695.

[35] a) J. Chen, J. Wang, K. Li, Y. Wang, M. Gruebele, A. L. Ferguson, S. C. Zimmerman, J. Am. Chem. Soc. 2019, 141, 9693. For an application of these Cu SCNPs in bioorthogonal catalysis in cells, see: b) J. Chen, $\mathrm{K}$ Li, J. S. L. Shon, S. C. Zimmerman, J. Am. Chem. Soc. 2020, 142, 4565. For an alternative design of related polymeric-based $\mathrm{Cu}$ heterogeneous catalysts, see: c) Q. Lu, S. Bai, Z. Chen, N. Zheng, X. Feng, Y. Bai, ACS Materials Lett. 2020, 2, 89.

[36] J. Clavadetscher, S. Hoffmann, A. Lilienkampf, L. Mackay, R. M. Yusop, S. A. Rider, J. J. Mullins, M. Bradley, Angew. Chem. Int. Ed. 2016, 55, 15662; Angew. Chem. 2016, 128, 15891.

[37] F. Wang, Y. Zhang, Z. Liu, Z. Du, L. Zhang, J. Ren, X. Qu, Angew. Chem. Int. Ed. 2019, 58, 6987; Angew. Chem.2019, 131, 7061.

[38] a) Y. You, F. Cao, Y. Zhao, Q. Deng, Y. Sang, Y. Li, K. Dong, J. Ren, X. Qu, ACS Nano 2020, 14, 4178. For an alternative strategy based on nanocopper-doped cross-linked lipoic acid nanoparticles, see: b) J Huang, L. Wang, P. Zhao, F. Xiang, J. Liu and S. Zhang, ACS Catal. 2018, 8, 5941.

[39] S. Li, L. Wang, F. Yu, Z. Zhu, D. Shobaki, H. Chen, M. Wang, J. Wang, G. Qin, U. J. Erasquin, L. Ren, Y. Wang, C. Cai, Chem. Sci. 2017, 8, 2107.

[40] a) J. Miguel-Ávila, M. Tomás-Gamasa, A. Olmos, P. J. Pérez, J. L. Mascareñas, Chem. Sci. 2018, 9, 1947; b) Very recently we described a formal $(2+2+2)$ cycloaddition promoted by ruthenium in live cells: $J$. Miguel-Avila, M. Tomás-Gamasa, J. L. Mascareñas, Angew. Chem. Int. Ed. 2020, 59, 17628; Angew. Chem. 2020, 132, 17781.

[41] a) N. J. Agard, J. A. Prescher, C. R. Bertozzi, J. Am. Chem. Soc. 2004, 126, 15046; b) M. F. Debets, S. S. van Berkel, J. Dommerholt, A. (Ton) J. Dirks, F. P. J. T. Rutjes, F. L. van Delft, Acc. Chem. Res. 2011, 44, 805; c) C. G. Gordon, J. L. Mackey, J. C. Jewett, E. M. Sletten, K. N. Houk, C. R. Bertozzi, J. Am. Chem. Soc. 2012, 134, 9199; d) J. Dommerholt, O. van Rooijen, A. Borrmann, C. F. Guerra, F. M. Bickelhaupt, F. L. van Delft, Nat. Comm. 2014, 5.

[42] R. J. Brea, N. K. Devaraja in Chemoselective and Bioorthogonal Ligation Reactions: Concepts and Applications, Vol. 1 (Eds. W. R. Algar, P. E. Dawon, I. L. Medintz), Wiley, Weinheim, 2017, pp 67-95.

[43] P. Destito, J. R. Couceiro, H. Faustino, F. López, J. L. Mascareñas, Angew. Chem. Int. Ed. 2017, 56, 10766; Angew. Chem. 2017, 129, 10906.

[44] a) W. Song, N. Zheng, Org.Lett. 2017, 19, 6200. See also: b) R. Chen, L. Zeng, Z. Lai, S. Cui, Adv. Synth. Catal. 2019, 361, 989.

[45] a) N. Calderon, Acc. Chem. Res. 1972, 5, 127; b) K. C. Nicolaou, P. G. Bulger, D. Sarlah, Angew. Chem. Int. Ed. 2005, 44, 4490; Angew. Chem. 2005, 117, 4564. c) A. Fürstner, Chem. Commun. 2011, 47, 6505; (d) R. H. Grubbs, D. J. O'Leary (Eds.), Handbook of Metathesis, Volume 2. Applications in Organic Synthesis, 2nd Ed, Ch.3, Wiley-VCH Verlag $\mathrm{GmbH} \&$ Co. KGaA. 2015.

[46] a) D. Burtscher, K. Grela, Angew. Chem. Int. Ed. 2009, 48, 442; Angew. Chem. 2009, 121, 450. b) S. A. Cochrane, Z. Huang, J. C. Vederas, Org. Biomol. Chem. 2013, 11, 630; c) J. Tomasek, J. Schatz, Green Chem. 2013, 5, 2317.

[47] Y. A. Lin, J. M. Chalker, N. Floyd, G. J. L. Bernardes, B. G. Davis J. Am. Chem. Soc. 2008, 130, 9642.

[48] A. Fürstner, K. Langemann, Synthesis, 1997, 1997, 792.

[49] For more examples of protein modification with cross metathesis, see: a) Y. A. Lin, J. M. Chalker, B. G. Davis, ChemBioChem, 2009, 10, 959; b) Y. A. Lin, J. M. Chalker, B. G. Davis, J. Am. Chem. Soc. 2010, 132, 16805; c) O. Boutureira, G. J. L. Bernardes, Chem. Rev. 2015, 115, 2174

[50] H. Ai, W. Shen, E. Brustad, P. G. Schultz, Angew. Chem. Int. Ed. 2009, 49, 935; Angew. Chem. 2009, 122, 947.
[51] M. Jeschek, R. Reuter, T. Heinisch, C. Trindler, J. Klehr, S. Panke, T. R. Ward, Nature 2016, 537, 661.

[52] T. Heinisch, T. R. Ward, Acc. Chem. Res. 2016, 49, 1711.

[53] S. N. W. Toussaint, R. T. Calkins, S. Lee, B. W. Michel, J. Am. Chem. Soc. 2018, 140, 13151.

[54] a) S. Eda, I. Nasibullin, K. Vong, N. Kudo, M. Yoshida, A. Kurbangalieva, K. Tanaka, Nat. Catal. 2019, 2, 780; For a related strategy applied to the detection of ethylene gas in fruits and Arabidopsis leaves, see: b) $\mathrm{K}$. Vong, S. Eda, Y. Kadota, I. Nasibullin, T. Wakatake, S. Yokoshima, K. Shirasu, K. Tanaka, Nat. Commun. 2019, 10, 5746. For a recent review on the therapeutic potential of artificial metalloenzymes, see: c) $\mathrm{K}$. Tanaka and K. Vong, Proc. Jpn. Acad., Ser. B 2020, 96, 79.

[55] F. Diederich, P. J. Stang (Eds.) Metal-catalyzed Cross-coupling Reactions. Wiley-VCH Verlag GmbH, 2008.

[56] a) A. L. Casalnuovo, J. C. Calabrese, J. Am. Chem. Soc. 1990, 112, 4324-4330; b) J. P. Genet, R. Blart, M. Savignac, Synlett 1992, 715.

[57] a) V. Polshettiwar, A. Decottignies, C. Len. A. Fihri, ChemSusChem 2010, 502; b) A. Chatterjee, T. R. Ward, Catal. Lett. 2016, 146, 820.

[58] a) J. M. Chalker, C. S. C. Wood, B. G. Davis, J. Am. Chem. Soc. 2009, 131,16346

[59] J.-H. Li, X.-D. Zhang, Y.-X. Xie, Eur. J. Org. Chem. 2005, 2005, 4256.

[60] For the development of strategies to neutralize the detrimental effect of $\mathrm{GSH}$, in the context of a Ir-based transfer hydrogenation, see: Y. M. Wilson, M. Dürrenberger, E. S. Nogueira, T. R. Ward, J. Am. Chem. Soc. 2014, 136, 8928.

[61] C. D. Spicer, T. Triemer, B. G. Davis, J. Am. Chem. Soc. 2011, 134, 800.

[62] a) R. M. Yusop, A. Unciti-Broceta, E. M. V. Johansson, R. M. SánchezMartín, M. Bradley, Nat. Chem. 2011, 3, 239; b) A. Unciti-Broceta, E. M. V. Johansson, R. M. Yusop, R. M. Sánchez-Martín, M. Bradley, Nat. Protoc. 2012, 7, 1207.

[63] For the affinity towards the mitochondria, see: M.P. Murphy, Biochim. Biophys. Acta, 2008, 1777, 1028.

[64] E. Indrigo, J. Clavadetscher, S. V. Chankeshwara, A. Lilienkampf, M. Bradley, Chem. Commun. 2016, 52, 14212.

[65] J. Clavadetscher, E. Indrigo, S. V. Chankeshwara, A. Lilienkampf, M. Bradley, Angew. Chem. Int. Ed. 2017, 56, 6864; Angew. Chem. 2017, $129,6968$.

[66] F. Wang, Y. Zhang, Z. Du, J. Ren, X. Qu, Nat. Commun. 2018, 9, 1209.

[67] P. Destito, A. Sousa-Castillo, J. R. Couceiro, F. López, M. A. CorreaDuarte, J. L. Mascarenas, Chem. Sci. 2019, 10, 2598.

[68] For the development of Cu-free versions, see: B. Liang, M. Dai, J. Chen, Z. Yang, J. Org. Chem. 2005, 70, 391.

[69] K. Sonogashira, Y. Tohda, N. Hagihara, Tetrahedron Lett. 1975, 16, 4467.

[70] K. Kodama, S. Fukuzawa, H. Nakayama, K. Sakamoto, T. Kigawa, T. Yabuki, N. Matsuda, M. Shirouzu, K. Takio, S. Yokoyama, K. Tachibana, ChemBioChem, 2007, 8, 232.

[71] N. Li, R. K. V. Lim, S. Edwardraja, Q. Lin, J. Am. Chem. Soc. 2011, 133, 15316.

[72] a) N. Li, C. P. Ramil, R. K. V. Lim, Q. Lin, ACS Chem. Biol. 2014, 10, 379; b) N. Li, C. P. Ramil, R. K. V. Lim, Q. Lin, ACS Chem. Biol. 2015, $10,379$.

[73] J. Li, S. Lin, J. Wang, S. Jia, M. Yang, Z. Hao, X. Zhang, P. R. Chen, J. Am. Chem. Soc. 2013, 135, 7330.

[74] a) W. D. Windt, P. Aelterman, W. Verstraete, Environ. Microbiol. 2005, 7, 314. b) Ackermann and coworkers have shown that $\mathrm{Pd}(\mathrm{II})$ catalyst can be used for the selective C-2 arylation of indoles with diaryliodonium salts, in water at rt, even in the presence of some aminoacids. However, the bioorthogonality of this process has not been further explored: Y. Zhu , M. Bauer, L. Ackermann, Chem. Eur. J. 2015, 21, 9980.

[75] K. K.-Y. Kung, H.-M. Ko, J.-F. Cui, H.-C. Chong, Y.-C. Leung, M.-K. Wong, Chem. Commun. 2014, 50, 11899.

[76] E. V. Vinogradova, C. Zhang, A. M. Spokoyny, B. L. Pentelute, S. L. Buchwald, Nature 2015, 526, 687. 
[77] a) A. J. Rojas, B. L. Pentelute, S. L. Buchwald, Org. Lett. 2017, 19, 4263; b) A. J. Rojas, C. Zhang, E. V. Vinogradova, N. H. Buchwald, J. Reilly, B. L. Pentelute, S. L. Buchwald, Chem. Sci. 2017, 8, 4257.

[78] R. P. Lyon, J. R. Setter, T. D. Bovee, S. O. Doronina, J. H. Hunter, M. E. Anderson, C. L. Balasubramanian, S. M. Duniho, C. I. Leiske, F. Li, P. D. Senter, Nat. Biotechnol. 2014, 32, 1059.

[79] R. A. A. Al-Shuaeeb, S. Kolodych, O. Koniev, S. Delacroix, S. Erb, S Nicolaÿ, J.-C. Cintrat, J.-D. Brion, S. Cianférani, M. Alami, A. Wagner, S. Messaoudi, Chem. Eur. J. 2016, 22, 11365.

[80] H. G. Lee, G. Lautrette, B. L. Pentelute, S. L. Buchwald, Angew. Chem. Int. Ed. 2017, 56, 3177; Angew. Chem. 2017, 129, 3225. b) K. Kubota, P. Dai, B. L. Pentelute, S. L. Buchwald, J. Am. Chem. Soc. 2018, 140, 3128.

[81] M. S. Messina, J. M. Stauber, M. A. Waddington, A. L. Rheingold, H. D. Maynard, A. M. Spokoyny, J. Am. Chem. Soc. 2018, 140, 7065.

[82] a) Y. K. Yang, S. Lee, J. Tae, Org. Lett. 2009, 11, 561; b) M. Jung Jou, X. Chen, K. M. K. Swamy, H. Na Kim, H.-J. Kim, S. Lee, J. Yoon, Chem. Commun. 2009, 7218; c) J. H. Do, H. N. Kim, J. Yoon, J. S. Kim, H.-J. Kim, Org. Lett. 2010, 12, 932; d) O. A. Egorova, H. Seo, A. Chatterjee, K. H. Ahn, Org. Lett. 2010, 12, 401; e) X. Cao, W. Lin, Y. Ding, Chem. Eur. J. 2011, 17, 9066; f) H. Seo, M. E. Jun, O. A. Egorova, K. H. Lee, K. T. Kim, K. H. Ahn, Org. Lett. 2012, 14, 5062; g) J. B. Wang, Q. Q. Wu, Y. Z. Min, Y. Z. Liu, Q. H. Song, Chem. Commun. 2012, 48, 744; h) N. T. Patil, V. S. Shinde, M. S. Thakare, P. Hemant Kumar, P. R. Bangal, A. K. Barui, C. R. Patra, Chem. Commun. 2012, 48, 11229.

[83] K. Tsubokura, K. K. H. Vong, A. R. Pradipta, A. Ogura, S. Urano, T. Tahara, S. Nozaki, H. Onoe, Y. Nakao, R. Sibgatullina, A. Kurbangalieva, Y. Watanabe, K. Tanaka, Angew. Chem. Int. Ed. 2017, 56, 3579; Angew. Chem. 2017, 129, 3633.

[84] C. Vidal, M. Tomás-Gamasa, P. Destito, F. López, J. L. Mascareñas, Nat. Commun. 2018, 9, 1913.

[85] a) R. Noyori, T. Ohkuma, M. Kitamura, H. Takaya, N. Sayo, H. Kumobayashi, S. Akutagawa, J. Am. Chem. Soc. 1987, 109, 5856; b) K. Mashima, K. Kusano, N. Sato, Y. Matsumura, K. Nozaki, H. Kumobayashi, N. Sayo, Y. Hori, T. Ishizaki, J. Org. Chem. 1994, 59, 3064; c) G. E. Dobereiner, R. H. Crabtree, Chem. Rev. 2010, 110, 681; d) A. Robertson, T. Matsumoto, S. Ogo, Dalton Trans. 2011, 40, 10304; e) C. Leiva, H. C. Lo, R. H. Fish, J. Organomet. Chem. 2010, 695, 145; f) D. Wang, D. Astruc, Chem. Rev. 2015, 115, 6621; g) J. Liu, S. Yang, W. Tang, Z. Yang, J. Xu, Green Chem. 2018, 20, 2118.

[86] S. Betanzos-Lara, Z. Liu, A. Habtemariam, A. M. Pizarro, B. Qamar, P. J. Sadler, Angew. Chem. Int. Ed. 2012, 51, 3897; Angew. Chem. 2012, 124, 3963.

[87] J. P. C. Coverdale, I. Romero-Canelón, C. Sanchez-Cano, G. J. Clarkson, A. Habtemariam, M. Wills, P. J. Sadler, Nat. Chem. 2018, 10, 347.

[88] A. H. Ngo, M. Ibañez, L. H. Do, ACS Catalysis, 2016, 6, 2637.

[89] S. Bose, A. H. Ngo, L. H. Do, J. Am. Chem. Soc. 2017, 139, 8792.

[90] C. Vidal, M. Tomás-Gamasa, A. Gutiérrez-González, J. L. Mascareñas, J. Am. Chem. Soc. 2019, 141, 5125.

[91] a) D. V. McGrath, R. H. Grubbs, Organometallics 1994, 13, 224; b) V. Cadierno, S. E. García-Garrido, J. Gimeno, A. Varela-Álvarez, J. A. Sordo, J. Am. Chem.Soc. 2006, 128, 1360; c) J. García-Álvarez, J. Gimeno, F. J. Suárez, Organometallics 2011, 30, 289; d) P. Lorenzo-Luis, A. Romerosa, M. Serrano-Ruiz, ACS Catal. 2012, 2, 1079; e) N. Ahlsten, A. Bartoszewicz, B. Martín-Matute, Dalton Trans. 2012, 41, 1660.

[92] Z. Du, C. Liu, H. Song, P. Scott, Z. Liu, J. Ren and X. Qu, Chem 2020, 6, 2060.

[93] J. Tsuji, H. Takahashi, M. Morikawa, Tetrahedron Lett. 1965, 6, 4387.

[94] a) G. Hata, K. Takahashi, A. Miyake, J. Chem. Soc. Chem. Comm. 1970 , 1392; b) K. E. Atkins, W. E. Walker, R. M. Manyik, Tetrahedron Lett. 1970 , $11,3821$.

[95] a) C. G. Frost, J. Howarth, J. M. J. Williams, Tetrahedron: Asymmetry, 1992, 3, 1089; b) B. M. Trost and D. L. Van Vranken, Chem. Rev. 1996, 96, 395; c) U. Kazmaier, (Ed.), Transition Metal Catalyzed Enantioselective Allylic Substitution in Organic Synthesis, Springer Berlin
Heidelberg, 2012; d) B. M. Trost, M. L. Crawley, Chem. Rev. 2003, 103, 2921; d) N. A. Butt, W. Zhang, Chem. Soc. Rev. 2015, 44, 7929.

[96] P. K. Sasmal, S. Carregal-Romero, W. J. Parak, E. Meggers, Organometallics, 2012, 31, 5968.

[97] a) M. I. Sánchez, C. Penas, M. E. Vázquez, J. L. Mascareñas, Chem. Sci. 2014, 5, 1901. See also, b) a) H. Ai, J. W. Lee, P. G. Schultz, Chem. Comm. 2010, 46, 5506.

[98] T. Völker, F. Dempwolff, P. L. Graumann, E. Meggers, Angew. Chem. Int. Ed. 2014, 53, 10536; Angew. Chem. 2014, 126, 10705.

[99] H. Saburi, S. Tanaka, M. Kitamura, Angew. Chem. Int. Ed. 2005, 44, 1730; Angew. Chem. 2005, 117, 1758.

[100] H.-T. Hsu, B. M. Trantow, R. M. Waymouth, P. A. Wender, Bioconjugate Chem. 2016, 27, 376.

[101] M. Tomás-Gamasa, M. Martínez-Calvo, J. R. Couceiro, J. L. Mascareñas, Nat. Comm. 2016, 7, 12538.

[102] The use of the active drug DNP required concentration $>500 \mu \mathrm{M}$ to get a reproducible damaging effect, whereas cells pre-treated with the catalysts Ru-13 needed only $150 \mu \mathrm{M}$ of the caged DNP to generate a reproducible effect.

[103] G. Y. Tonga, Y. Jeong, B. Duncan, T. Mizuhara, R. Mout, R. Das, S. T. Kim, Y.-C. Yeh, B. Yan, S. Hou, V.M. Rotello, Nat. Chem. 2015, 7, 597.

[104] Y. Jeong, G. Y. Tonga, B. Duncan, B. Yan, R. Das, C. Sahub, V. M. Rotello, Small 2018, 14.

[105] R. Das, R. F. Landis, G. Y. Tonga, R. Cao-Milan, D. C. Luther, V. M. Rotello, ACS Nano 2019, 13, 229.

[106] X. Zhang, Y. Liu, S. Gopalakrishnan, L. Castellanos-Garcia, G. Li, M. Malassine, I. Uddin, R. Huang, D. C. Luther, R. W. Vachet, V. M. Rotello, ACS Nano 2020, 14, 4767.

[107] a) X. Zhang, S. Fedeli, S. Gopalakrishnan, R. Huang, A. Gupta, D. C. Luther, V. Rotello, ChemBioChem 2020. DOI: 10.1002/cbic.202000207. See also: b) R. Cao-Milán, S. Gopalakrishnan, L. D. He, R. Huang, L.-S. Wang, L. Castellanos, D. C. Luther, R. F. Landis, J. M. V. Makabenta, C.-H. Li, X. Zhang, F. Scaletti, R. W. Vachet,V. M. Rotello, Chem 2020, $6,1113$.

[108] Amsacrine inhibits DNA synthesis by binding to and intercalating with DNA; it also inhibits topoisomerase II activity and may exert an effect on cell membranes. See: a) Erfa Canada Inc. AMSA PD® injection product monograph. Westmount, Quebec; 16 August 2005; b) Rose BD editor. Amsacrine. UpToDate 16.1 ed. Waltham, Massachusetts: UpToDate®; 2008.

[109] M. A. Miller, B. Askevold, H. Mikula, R. H. Kohler, D. Pirovich, R. Weissleder, Nat. Comm. 2017, 8, 15906.

[110] a) Interestingly, preliminary results indicate that the same $\mathrm{Pd}$ nanocatalysts can promote an intramolecular Heck reaction leading to a coumarin fluorophore inside cells. See reference 109. b) M. A. Miller, H. Mikula, G. Luthria, R. Li, S. Kronister, M. Prytyskach, R. H. Kohler, T. Mitchison, R. Weissleder, ACS Nano 2018, 12, 12814.

[111] M. Martinez-Calvo, J. R. Couceiro, P. Destito, J. Rodriguez, J. Mosquera, J. L. Mascareñas, ACS Catal. 2018, 8, 6055-6061.

[112] Y. Okamoto, R. Kojima, F. Schwizer, E. Bartolami, T. Heinisch, S. Matile, M. Fussenegger, T. R. Ward, Nat. Commun. 2018, 9, 1943.

[113] $\mathrm{Cu}(\mathrm{I})$ has also been occasionally used for this reaction, to the best of our knowledge, only if a tertiary propargyl carbamate is employed, see: A. A. Kislukhin, V. P. Hong, K. E. Breitenkamp, M. G. Finn, Bioconjugate Chem. 2013, 24, 684.

[114] For studies on the mechanism see: a) B. Liu, H. Wang, T. Wang, Y. Bao, F. Du, J. Tian, Q. Li, R. Bai, Chem. Comm. 2012, 48, 2867; b) D. Rambabu, S. Bhavani, N. K. Swamy, M. V. Basaveswara Rao, M. Pal, Tetrahedron Lett. 2013, 54, 1169. See also reference 114.

[115] J. Li, J. Yu, J. Zhao, J. Wang, S. Zheng, S. Lin, L. Chen, M. Yang, S. Jia, X. Zhang, P. R. Chen, Nat. Chem. 2014, 6, 352.

[116] J. Wang, B. Cheng, J. Li, Z. Zhang, W. Hong, X. Chen, P. R. Chen, Angew. Chem. Int. Ed. 2015, 54, 5364; Angew. Chem. 2015, 127, 5454. 
[117] J. T. Weiss, J. C. Dawson, K. G. Macleod, W. Rybski, C. Fraser, C. Torres-Sánchez, E. E. Patton, M. Bradley, N. O. Carragher, A. UncitiBroceta, Nat. Comm. 2014, 5.

[118] J. T. Weiss, J. C. Dawson, C. Fraser, W. Rybski, C. Torres-Sánchez, M. Bradley, E. E. Patton, N. O. Carragher, A. Unciti-Broceta, J. Med. Chem. 2014, 57, 5395.

[119] B. Rubio-Ruiz, J. T. Weiss, A. Unciti-Broceta, J. Med. Chem. 2016, 59 , 9974.

[120] T. L. Bray, M. Salji, A. Brombin, A. M. Pérez-López, B. Rubio-Ruiz, L. C. A. Galbraith, E. E. Patton, H. Y. Leung, A. Unciti-Broceta, Chem. Sci. 2018, 9, 7354.

[121] a) M. Sancho-Albero, B. Rubio-Ruiz, A. M. Pérez-López, V. Sebastian, P. Martín-Duque, M. Arruebo, J. Santamaría, A. Unciti-Broceta, Nat Catal 2019, 2, 864-872. b) Z. Du, X. Qu, Nat. Catal. 2019, 2, 837.

[122] For an alternative strategy based on Pd nanosheets captured within agarose and alginate hydrogels, for Taxol prodrug uncaging in cancer cell culture, see: A. M. Pérez-López, B. Rubio-Ruiz, T. Valero, R. Contreras-Montoya, L. Álvarez de Cienfuegos, V. Sebastián, J. Santamaría and A. Unciti-Broceta, J. Med. Chem. 2020, 63, 9650.

[123] B. J. Stenton, B. L. Oliveira, M. J. Matos, L. Sinatra, G. J. L. Bernardes, Chem. Sci. 2018, 9, 4185.

[124] R. Martínez, C. Carrillo-Carrión, P. Destito, A. Alvarez, M. TomásGamasa, B. Pelaz, F. López, J. L. Mascareñas, P. del Pino, Cell. Rep. Phys. Sci. 2020, 1, 100076.

[125] S. Learte-Aymamí, C. Vidal, A. Gutiérrez-González, J. L. Mascareñas Angew. Chem. Int. Ed. 2020, 59, 9149; Angew. Chem. 2020, 132, 9234.

[126] S. Learte-Aymamí, N. Curado, J. Rodríguez, M. E. Vázquez, J. L. Mascareñas, J. Am. Chem. Soc. 2017, $139,16188$.

[127] A. M. Pérez-López, B. Rubio-Ruiz, V. Sebastián, L. Hamilton, C. Adam, T. L. Bray, S. Irusta, P. M. Brennan, G. C. Lloyd-Jones, D. Sieger, J. Santamaría, A. Unciti-Broceta, Angew. Chem. Int. Ed. 2017, 56, 12548; Angew. Chem. 2017, 129, 12722.

[128] $50 \mu \mathrm{M}$ was the saturation limit. At higher concentration, gold-bound biomolecules will coat most active sites on the Au-NP surface, hindering gold-alkyne coordination.

[129] A. Kumar, S. Kumar, N. Kumari, S. H. Lee, J. Han, I. J. Michael, Y.-K. Cho and I. S. Lee, ACS Catalysis 2019, 9, 977.

[130] a) M. Jbara, E. Eid, A. Brik, J. Am. Chem. Soc. 2020, 142, 8203-8210; b) L. Oliveira, B. J. Stenton, V. B. Unnikrishnan, C. R. de Almeida, J. Conde, M. Negrão, F. S. S. Schneider, C. Cordeiro, M. G. Ferreira, G. F. Caramori, J. B. Domingos, R. Fior and G. J. L. Bernardes, J. Am. Chem. Soc. 2020, 142, 10869.

[131] a) X. Wang, Y. Liu, X. Fan, J. Wang, W. S. C. Ngai, H. Zhang, J. Li, G. Zhang, J. Lin, P. R. Chen, J. Am. Chem. Soc. 2019, 141, 17133. See also: b) Y. Liu, S. Pujals, P. J. M. Stals, T. Paulöhrl, S. I. Presolski, E. W. Meijer, L. Albertazzi and A. R. A. Palmans, J. Am. Chem. Soc. 2018, 140, 3423.

[132] J. Wang, S. Zheng, Y. Liu, Z. Zhang, Z. Lin, J. Li, G. Zhang, X. Wang, J. Li, P. R. Chen, J. Am. Chem. Soc. 2016, 138, 15118.

[133] E. Lindberg, S. Angerani, M. Anzola, N. Winssinger, Nat. Commun 2018, 9, 3539.

[134] R. Huang, C. H. Li, R. Cao-Milan, L. D. He, J. M. Makabenta, X. Zhang, E. Yu, V. M. Rotello, J. Am. Chem. Soc. 2020. 142, 10723. 
WILEY-VCH

\section{REVIEW}

REVIEW

In this Review, we describe the most relevant advances towards translating the potential of transition metal catalysts to biological settings, including living cells or small-animal models such as mice or zebrafish. We pay especial attention to the molecular and mechanistic aspects of the transformations.

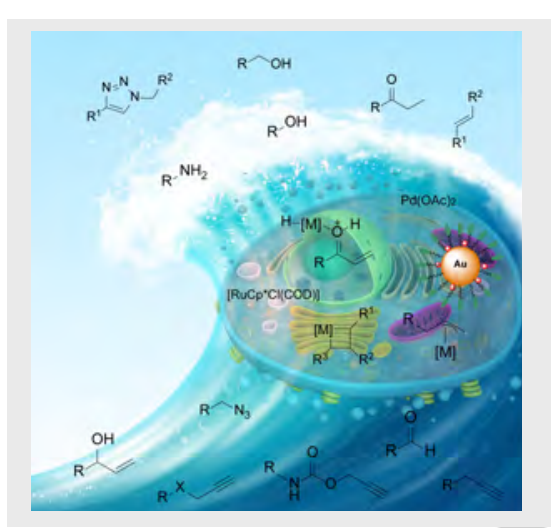

Paolo Destito, Cristian Vidal, Fernando López* and José L. Mascareñas*

Page No. - Page No.

Transition Metal-Promoted Reactions in Aqueous Media and Biological Settings

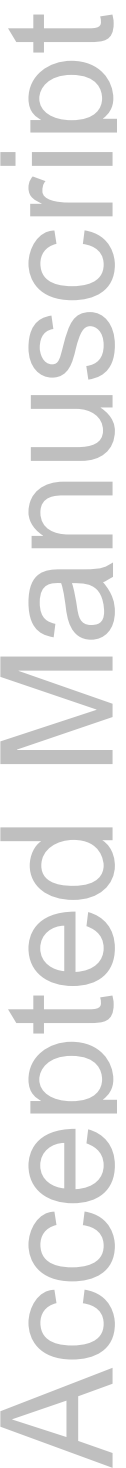

